Aus der Abteilung Ethik und Geschichte der Medizin

(Prof. Dr. med. C. Wiesemann)

im Zentrum Psychosoziale Medizin

der Medizinischen Fakultät der Universität Göttingen

\title{
Hans Reichenbach (1864 - 1937) Hygieniker und Wissenschaftler
}

INAUGURAL-DISSERTATION

zur Erlangung des Doktorgrades

der Medizinischen Fakultät

der Georg-August-Universität zu Göttingen

vorgelegt von

Constantin Benjamin Vogiatzis

aus Aachen

Göttingen 2010 
Dekan: Prof. Dr. med. C. Frömmel

I. Berichterstatter: Prof. Dr. phil. Dr. med habil. V. Zimmermann

II. Berichterstatter: Prof. Dr. med H. Dunkelberg

Tag der mündlichen Prüfung: 14.09.2010 


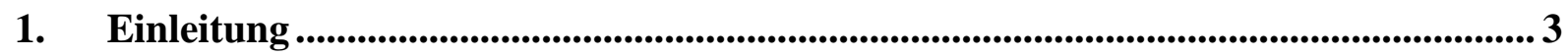

1.1. Die Hygiene als Wissenschaft ................................................................................ 6

1.2. Historische Einordnung der Hygiene .............................................................. 12

2. Ausbildung und beruflicher Werdegang Reichenbachs ......................................... 15

3. Reichenbachs Zeit am Hygieneinstitut Göttingen.................................................... 19

4. Reichenbach und seine berufliche Laufbahn im Bezug zu den

Geschehnissen der damaligen Zeit................................................................................... 22

5. Das wissenschaftliche Werk Reichenbachs im Kontext der Zeit ................................ 28

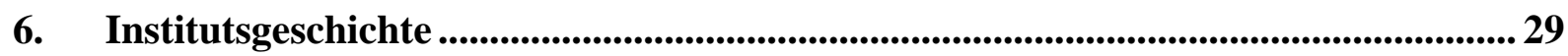

7. Das wissenschaftliche Werk Reichenbachs................................................................ 32

7.1. Bakterien in Luft, Wasser, Erdboden und Milch............................................. 33

7.2. Die Vererbung erworbener Eigenschaften bei einzelligen Lebewesen......... 40

7.3. Die desinfizierenden Bestandteile der Seifen .................................................4 47

7.4. Die Leistung der Formaldehyd-Desinfektion ........................................................ 53

7.5. Die Tageslichtmessung in Schulen ..........................................................59

7.6. Zur Frage der Tageslichtmessung .................................................................. 63

7.7. Über den Einfluss der Farbe künstlicher Lichtquellen auf die Sehschärfe. 66

7.8. Über Wärmestrahlung von Leuchtflammen................................................... 71

7.9. Das Mikroskop und seine Nebenapparate .................................................. 81

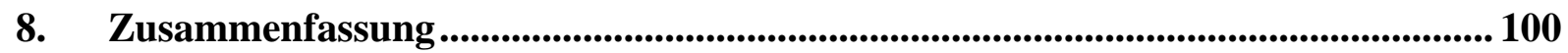

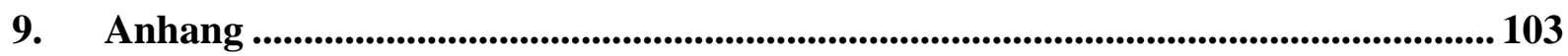

9.1. Verzeichnis der Veröffentlichungen Hans Reichenbachs............................ 104

9.2. Promotionen unter Reichenbach am Hygienischen Institut Göttingen ..... 112

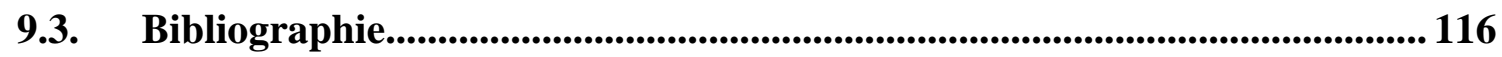

9.3.1. Quellen Göttinger Universitätsarchiv (GUA)................................. 116

9.3.2. Literatur ...........................................................................................116 


\section{Einleitung}

Der aus Lüneburg stammende Hygieniker Hans Reichenbach lebte von 1864 bis 1937. Ab 1911 war er für mehr als 20 Jahre Ordinarius am Hygieneinstitut Göttingen. Diese Zeit ist beruflich gesehen sicherlich der wichtigste Abschnitt in seinem Leben. Auch wenn auffällig ist, dass die größere Anzahl seiner wissenschaftlichen Veröffentlichungen vor der Berufung nach Göttingen erschienen ist. Dieser Umstand ist möglicherweise darauf zurückzuführen, dass in die Amtszeit Reichenbachs nicht nur der erste Weltkrieg fiel, sondern auch die große Rezession zu Zeiten der Weimarer Republik. Beides waren Zeitabschnitte, in denen Forschungsarbeit am beschriebenen Institut keine Priorität haben konnte.

Trotz der erschwerten Bedingungen hat es Reichenbach geschafft, mit viel persönlichem Engagement und Einsatz das Hygieneinstitut aufrechtzuerhalten. Dies ist als seine besondere Leistung anzuerkennen. Ebenso ist es ihm gelungen, die im Krieg anstehenden Aufgaben, wie zum Beispiel die Erstellung von lebenswichtigem Impfstoff, effizient auszuführen.

Ziel dieser Arbeit ist es, die Zeit, die Reichenbach in Göttingen verbracht hat, zu beleuchten und sein Schaffen am Institut darzustellen. Darüber hinaus soll sein wissenschaftliches Werk behandelt werden.

Zu Beginn der Arbeit wird eine Rede Reichenbachs vorgestellt, welche er 1926 zum Anlass der Reichsgründungsfeier der Universität Göttingen gehalten hat. Diese Rede, mit dem Titel „Die Hygiene als Wissenschaft“, ist insofern von besonderer Bedeutung, als dass Reichenbach hier das Fach aus seiner Sicht vorstellt. Sie soll zum Einstieg einen Eindruck über das Spektrum der Hygiene zur damaligen Zeit vermitteln. Abgerundet wird das Bild durch einen anschließenden geschichtlichen Überblick über das Fach der Hygiene. Im Weiteren folgt eine Darstellung über Reichenbachs Ausbildung und seinen beruflichen Werdegang. Genauer wird auf seine Zeit als Professor am Hygieneinstitut Göttingen eingegangen. Es werden die Schwierigkeiten der Zeit und deren Einfluss auf die Arbeit am Institut anhand von Aktennotizen aus dem Universitätsarchiv aufgezeigt. Die Darstellung Reichenbachs wird durch einen Abriss der geschichtlichen Entwicklung des Hygieneinstituts in Göttingen ergänzt.

Um einen Eindruck von der wissenschaftlichen Arbeit Reichenbachs zu vermitteln, werden neun Veröffentlichungen aus Schwerpunktbereichen seiner Forschungsarbeit vorgestellt. Die Darstellung seiner Arbeiten beginnt mit zwei Aufsätzen aus dem Bereich der Bakteriologie. Die erste Abhandlung mit dem Titel „Bakterien in Luft, Wasser, Erdboden und Milch“ beschäftigt sich mit dem Vorkommen pathogener und nicht pathogener Keime in den genannten Medien. „Die Vererbung erworbener Eigenschaften bei einzelligen Lebewesen“, 
als zweite dargestellte Forschungsarbeit, geht der Frage nach, welche Beobachtungen man im Hinblick auf die Vererbung bei Einzellern machen kann und ob ein Rückschluss auf die Vererbung bei höheren Lebewesen zulässig ist.

Des Weiteren setzte sich Reichenbach intensiv mit dem Bereich der Desinfektion auseinander. Aus heutiger Sicht gesehen bestand zur damaligen Zeit an dieser Thematik besonders großes Interesse, da es bezüglich der Desinfektionsverfahren noch Verbesserungsbedarf gab. Zu diesem Bereich werden in der Arbeit zwei seiner Werke vorgestellt. „Die desinfizierenden Bestandteile der Seifen“ sowie „Die Leistung der Formaldehyd-Desinfektion“.

Folgend wird sein Interesse an der Beleuchtungshygiene aufgezeigt. Zwei der hierzu dargestellten Arbeiten beschäftigen sich mit der Problematik der Tageslichtmessung. Hier war die Frage der ausreichenden Arbeitsplatzbeleuchtung von besonderer Relevanz.

Um zu zeigen, wie vielschichtig das Fach Hygiene gerade in seinen Anfangsjahren selbst in einzelnen Sachgebieten war, werden zur Beleuchtungshygiene zwei weitere Artikel behandelt. Einer der beiden Aufsätze geht der Frage nach, ob die Farbe einer Lichtquelle Einfluss auf die Sehschärfe hat. Die zweite Arbeit, „Über Wärmestrahlung von Leuchtflammen“, behandelt die Thematik der Wärmeentwicklung von Lampen.

Die letzte Arbeit, die in diesem Rahmen vorgestellt wird, ist eine Abhandlung über das Mikroskop. Reichenbach geht zum einen auf die einzelnen Komponenten des Mikroskops ein und zum anderen gibt er Hinweise für den praktischen Umgang mit diesem. Der Abschnitt über das wissenschaftliche Werk Reichenbachs schließt mit einer Auflistung seiner Veröffentlichungen ab.

Speziell zur Person Reichenbachs und zu seinem wissenschaftlichen Werk gibt es bis dato keine Veröffentlichung. Es liegt ein maschinengeschriebener Bericht einer Institutsangestellten von 1960 vor, der einen Überblick über die ersten fünfundsiebzig Jahre des Hygieneinstituts aus Sicht der Angestellten gibt und somit auch den Zeitraum, in dem Reichenbach Ordinarius war, beschreibt. ${ }^{1}$ Dieser Bericht wurde bis dato nicht untersucht und wird im Rahmen dieser Arbeit erstmalig ausgewertet. Darüber hinaus legte Rieberer 1990 eine medizinische Dissertation vor, die einen Abriss über „Das Institut für Medizinische Chemie und Hygiene der Universität Göttingen von der Gründung 1883 bis 1955“² gibt. In der erwähnten Arbeit wird der Amtszeitraum Reichenbachs kurz wiedergegeben. 
Das Ziel der vorliegenden Arbeit ist weniger, die Institutsgeschichte zu beleuchten, als vielmehr die Person Reichenbachs und dessen Gesamtwerk in oben beschriebener Weise vorzustellen.

Wie sich im Laufe der Arbeit zeigte, war eine der Hauptschwierigkeiten die Beschaffung der Quellen. Es war möglich, anhand von Institutsakten die Person Reichenbach und dessen Werk zu skizzieren. Die Auswertung der gefundenen Quellen wurde dadurch erschwert, dass ein großer Teil der Schriften handschriftlich in Sütterlin verfasst worden ist. Neuere Medien erwiesen sich für die Recherche als nicht brauchbar. So konnten im Internet über die Person Reichenbach keine relevanten Daten gefunden werden.

Es gab durchaus interessante Bereiche, zu denen keine näheren Informationen ausfindig zu machen waren. Es wäre beispielsweise von Interesse gewesen, Reichenbachs Einstellung zum aufkommenden Nationalsozialismus näher zu beleuchten. Aufgrund der lückenhaften Informationen konnte dieser Punkt nur kurz angerissen werden. 


\subsection{Die Hygiene als Wissenschaft ${ }^{3}$ \\ Festrede zur Reichsgründungsfeier der Georg August Universität Göttingen (1926)}

In seiner Festrede gab Reichenbach einen Überblick darüber, was die Hygiene in wissenschaftlicher Hinsicht war.

Dies war ihm ein besonderes Anliegen, „einmal deshalb, weil heute mehr als je auf seine Wissenschaft besondere Hoffnungen gesetzt werden; gilt sie doch in weitesten Kreisen als der wichtigste Faktor für die Wiedergewinnung aller der gesundheitlichen Werte, die unserem Volk durch den Krieg und die Zeit nach dem Krieg verloren gegangen sind, und zweitens, weil [...] die Hygiene als reine Wissenschaft von jeher um ihre Gleichberechtigung hat kämpfen müssen und auch heute noch nicht überall die Anerkennung findet, die den Übrigen theoretischen medizinischen Fächern entgegengebracht wird. “4

Reichenbach führte aus, dass „die Hygiene eine sehr populäre, vielleicht die populärste Wissenschaft “5 ${ }^{*}$ war und jeder gebildete Mensch den Anspruch stellte, in Fragen der Hygiene mitzureden, ohne jedoch dafür qualifiziert zu sein.

Erschwerend kam hinzu, dass viele Nicht-Fachzeitungen über alltägliche Fragen der Hygiene schrieben und häufig Halbwahrheiten oder schlichtweg falsche Informationen veröffentlicht wurden. Dies trug in der Gesamtheit dazu bei, dass ein fehlerhaftes Bild über den Aufgabenbereich dieser Wissenschaft vorherrschte.

Andererseits räumte Reichenbach ein, dass eine befriedigende Begriffsbestimmung der Hygiene nicht leicht zu geben sei, da das Fach im steten Wandel stand.

Zur Begriffsklärung zitierte er Pettenkofer (*1818 - †1901), einen der Begründer der wissenschaftlichen Hygiene, der sie als „Lehre von der Einwirkung der Umgebung auf den menschlichen Organismus “6 bezeichnete.

Dies traf, so Reichenbach, den wissenschaftlichen Kern der Hygiene präzise. Doch war das Fach darüber hinaus zusätzlich bestrebt, das Umfeld für den Menschen positiv zu gestalten. Zudem versuchte die Hygiene, den menschlichen Körper gegenüber äußeren Einflüssen zu stärken, was beispielsweise durch richtige Ernährung und körperliche Ertüchtigung geschehen sollte.

Diese Punkte mit berücksichtigend, kam Reichenbach zu folgender Begriffsformulierung:

Vgl. Reichenbach (1926)

Reichenbach (1926) S. 3

Reichenbach (1926) S. 3

Reichenbach (1926) S. 4 
„So können wir denn jetzt die Hygiene definieren als die Wissenschaft, die uns lehrt, die Beziehung zwischen dem Menschen und seiner Umwelt zu erforschen und diese Beziehungen, sei es durch Einwirkung auf die Umwelt, sei es durch Einwirkung auf den Organismus, für den letzteren möglichst günstig zu gestalten. “7

Entsprechend dieser Definition hatten die im weiteren Verlauf beschriebenen Punkte für die Hygiene eine große Bedeutung.

Die atmosphärische Luft, die den Menschen ständig umgibt, war nach Reichenbachs Definition eines der typischen Forschungsgebiete der Hygiene. Die Luft unterliegt chemischen und physikalischen Änderungen, die einer hygienischen Betrachtung bedürfen.

Zu den physikalischen Faktoren zählen Größen wie Luftdruck und Temperatur, die direkte Auswirkungen auf den Menschen ausüben und beispielsweise Einfluss auf den Wärmehaushalt des Körpers nehmen. Es war Aufgabe der Hygiene, den Einfluss dieser Änderungen zu erfassen.

$\mathrm{Zu}$ diesem Feld der Hygiene gehört auch die Auseinandersetzung mit der Luftverschmutzung und deren Einflussnahme auf den Menschen.

Aber nicht nur die Luft, klimatische Faktoren allgemein haben Auswirkungen auf den menschlichen Körper. Man weiß beispielsweise damals wie heute, dass einfache Erkältungskrankheiten durch die Wetterlage bedingt sein können.

„Die Schwierigkeiten, die sich hier der Forschung entgegenstellten, kann ich nur andeuten; sie liegen im wesentlichen darin, dass wir im Experiment am Menschen wohl die Wirkung einzelner klimatischer Faktoren untersuchen, aber nicht die Gesamtwirkung des Klimas reproduzieren können. Auch müssen solche Versuche sich selbstverständlich in physiologischen Grenzen halten: die Schädigungen - und damit das ganze Gebiet der Erkältungskrankheiten sind dem Experiment am Menschen nicht zugängig.

Tiere aber reagieren auf Witterungseinflüsse so wesentlich anders, dass vom Tierexperiment Schlüsse auf das Verhalten vom Menschen nur mit äußerster Vorsicht gezogen werden dürfen. “ 8

Unmittelbar zu den Beobachtungen der klimatischen Faktoren gehörte die wissenschaftliche Analyse der Kleidung. Hier hatte die wärmende Komponente besondere Bedeutung, außerdem wurden Luftdurchlässigkeit und Wasserfestigkeit des Materials durch die Hygiene untersucht. Man konnte feststellen, dass die Art des Materials weniger bedeutend für diese Eigenschaften der Kleidung war als dessen Verarbeitung. 
„Vieles zu verbessern ist noch in der Form und dem Schnitt der Kleidung, hier aber hat sich die Mode als ein so überwiegender Faktor erwiesen, dass von hygienischen Anregungen keine allzu große Wirkung zu erwarten ist. “9

Ein weiterer Anspruch der Hygiene war es, Ernährungsfragen zu erörtern. Hier gingen die Hygieniker unter anderem der Frage der nötigen Menge an Kalorien und Eiweißen nach und beschäftigten sich mit der Zusammensetzung der Nahrung. Weiterhin war zu klären, welche Nahrungsmittel pathologische Eigenschaften hatten.

„Dass auch die Ernährungslehre noch ganz neue Probleme birgt, zeigt die Entdeckung der Vitamine, jener rätselhaften Stoffe, die, ohne Nährstoffe zu sein, doch für den normalen Ablauf der Körperfunktionen unentbehrlich sind “10

Hier hatte man, wie Reichenbach ausführte, trotz intensiver Bemühungen noch viel Forschungsarbeit zu leisten.

Ein völlig anderes Gebiet der hygienischen Forschung war die Begutachtung des Bodens. Mit den neu gewonnenen Erkenntnissen über Bakterien konnte mit der überholten Meinung gebrochen werden, dass die Bodenbeschaffenheit verantwortlich für die Ausbreitung von Infektionskrankheiten sei. Man war früher davon ausgegangen, dass die Erreger einen Reifungsprozess im Boden mit spezieller Beschaffenheit durchlaufen mussten, ehe sie eine neue Infektion verursachen konnten.

In der damals modernen Hygiene war das Interesse im Bezug auf Böden und deren Beschaffenheit ein anderes. Nun betrachtete man in erster Linie die filtrierenden Eigenschaften des Bodens und die Frage der Grundwasserversorgung, welche für die Zivilisation von großer Bedeutung waren. In diesem Bereich war es Aufgabe der Hygiene die Versorgungsanlagen so zu konzipieren, dass möglichst keine schädlichen Keime in das Wasser gelangen konnten.

Zum Spektrum der modernen Hygiene gehörte auch das gesamte Gebiet der Verbreitung und Verhütung von Infektionskrankheiten. ${ }^{11}$ Diese hätten, so Reichenbach, in der Hygiene einen großen Stellenwert und mit der erfolgreichen Erforschung der Bakterien könnte man hier grundlegende Erkenntnisse erlangen. So hätte man die Bedeutung der Kontaktinfektion als Verbreitungsursache vieler Infektionskrankheiten ausfindig machen können. Außerdem hatte man Vektoren für die Übertragung einiger Infektionskrankheiten ausfindig gemacht und somit Grundlegendes zum Verständnis der Ausbreitung von Krankheiten, wie der Malaria, erfahren.

Reichenbach (1926) S. 18

Reichenbach (1926) S. 22

Vgl. Reichenbach (1926) S. 15 
Durch diese Erkenntnisse konnte man, wie gerade erwähnt, mit der Vorstellung aufräumen, dass der Boden für die Infektionen verantwortlich war.

In Verbindung mit den Infektionskrankheiten war die Hygiene auch mit den Schutzimpfungen betraut und es konnten mit ihrer Hilfe Krankheiten wie Pest, Cholera und Typhus weitgehend eingedämmt werden.

Für die Seuchenbekämpfung war die Desinfektion eine weitere wichtige Maßnahme. Auf diesem Gebiet leistete und leistet die Hygiene viel Forschungsarbeit, indem sie die zur Verfügung stehenden Desinfektionsmittel und Verfahren prüfte.

Weitere große Arbeitsfelder waren die Schul- und Gewerbehygiene. Hier setzte sich der Hygieniker mit den Einflüssen der auf den Menschen einwirkenden Faktoren am Arbeitsplatz auseinander.

Ebenfalls ein Gebiet der Forschung war die Wohnungshygiene. Die Wohnsituation hatte, so Reichenbach, zweifelsohne direkten Einfluss auf den gesundheitlichen Zustand des Menschen.

„Wenn man aber versucht, den Einfluss der Wohnung in exakter Weise wissenschaftlich zu begründen, wenn man den einzelnen Faktoren nachgeht und ihre Bedeutung für die Gesundheit kritisch betrachtet, so bleibt von wirklich greifbaren und beweisbaren Schädigungen nicht viel übrig. “12

Reichenbach beschrieb, dass der Bereich der Wohnungshygiene in seinen Anfängen stünde und es hier noch viel Forschungsarbeit zu leisten gäbe.

Ein Aufgabenbereich, der im Zusammenhang mit der Wohnfrage zu sehen war, war der der Abfallentsorgung. Hier galt es, die Zersetzung der Abfallstoffe und damit die Entstehung pathogener Keime zu vermeiden.

„Auch die Leichenbestattung gehört in dieses Kapitel. Die Hygiene hat gezeigt, dass die vielfach befürchteten und in ihrer Bedeutung stark übertriebenen gesundheitlichen Nachteile der Friedhöfe bei guter Anlage und ordnungsmäßigem Betriebe nicht von Belang sind.

Aus rein hygienischen Gründen ist deshalb die Leichenverbrennung nur in seltenen Fällen erforderlich. “13

Ein Fakt, der die Stellung der Hygiene als Wissenschaft schwächte, war der, dass sich das Fach aus vielen Teilgebieten anderer Wissenschaften bediente.

Wichtige Bereiche der Hygiene setzten sich aus Teilen der Chemie, Physik und Meteorologie zusammen. Aus letztem Fach entnahm man Informationen über Luft, Licht, Wasser und 
Boden. Die Hygiene bediente sich darüber hinaus auch aus den Fächern Pathologie und Physiologie. Durch diese Eigenart der Hygiene wurde sie von vielen Wissenschaftlern als überflüssig empfunden. Der wohl bekannteste Kritiker der Hygiene war Virchow (*1821 †1902), der sich 1884 gegen die Etablierung eines eigenständigen Faches Hygiene an den Universitäten aussprach. Er betrachtete sie nicht als eigenständige Wissenschaft und befand, dass Hygiene als Lehrfach an einer Universität nicht in Frage käme. ${ }^{14}$

Dazu merkte Reichenbach an, dass die wissenschaftliche Entwicklung der letzten Jahre, insbesondere der Hygiene, den Beweis geliefert hätte, dass diese Einschätzung falsch sei.

Er stellte fest, dass viele neue Errungenschaften aus dem Bereich der Hygiene stammten, von denen auch andere Disziplinen profitierten.

„Daß die gesamte moderne Bakteriologie, auch in ihrem rein botanischen Teil, sich auf den Arbeiten von Robert Koch $\left({ }^{*} 1843-+1910\right)$ aufbaut, ist so allgemein bekannt, dass es keiner besonderen Erwähnung bedarf, und auch später noch sind eine ganze Reihe von bakteriologischen Untersuchungsverfahren von Hygienikern gefunden worden, die der Botanik zugute gekommen sind. “15

Als weiteren bedeutenden Hygieniker nannte Reichenbach Max von Pettenkofer (*1818 $† 1901)$, der als erster eine brauchbare Methode zur Messung des Kohlesäuregehalts der atmosphärischen Luft entwickelte.

Auch die Möglichkeit der Lichtmessung war ein Verdienst der Hygiene.

„Die Anerkennung als selbstständiges Lehr- und Forschungsgebiet wird man also der Hygiene nicht versagen können - trotz der außerordentlichen Mannigfaltigkeit ihrer Probleme und trotz der engen Berührung mit ihren zahlreichen Hülfswissenschaften. “16

Am Ende seines Vortrages klärte Reichenbach noch zwei wichtige Begriffe, die häufig im Zusammenhang mit der Hygiene fielen: die Sozial- und die Rassenhygiene.

Die Sozialhygiene war mit der Hygiene, so wie sie bisher betrachtet wurde, vergleichbar, nur dass an Stelle des Einzelnen eine Bevölkerungsgruppe stand. Es wurden die Wechselwirkungen und Einflüsse der Umwelt auf die Population betrachtet. In der Definition waren sich beide Fächer somit sehr nahe. Die Ziele der Sozialhygiene gingen aber weit über die Aufgaben der Hygiene hinaus. Die Sozialhygieniker strebten z.B. die Verbesserung der wirtschaftlichen Lage an, sie setzten sich für Fragen der Versicherungsgesetzgebung ein und suchten die Wohn- und Bodenpolitik zu beeinflussen. All dies geschah in dem Bestreben,

\footnotetext{
Vgl. Reichenbach (1926) S. 9

Reichenbach (1926) S. 12

Reichenbach (1926) S. 12
} 
hygienische Verhältnisse einer breiten Population zugänglich zu machen. Die Sozialhygiene sei als ein eigenständiges Teilgebiet der eigentlichen Hygiene zu betrachten.

Die Rassenhygiene unterschiede sich von der von Reichenbach vertretenen klassischen Hygiene schon dadurch, dass nicht die gegenwärtige Generation im Mittelpunkt der Bemühungen stände, sondern die zukünftigen Generationen. Die Rassenhygiene hätte daher zum Ziel, die Fortpflanzung der Tüchtigen zu fördern und die der Minderwertigen zu verhindern. Diese Ziele ließen sich mit den Mitteln der Hygiene nicht erreichen und könnten nicht als Teil der eigentlichen Hygiene betrachtet werden (vgl. S. 24 f. dieser Arbeit).

„In der Konstatierung dieser Tatsache bitte ich dringend, keine Herabsetzung der Rassenhygiene sehen zu wollen, sondern nur die Erklärung und Entschuldigung dafür, dass unter den führenden Männern der Rassenhygiene kein einziger Hochschullehrer der Hygiene vertreten ist.

Wir sind am Schlusse. Ich glaube, Ihnen gezeigt zu haben, dass die Hygiene, trotz ihrer eigenartigen Bedingungen als gleichberechtigte Wissenschaft in der Reihe der anderen medizinischen Fächer dasteht. Und sie haben auch gesehen, dass für lange Zeit an hygienischen Aufgaben kein Mangel ist. Nicht nur auf dem Gebiet der Infektionskrankheiten, wo die ungelösten Fragen in fast erdrückender Fülle und verwirrender Mannigfaltigkeit auf uns einstürmen, sondern auch in den übrigen Zweigen der Hygiene ist unendlich viel zu tun. “17

17 Reichenbach (1926) S. 31 


\subsection{Historische Einordnung der Hygiene}

Das Wort Hygiene, welches sich aus dem Namen der griechischen Gesundheitsgöttin „Hygieia“ ableitet, bezeichnet im weitesten Sinn die Maßnahmen zur Krankheitsverhütung. Sucht man in der Geschichte nach den Anfängen der Hygiene, wird man feststellen, dass dieser Gedanke die Menschheit schon seit jeher begleitet. Auch der Historiker Eulner (*1925 - †1980) beginnt somit in seinem Werk: „Die Entwickelung der medizinischen Spezialfächer“ das Kapitel Hygiene mit einem Zitat von Max Rubner (*1854 - †1932): „Die Geschichte der Gesundheitspflege ist so alt wie das Menschengeschlecht überhaupt, Gesundheitspflege ist die bewusste Vermeidung aller der Gesundheit drohenden Gefahren und die Betätigung gesundheitsmehrender Handlungen. “18

Von dem natürlichen menschlichen Bestreben, sich vor Krankheit zu schützen, bis hin zu einer modernen wissenschaftlich arbeitenden Hygiene war es ein weiter Weg.

Als Begründer der universitären Hygiene gilt Johann Peter Frank (*1745 - †1821). Er gründete 1804 den ersten Lehrstuhl für „Staatsarzneikunde“ in Wien, und verbesserte dadurch die hygienische Ausbildung für Ärzte entscheidend. Darüber hinaus war es Frank, der erstmals den gesamten Stoff der Hygiene in einem Werk „System einer vollständigen medizinischen Polizei“ zusammenfasste. Ebenfalls in diese Zeit fallen die Anfänge der medizinischen Statistik und die ersten Ansätze im Bereich der Sozialhygiene.

„Es scheint demnach, als ob bereits um 1800 alle Voraussetzungen zur vollen Entwicklung einer wissenschaftlichen Hygiene gegeben wären. “19

Aber erst die Industrielle Revolution, die sich von England aus bereits im späten 18. Jahrhundert ausprägte, konnte durch ihre neuen Herausforderungen eine Grundlage für die wissenschaftlich arbeitende Hygiene schaffen. Das rasche Wachstum der Städte und die damit verbundenen Aufgaben der Wasserver- und Entsorgung und der Müllbeseitigung, um nur die wichtigsten Punkte zu nennen, forderten eine systematische Herangehensweise. Darüber hinaus zeigte die Cholera, die 1831 Europa erreichte, wie hilflos man ohne eine wissenschaftliche und effiziente Vorgehensweise gegenüber den Seuchen ausgesetzt war. Eulner schrieb hierzu: „Die Cholera hat Pettenkofer erst eigentlich zum Hygieniker werden lassen. “20

Max von Pettenkofer (*1818 - †1901) war der Erste, dem es gelang, die Hygiene als wissenschaftlich anerkannte Disziplin an einer deutschen Hochschule einzuführen und zu

\footnotetext{
Rubner (1911) S. 19

Eulner (1970) S. 142

Eulner (1970) S. 142
} 
etablieren. Pettenkofer, der an der Universität München das Ordinariat für medizinische Chemie innehatte, nutzte eine Audienz bei König Ludwig dem II., um ihn von der Bedeutung der Hygiene zu überzeugen. So kam es, dass in München schon 1865 ein eigenes Ordinariat für Hygiene gegründet wurde und zusätzlich das Fach ab 1872 in ganz Bayern Bestandteil der Examensprüfung wurde. „Wohl kaum hätten Denkschriften und Gutachten von noch nicht arrivierten Fachvertretern auf dem Wege über die Ministerialbürokratie so rasch zu solchen Erfolgen geführt. Nun war ein entscheidender Einbruch gelungen, das Beispiel musste Schule machen. “21

Anfangs blieb jedoch der in München gegründete Lehrstuhl der einzige, der ausschließlich der Hygiene gewidmet war. In der darauf folgenden Zeit wurde in Bayern zunächst der universitäre Hygieneunterricht durch die Lehrstühle der Medizinischen Chemie abgedeckt und erst nach und nach wurden eigenständige Institute eingerichtet.

Dass sich die Bewegung letztendlich gegen zahlreiche Skeptiker, die ein eigenständiges Ordinariat für Hygiene ablehnten, durchsetzten konnte, geht nicht zuletzt auf die Erfolge zurück, die auf dem Gebiet der Bakteriologie zu verzeichnen waren.

„In diese Jahre fällt der rasche Aufschwung der Bakteriologie, ausgelöst durch die Arbeiten Pasteurs. 1876 erschien Kochs Arbeit „Zur Ätiologie des Milzbrandes“, 1878 folgten seine „Untersuchungen über die Ätiologie der Wundinfektionskrankheiten. “22

Louis Pasteur (*1822 - †1895), ein französischer Wissenschaftler und Pionier auf dem Gebiet der Mikrobiologie, konnte vor allem im Bereich der Impfungen Fortschritte verzeichnen. Es gelang ihm beispielsweise, nach vorangegangenen Tierversuchen, 1885 eine erfolgreiche Tollwutimpfung am Menschen durchzuführen.

Robert Koch (*1843 - †1910), der ab 1885 den Lehrstuhl für Hygiene in Berlin innehatte, gelang es nicht nur, Keime mikroskopisch darzustellen, auch konnte er, nachdem er Bakterienkulturen angelegt hatte, Krankheiten im Tierversuch reproduzieren und somit deren Ätiologie belegen.

Die Gegner einer eigenständigen universitären Hygiene, gegen die sich das Fach behaupten musste, waren Größen wie Theodor Billroth (*1829 - †1894) und Rudolf Virchow (*1821 †1902). Gerade letzterer vertrat die Meinung, dass ein eigenständiger Lehrstuhl für das Fach unnötig sei, da der Stoff schon mit den vorhandenen Bereichen Physik, Chemie und Mikroskopie abgedeckt wäre.

Allem Widerstand zum Trotz konnten sich in den Jahren bis 1897 an allen deutschen Universitäten Hygieneinstitute etablieren. Einzige Ausnahme blieb bis 1906 Tübingen. 
In den Anfangsjahren der Hygiene war das Fach in zwei Lager gespalten. Auf der einen Seite standen die Anhänger der klassischen Hygiene um Pettenkofer, auf der anderen Seite waren es die bakteriologisch orientierten Vertreter um Virchow.

Im Laufe der Zeit gelang ein Zusammenführen der beiden Gruppen. Ein gutes Beispiel dafür ist Carl Flügge (*1847 - †1932), der 1883 das erste Hygieneinstitut Preußens in Göttingen gründete. Flügge war nicht nur Schüler Pettenkofers gewesen, er arbeitete auch lange Zeit unter Koch und stand somit für das Zusammenwachsen der verschiedenen Richtungen. Ein weiteres Beispiel dafür, dass sich die Bereiche im Laufe der Zeit annäherten, ist die Tatsache, dass ab 1901 auf Bestreben Friedrich Althoffs (*1839 - †1890) den Hygieneinstituten bakteriologische Untersuchungsämter angegliedert wurden.

Was die Hygiene gerade in der Anfangsphase von den meisten anderen Fächern unterschied, war die Schwierigkeit ihrer begrifflichen Abgrenzung. Wie die Betrachtung der geschichtlichen Entwicklung der Hygiene zeigt, war das Fach nicht klar umschrieben. Es bestanden fließende Übergänge zu anderen Fächern, die Reichenbach als „Hilfswissenschaften“ der Hygiene bezeichnete. ${ }^{23}$ Dass die Hygiene von der Regierung unterstützt und von der Bevölkerung wohlwollend betrachtet wurde, wurde nicht immer positiv aufgefasst.

„Mit gemischten Gefühlen erlebten die Vertreter anderer aufstrebender Spezialfächer, wie der Hygiene scheinbar ohne ernsthaften Kampf alles das zufiel, worum sie selbst zäh, aber erfolglos sich bemühten: Lehrstühle, Institute, Anerkennung als Pflicht- und Prüfungsfach, das wohlwollende Interesse der Öffentlichkeit. “24

Mitte des zwanzigsten Jahrhunderts kam es zu Teilungstendenzen der Hygiene in die beiden Bereiche Hygiene und Mikrobiologie. Die Auflösung der Hygieneprofessur in einzelne Lehrstühle war unaufhaltsam. Eulner schrieb hierzu im Jahre 1970:

„Die Mikrobiologie, einst sekundär in den Arbeitsbereich der Hygieniker einbezogen und mächtigster Impuls für die Entwicklung des Gesamtfaches, hat den Rahmen gesprengt, in den sie hineingewachsen war. Die Hygiene wendet sich wieder dem Programm Pettenkofers und Franks zu. “25

23 Vgl. Reichenbach (1926) S. 8

24 Eulner (1970) S. 149

25 Eulner (1970) S. 153 


\section{Ausbildung und beruflicher Werdegang Reichenbachs}

Hans Reichenbach wurde als Sohn eines Fabrikanten am 30.11.1864 in Lüneburg geboren.

Sein Abitur absolvierte er im Alter von 19 Jahren an einem Lüneburger Gymnasium. Noch im selben Jahr, 1884, schrieb er sich zum Medizinstudium an der Georg-August-Universität Göttingen ein. Im März 1889 schloss er das Studium mit dem Staatsexamen erfolgreich ab. ${ }^{26}$ Im Juli 1889 promovierte er bei Professor Wilhelm Ebstein $(* 1836$ - †1912) zum Thema: „Mitteilungen aus der syphilitischen Abteilung des Ernst August Hospitals“ ${ }^{27}$.

Die Promotion Reichenbachs beschäftigte sich mit der Erfassung von Syphiliskranken, die im Ernst August Hospital von Göttingen im Zeitraum von 1877 bis 1887 behandelt worden waren. Reichenbach erfasste neben den Personalien die Anamnesedaten, sowie den Befund von insgesamt 538 Patienten. Darüber hinaus wertete er die angewandten Therapieschemata und den jeweiligen Behandlungserfolg aus. ${ }^{28}$

Seine erste Anstellung erhielt Reichenbach 1889 im medizinischen Labor der Universität Göttingen. Schon wenig später wechselte er an das Hygieneinstitut, welches unter der Leitung von Gustav Wolfhügel stand. Die wissenschaftliche Hygiene befand sich zu diesem Zeitpunkt noch in einem frühen Stadium. Das Hygieneinstitut Göttingen war das erste seiner Art in Preußen und existierte erst seit 6 Jahren. $^{29}$

Reichenbach war schon nach kurzer Zeit am Institut klar, dass er sich dem Fach Hygiene langfristig widmen wollte. So nutzte er das folgende Jahr, um in den Hygieneinstituten in München, Marburg und Berlin sein Wissen auf diesem Gebiet zu vertiefen. Die genannten Institute standen unter der Leitung von Pettenkoffer, Rubner und Koch. ${ }^{30}$

Im Jahre 1891 kehrte Reichenbach nach Göttingen zurück, wo er bis 1904 als Assistent arbeitete. In diese Zeit fiel auch seine Hochzeit mit Maria Hermine Elisabeth, geborene Brügmann. $^{31}$

Im Jahre 1898 habilitierte er sich in Göttingen für das Fach Bakteriologie und Hygiene und bekam im selben Jahr die „Venia Legendi“ verliehen. ${ }^{32}$

Als Privatdozent übernahm Reichenbach zahlreiche Lehrtätigkeiten am Institut. Er gab bakteriologische Kurse und referierte über Immunität und Schutzimpfungen, sowie die Schulhygiene. Auch hielt er folgende Vorlesungen: Bakteriologie, hygienische

\footnotetext{
Vgl. GUA Personalakte Reichenbach, Lebensbeschreibung

Vgl. Reichenbach (1889)

Vgl. Reichenbach (1889)

Vgl. Eulner (1970) S. 146

Vgl. GUA Personalakte Reichenbach, Lebensbeschreibung

Vgl. Göttinger Zeitung (1929) o. S.

Vgl. Fischer (1933) S. 1280
} 
Untersuchungsmethoden und Gesundheitslehre. Darüber hinaus bot er eine praktische Übung zur hygienischen Untersuchungstechnik an. ${ }^{33}$ Auch im Bereich der nicht-studentischen Lehre war Reichenbach tätig. Hier bildete er Desinfektoren aus. ${ }^{34}$

Nach dem Tod von Wolfhügel leitete Reichenbach ab Januar 1899 vorübergehend das Hygieneinstitut. Im Oktober desselben Jahres übernahm Esmarch die Leitung.

Aus einem Schreiben des Ministers für Medizinalangelegenheiten vom 10.11 .1903 an den Kurator der Universität Göttingen geht hervor, dass Reichenbach fünf Jahre nach seiner Ernennung zum Privatdozenten den Titel des Professors verliehen bekam. ${ }^{35}$

Von Göttingen aus ging Reichenbach nach Breslau, wo er als Abteilungsvorsteher unter Flügge arbeitete. Hier blieb Reichenbach bis 1909, dem Jahr, in dem er seine erste Stelle als außerordentlicher Professor in Bonn antrat.

Im Jahre 1911 fragte der Kurator der Universität Göttingen bei Flügge $(* 1847$ - †1932) an, wen er als Nachfolger für Esmarch (*1855 - †1912) empfehlen würde. In seinem Antwortschreiben schlug Flügge zur Besetzung des Lehrstuhls an erster Stelle den Ordinarius Kruse $(* 1864$ - †1943) vor, dessen langjährige Erfahrung er besonders hervorhob. Erst an zweiter Stelle sprach er sich für Reichenbach aus, den er fachlich und menschlich als geeignet empfand.

„Unter den Extra- Ordinarien steht weitaus an erster Stelle Reichenbach, den ich außerordentlich hoch einschätze. “36

Er erwähnte Reichenbachs Publikationen und seine Lehrfähigkeit als sehr beachtenswert.

Über den Menschen Reichenbach berichtete er folgendes.

„Er ist ein äußerst zurückhaltender, vornehmer und verträglicher Mensch, der wegen dieser Eigenschaften auch Esmarch sehr sympathisch sein dürfte. “37

Im August 1911 bekam Reichenbach seinen Ruf zum ordentlichen Professor an die Medizinische Fakultät nach Göttingen. ${ }^{38}$ An seinen Amtsantritt knüpfte Reichenbach Bedingungen und so wurden die Räumlichkeiten renoviert und darüber hinaus finanzielle Mittel zur Beschaffung neuer Gerätschaften zur Verfügung gestellt. ${ }^{39}$

33 Vgl. Rieberer (1990) S. $218-221$

34 Vgl. GUA Institut für Medizinische Chemie und Hygiene, Schreiben vom 29.05.1912

35 Vgl. GUA Personalakte Reichenbach, Schreiben vom 10.11.1903

36 GUA Dekanatsakte Cramer, Schreiben vom 10.06.1911

37 GUA Dekanatsakte Cramer, Schreiben vom 10.06.1911

38 Vgl. Vgl. GUA Personalakte Reichenbach

39 Vgl. Hartung (1963) S. 17 f. 
Über ihren neuen Chef Reichenbach, der sein Amt am 01.10.1911 antrat, schrieb die angestellt Else Hartung: „[...]dass der Berufene der Berufenste war blieb außer Zweifel. Es begann eine Zeit eifriger, ernsthafter Arbeit, eine glückliche Zeit. “40

Im Lauf der Zeit wurden Reichenbach weitere Ämter anvertraut, so z.B. war er von 1916 1917 medizinischer Dekan. Für den Zeitraum von 1918 - 1919 wurde Reichenbach zum Rektor der Universität gewählt. ${ }^{41}$ Von 1922 - 1934 war er Vorsitzender des ärztlichen und zahnärztlichen Prüfungsausschusses. Darüber hinaus war Reichenbach Mitglied im Reichsgesundheitsrat und saß im Preußischen Gesundheitsrat Berlin. ${ }^{42}$

Auch über seine universitären Verpflichtungen hinaus war Reichenbach aktiv. So vertrat er von .1919 bis 1924 als Mitglied des Bürgervorsteherkollegiums den 13. Bezirk der Stadt Göttingen. ${ }^{43}$ Der Bürgervorsteher, welcher vom Volk gewählt wurde und dieses vertrat, hatte Einfluss auf städtebauliche Projekte. Weiterhin war Reichenbach Mitglied der städtischen Baukommission. Er verwaltete zudem die Turn- und die Fechthalle. ${ }^{44}$

Im Dezember 1916 wurde Reichenbach der Titel des „Geheimen Medizinalrats“ verliehen. ${ }^{45}$ In den letzten Jahren als Professor am Institut hatte Reichenbach immer häufiger gesundheitliche Beschwerden, und er musste sich wegen einer Herzschwäche häufiger krankschreiben lassen. Die erste nachvollziehbare Krankschreibung erfolgte am 25.03.1930. Aus seiner Personalakte wird ersichtlich, dass er aufgrund einer Herzschwäche mehrere Kuraufenthalte in Badenweiler, einem kleinen Ort am Rande des Schwarzwaldes, verbrachte. Trotz seiner gesundheitlichen Beschwerden behielt er auch nach seiner Pensionierung im März 1933 die Leitung des Hygieneinstitutes bei. ${ }^{46}$ Erst im Alter von 70 Jahren schied er am 30.09.1934 aus seinem Amt aus. Seine Nachfolge trat ab dem 01.10. 1934 Franz Schütz an. ${ }^{47}$ Über diese Zeit schrieb eine Institutsmitarbeiterin:

„Es war eine Freude zu erleben, wie sich der junge und der alte Chef zusammensetzten, alle Aufgaben und Pläne gemeinsam besprachen, und Professor Schütz immer bereit war, aus den reichen Erfahrungen des Älteren, besonders bei der Begutachtung von Wasser- und Abwasserproben, Badewässern und anderem, zu lernen. Tagtäglich, drei Jahre lang, arbeitete Geh. Rat Reichenbach noch in seinem gewohnten Labor im Institut bis zwei Tage vor seinem Tode. An diesem zweitletzten Tage seines Lebens erst verließ ihn die Freude an

\footnotetext{
$40 \quad$ Hartung (1963) S. 17

41 Vgl. Göttinger Zeitung (1929) o. S.

42 Vgl. Hartung (1963) S. 22 f.

43 Vgl. Göttinger Zeitung (1929) o. S.

44 Vgl. Hartung (1963) S. 22

45 Vgl. GUA Personalakte Reichenbach, Schreiben vom 19.12.1916

46 Vgl. GUA Personalakte Reichenbach

47 Vgl. GUA Dekanatsakte Beumer, Schreiben vom 02.01.1935
} 
der von ihm über alles gehenden Institutsarbeit: am Montag, den 18. Januar 1937, entschlief Geh. Rat Reichenbach ohne Krankenlager. “48

Die Trauerrede, die Reichenbachs Amtsnachfolger Franz Schütz hielt, gibt ein Bild darüber, wie Reichenbach von seinen Kollegen und Mitarbeitern gesehen wurde.

„Tief erschüttert stehen die Mitglieder des Hygienischen Instituts und der Reichenbachschule an der Bahre ihres einstigen Chefs. Jahre, ja Jahrzehntelang hat er unter uns geweilt und noch können wir es gar nicht fassen, dass dieses bis in die letzten Tage noch so arbeitsreiche Leben jetzt nicht mehr sein soll. Doch rasch tritt der Tod den Menschen an. Uns raubt er heute den großen Forscher, dessen Namen mit goldenen Lettern in das Buch unserer Wissenschaft, der Hygiene, eingeschrieben ist, uns raubt er den einstigen Chef, der nicht minder seinen Namen unvergesslich eingegraben hat in die Herzen aller, denen es vergönnt war, in der täglichen Arbeit ihm näher zu stehen.

Es ist hier nicht der Ort, die wissenschaftlichen Arbeiten des Verblichenen in ihrer Bedeutung einzeln aufzuführen. Nur das sei gesagt, worin für uns die große Bedeutung Reichenbachs liegt. Er war einer von den wenigen Vertretern unseres Faches, der Hygieniker und Bakteriologe gleichzeitig war. Er war ein Mann der reinen Wissenschaft: sein Forscherdrang nach Wahrheit war unbestechlich, sein Mut, das, was er als recht erkannt hatte, auch wenn es sein musste, gegen eine Welt von Gegnern zu verteidigen, unerschütterlich.

Wenn ich als Nachfolger das Amt verwalte, das er bald ein Menschenalter hindurch geführt hat, so weiß ich die Verantwortlichkeit und das Vermächtnis zu wahren, das er mir übergeben hat: In Treue an unserem Fache zu arbeiten, keine Mühe zu scheuen in dem unablässigen Streben nach einem gesunden Leben all unserer Volksgenossen, ein Führer zu sein der jungen Generation, die nach uns kommt und das Erbe von uns übernimmt, und nie zu erlahmen in dem Streben, die Wahrheit zu erkennen.

Ein weißes Leinentuch deckt heute die Erde seiner geliebten Heimat, in die er nun zur letzten Ruhe eingeht, aber wir wissen: ein Frühling wird kommen, in dem die Saat aufgeht, die er in so vielen Herzen gesät, seine Kraft, sein Wesen, wird sie erfüllen in seinem Geist weiter zu arbeiten, das ist das köstlichste Vermächtnis, das er uns hinterlassen hat und das uns heilig ist. Ich grüsse in dem Entschlafenen einen unserer großen Führer, der nun eingeht in die lange Unendlichkeit. Der Name und der Mann Reichenbach aber werden bleiben, solange ein deutscher Forscher danach strebt, unser Volk glücklich und damit gesund zu machen. “49

\footnotetext{
$48 \quad$ Hartung (1963) S. 27
}

49 Hartung (1963) S. 27 f. 


\section{Reichenbachs Zeit am Hygieneinstitut Göttingen}

\section{Die Lehre am Institut}

Von Beginn an übernahm Reichenbach die Lehre an seinem Institut und hielt eine Reihe von regelmäßig stattfindenden Vorlesungen. Zu seiner Lehrtätigkeit äußerte sich Flügge im Jahre 1911, als er Reichenbach für den Lehrstuhl der Hygiene empfahl, mit den Worten:

„Besonders rühmend muss ich sein Lehrtalent hervorheben. “50

Aus anderer Quelle geht hervor, dass Reichenbach auch unter der Studentenschaft für seinen guten Unterricht sehr geschätzt wurde. Als Examensprüfer hatte Reichenbach den Ruf anspruchsvoll zu sein, wenn er auch nicht so „gefürchtet“ war wie der damalige Professor für Pharmakologie. ${ }^{51}$

Während seiner gesamten Amtszeit hielt er die Vorlesungen Hygiene I und II und den Kursus Hygiene und Bakteriologie. Ab dem Sommersemester 1919 hielt er zusätzlich das HygieneKolloquium. Reichenbach stand in dem Ruf, dass ihm die Lehre besonders wichtig war. Dies lässt sich auch anhand der Tatsache vermuten, dass nach dem ersten Weltkrieg aufgrund der großen Studentenzahlen Kurse dreifach abgehalten wurden, um eine adäquate Lehre zu ermöglichen. So wurde zweimal in der Woche der Kurs Bakteriologie von 20 - 23 Uhr gehalten, und die Hauptvorlesung für Bakteriologie begann im Sommer Semester schon um 7 Uhr morgens. $^{52}$

Nachdem das Zahnmedizinische Institut im Jahre 1920 wiedereröffnet worden war, las er dort für die Zahnmediziner „Wichtigste Kapitel der Hygiene“. ${ }^{53}$

Die Eröffnung der Zahnmedizinischen Abteilung spiegelte sich auch in den Themenbereichen der von Reichenbach betreuten Promotionen wider. Etwa die Hälfte der über zwanzig unter Reichenbachs Leitung entstandenen Promotionen waren aus dem Bereich der Zahnmedizin. Zusätzlich zu den regelmäßig gehaltenen Vorlesungen hielt er Sonderveranstaltungen ab, die nicht ständig im Lehrplan vorkamen. So bildete er beispielsweise Feldunterärzte in hygienischen Fragen aus oder hielt eine Vorlesungsreihe „Schulhygiene und Gesundheitspflege in Erziehungsanstalten“. Auch referierte er zum Thema „Medizinalstatistik“, las über Infektionserreger und Infektionskrankheiten und gab Ausbildungskurse für Desinfektoren und Wiederholungskurse für staatlich geprüfte

\footnotetext{
GUA Dekanatsakte Cramer, Schreiben vom 10.06.1911

Vgl. Hartung (1963) S. 22

Vgl. Hartung (1963) S. 20

Vgl. Rieberer (1990) S. 234 - 240
} 
Desinfektoren. ${ }^{54}$ Reichenbach hielt zudem einen Brunnenbaukurs ab, und in den Kriegsjahren des ersten Weltkrieges gab er einen Sonderkurs zur Bekämpfung von Läusen. ${ }^{55}$

Reichenbach gründete am 01.05.1926 eine MTA - Schule ${ }^{56}$, die zu ihrem zehnjährigen Bestehen in Reichenbachschule umbenannt wurde. ${ }^{57}$ Die Reichenbachschule blieb noch bis 1975 dem Hygieneinstitut angegliedert. ${ }^{58}$

\section{Das Aufgabenspektrum des Instituts}

Das Aufgabenspektrum des Institutes war breit angelegt, es wurden die großen Bereiche der Hygiene abgedeckt. Das Institut bestand zum einen, wie damals üblich, aus einem Medizinalamt, welches gesundheitspolizeiliche Aufgaben übernahm, und zum anderen aus dem Institut für Medizinische Chemie und Hygiene.

Zur Aufgabe der medizinalen Untersuchungsämter gehörten Analysen, die der Feststellung und der Weiterverfolgung ansteckender Krankheiten dienten. Hauptgrund der Untersuchungen war es, die Bevölkerung vor der Weiterverbreitung dieser Krankheiten zu schützen. ${ }^{59}$ Beispielsweise wurde im Jahre 1911 nach Typhusvorkommen im Kreis Alfeld eine systematische Untersuchung auf Bazillenträger durchgeführt. Im Verlauf von 6 Monaten wurden zu diesem Zweck 491 Proben untersucht. ${ }^{60}$

Die Aufgaben des Hygienischen Instituts reichten von bakteriologischen Untersuchungen für die Krankenhausabteilungen, über die Herstellung von Impfstoffen für das Heer oder die Beurteilung von Brunnenanlagen für die Stadt, bis hin zur Forschungsarbeit.

Gerade der Trinkwasser- Hygiene war Reichenbach verschrieben. Er legte ein Verzeichnis über die von ihm durchgeführten Wasseruntersuchungen im Hildesheimer Regierungsbezirk an, das von seinem Nachfolger fortgesetzt wurde. ${ }^{61}$ Die Wasserproben wurden vor Ort von den im Landkreis tätigen Desinfektoren entnommen. Nur in besonderen Fällen wurden die Brunnen durch Institutsmitarbeiter begutachtet oder durch sie die Wasserproben gewonnen. Bei Routine-Analysen sendeten die Desinfektoren die Proben in sterilen Flaschen auf dem schnellsten Weg ins Hygienische Untersuchungslabor. ${ }^{62}$

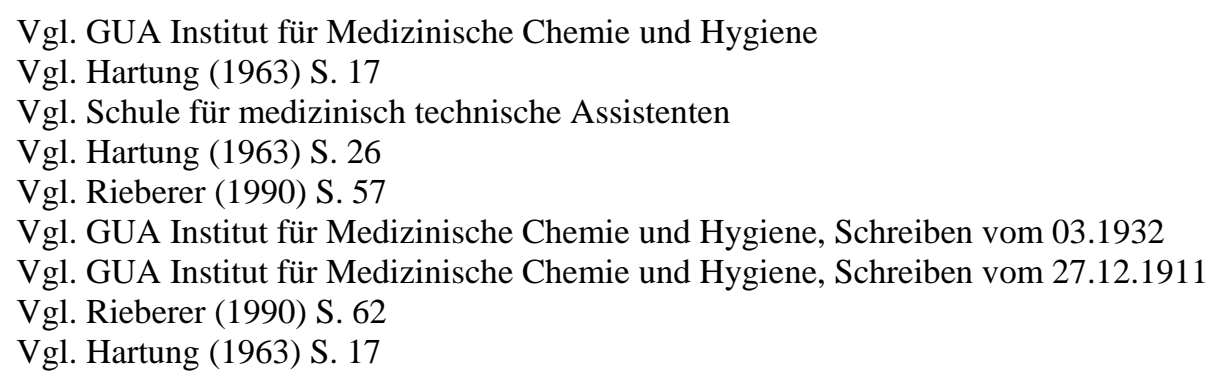


Auch stellte Reichenbach Untersuchungen über die hygienischen Eigenschaften der Kunstseide an. Die Versuche, die durch die „Bamberger Kunstseide“ finanziert wurden, beschäftigten sich vor allem mit dem Einfluss bewegter Luft auf den bekleideten Körper. ${ }^{63}$ Ebenfalls kam er anderen Bereichen universitärer Aktivitäten nach. So richtete das Institut vom 12. bis 14 Mai 1924 die 10. Tagung der deutschen Vereinigung für Mikrobiologie aus, die in den Räumen der Anatomie in Göttingen stattfand. Weiterhin ist belegt, dass sich im Sommer 1926 das Institut an einer Ausstellung für Gesundheitspflege, Soziale Hygiene und Leibesübungen in Düsseldorf beteiligte. ${ }^{64}$

Exemplarisch für die Arbeit am Medizinalamt sei zusammenfassend der Jahresbericht für 1932 wiedergegeben: ${ }^{65}$ Die Gesamtzahl der untersuchten Proben für dieses Jahr lag bei

23 471, die an den Proben durchgeführten Untersuchungen beliefen sich auf 29 840. Die Proben wurden auf folgende Krankheiten hin untersucht:

1) Typhus und Paratyphus, Nahrungsmittelvergiftung, Ruhr etc.

2) Diphtherie, Angina Plaut- Vincenti etc.

3) Hämolytische Streptokokken

4) Tuberkulose

5) Genickstarre (Liquoruntersuchung)

6) Gonorrhö

7) Syphilis

8) Sonstige bakteriologische Untersuchungen

9) Klinische und ähnliche Untersuchungen z.B. Blutausstrich, Blutgruppentests, Untersuchung auf Bleivergiftung und ähnliches

10) Wasseruntersuchungen.

63 Vgl. GUA Institut für Medizinische Chemie und Hygiene, Verschiedenes und Rieberer (1990) S. 62 64 Vgl. Hartung (1963) S. 23

65 Vgl. GUA Institut für Medizinische Chemie und Hygiene, Verschiedenes, Bericht vom 15.06.1932 


\section{Reichenbach und seine berufliche Laufbahn im Bezug zu den Geschehnissen der damaligen Zeit}

Die Schaffensphase Reichenbachs fiel in eine bewegte, von Krisen heimgesuchte Zeit. Die Industrialisierung um 1900, mit der eine Abwendung vom Agrar- zum Industriestaat einherging, schaffte eine Grundlage für die moderne Hygiene. Was Eulner in seinem Werk „Die Entwicklung der medizinischen Spezialfächer“ so formulierte:

„Die Zeit war reif für eine staatlich autorisierte, streng wissenschaftlich arbeitende Hygiene. Die Industrialisierung, das rasche Wachstum der Städte stellte immer neue Aufgaben, die die Mitarbeit des Hygienikers geradezu forderten: Wasservorsorgung, Abwässerbeseitigung, Lebensmittelüberwachung, Bestattungswesen, Seuchenabwehr. Der Typhus schien allgegenwärtig, und die Cholera hielt das 19. Jahrhundert bis zuletzt in Atem. “66

Auf der anderen Seite war die Amtszeit Reichenbachs durch die damaligen Unruhen, die eine effiziente Forschung immer wieder verhinderten, gezeichnet. Besonders schwer waren, wie Aktennotizen aus dem Hygieneinstitut zeigen, die Jahre 1914 bis 1918, in denen der erste Weltkrieg die finanziellen Mittel stark einschränkte. Aber nicht nur finanziell war die Lage schwierig. Es bestand ein allgemeiner Engpass darin, überhaupt an die für die Forschungsarbeiten benötigten Mittel heranzukommen. So schrieb Reichenbach im Dezember 1916 in einem Brief an den Minister für Inneres:

„Am Personalbestand des Amtes hat sich gegen das Vorjahr nichts geändert. Das Fehlen eines medizinisch gebildeten Assistenten wurde durch die ständige Mitarbeit des Direktors ausgeglichen.

Noch viel mehr als im Vorjahr traten die durch den Krieg bedingten Schwierigkeiten in der Beschaffung von Materialien und Geräten hervor. Nachdem die zu Anfang des Krieges hingelegten Vorräte von Agar- Agar ${ }^{67}$ und Fleischextrakt aufgebraucht waren, mussten neue Mengen zu wesentlich erhöhten Preisen gekauft werden. Auch bei den übrigen Bedürfnissen, Glassachen, Versandmaterial, Drucksachen, etc. sind die Preise sehr stark gestiegen “. 68

Reichenbach gelang es trotz der widrigen Umstände, die Kosten zur Aufrechterhaltung des Betriebes gering zu halten. Dies belegte er dem Minister für Inneres im Jahre 1918 mit einer Kostenrechnung, die Reichenbach wie folgt kommentierte:

\footnotetext{
66 Eulner (1970) S.143

67 Agar- Agar ist ein Gelierzusatz für die Herstellung von Nährböden für Mikroorganismen

68 GUA Institut für Medizinische Chemie und Hygiene, Schreiben vom 20.12.1916
} 
„Es geht daraus hervor, dass trotz der Teuerung die Kosten für die einzelnen Untersuchungen immer noch erheblich niedriger sind, als im Frieden, sie sind auch, das möchte ich besonders hervorheben, niedriger als bei allen anderen Untersuchungsämtern, von denen mir die Zahlen bekannt sind.

Der Grund für diesen billigen Betrieb liegt selbstverständlich hauptsächlich darin, dass die Anzahl der Untersuchungen gegen früher fast auf das Doppelte gestiegen ist, während die Generalunkosten nicht in demselben Maße gewachsen sind. Besonders sind die Kosten für das Personal gegen früher nicht erheblich vermehrt. Dass mit demselben Personal die doppelte Arbeit bewältigt werden konnte, hat außer in der stark vermehrten Arbeitsleistung des einzelnen auch darin seinen Grund, dass statt des Assistenten eine dritte Laborantin beschäftigt und dass die Arbeit des Assistenten vom Institutsdirektor versehen wurde. So gerne ich bislang diese Arbeit auf mich genommen habe und so bereitwillig ich es auch weiterhin während der Kriegsdauer tun werde, wird es mir doch später, wenn der Institutsbetrieb wieder meine Arbeitskraft in vollem Masse in Anspruch nimmt, nicht mehr möglich sein, in der bisherigen Weise mitzuarbeiten. “69

Trotz aller Bemühungen Reichenbachs, die Kosten niedrig zu halten, kam es immer wieder zu Engpässen. Im Jahre 1915 war es dem Institut nicht möglich, die Lohnrechnungen für den Monat Dezember zu zahlen. Im darauf folgenden Jahr reichten die dem Institut zur Verfügung gestellten Mittel nicht aus, die Gehälter für die Monate November und Dezember auszuzahlen. Dieselbe Situation lag im Jahre 1917 vor. Reichenbach richtete sich jeweils an den Minister für Inneres, um finanzielle Hilfe zu erwirken.

Die Zuschüsse, die zur Aufrechterhaltung des Betriebs nötig waren, wurden teilweise sehr verzögert gezahlt. Dies geht auch aus einem Brief Reichenbachs an den Minister hervor, indem er sich über diese späte Bereitstellung der finanziellen Mittel beklagte.

„Eure Exzellenz erlaube ich mir zum Schluss ehrerbietigst darauf aufmerksam zu machen, dass die bisher übliche späte Überweisung des Zuschusses zu großen Unzuträglichkeiten führt. Durch die späte Überweisung des Zuschusses, die in diesem Jahre erst am 12. Dezember und zwar auf wiederholte Vorstellungen erfolgte, ist das Untersuchungsamt in die peinliche Lage versetzt, weitaus den größten Teil des Etatjahrs ohne verfügbare Mittel zu sein. Es ist nur durch das Entgegenkommen des Herrn Kurators, der eine vorschüssige Zahlung der dringendsten Rechnungen durch die Universitätskasse genehmigte, möglich geworden den Betrieb aufrecht zu erhalten. “70

69 GUA Institut für Medizinische Chemie und Hygiene, Schreiben vom 29.04.1918

70 GUA Institut für Medizinische Chemie und Hygiene, Schreiben vom 29.04.1918 
Wie zu ersehen ist, war in den Kriegsjahren das Hygieneinstitut unterbesetzt, da zu Beginn des Krieges 1914 sämtliche männliche Mitarbeiter des Instituts zur Waffe einberufen wurden. „Der Chef war (unter sehr erschwerten Umständen) mit Institut und Untersuchungsamt, mit allen Vorlesungen, Übungen und Kursen auf seine eigene Kraft und die der wenigen weiblichen Hilfskräfte angewiesen. “71

Darüber hinaus wurde ein Teil der zu leistenden Arbeit darauf verwandt, Impfstoffe für das Heer bereitzustellen und ebenfalls für das Heer bakteriologische Untersuchungen durchzuführen. Dies kommentierte eine Institutsangestellte folgendermaßen:

„Eine ganz große Belastung bedeutete es für den verkleinerten Institutsbetrieb, dass von der Militärverwaltung die Herstellung von Choleraimpfstoff zu Hunderten von Litern verlangt wurde. Auch Typhusimpfstoff musste hergestellt werden. “ 72

Im Rahmen der Impfstoffherstellung war auch Frau Reichenbach monatelang im Institut eingespannt. Sie half täglich beim Einfüllen, Zustöpseln und Etikettieren des Impfstoffes. ${ }^{73}$

Reichenbach bemühte sich besonders auch während der Kriegszeit, den Betrieb trotz der schweren Lage aufrecht zu erhalten und, ungeachtet der Unterbesetzung, die für das Heer notwendigen hygienischen Aufgaben effizient durchzuführen. Dies spiegelt sich auch in einem Schreiben wider, in dem Reichenbach vom Rektor der Georg August Universität für eine Kriegsauszeichnung vorgeschlagen wurde.

„Von den Kollegen, die sich während des Krieges hier ganz besondere Mühe für das Allgemeinwohl gegeben haben, ist einer der ersten Geh. Med. Rat Prof. Dr. Reichenbach.

Er hat die ganze Kriegszeit hindurch in unermüdlicher und rastloser Tätigkeit, durch die er sich gelegentlich weit über die Grenzen seiner gesundheitlichen Kräfte angestrengt hat, den durch die Kriegsverhältnisse besonders schwierigen Betrieb seines Institutes im Dienste der vaterländischen Interessen aufrecht erhalten und sich in der ganzen Zeit kaum einmal eine kurze Erholung gegönnt.

Außerdem hat er in unmittelbarem Dienst der Heeresverwaltung durch Herstellung von Impfstoffen in hervorragendem Maße dazu geholfen, dass wir in diesem Kriege von Seuchen so glücklich verschont geblieben sind. “74

Ob Reichenbach die erwähnte Auszeichnung tatsächlich erhalten hat, ist nicht zu eruieren.

\footnotetext{
Hartung (1963) S. 18

Hartung (1963) S. 19

Vgl. Hartung (1963) S. 19

GUA Personalakte Reichenbach, Schreiben vom 12.1917
} 
Was sich jedoch rekonstruieren lässt, ist die Tatsache, dass er, bedingt durch seine wichtige Tätigkeit am Institut, nie im Heer dienen musste und auch nie in einem medizinischen Dienst im Kriegsgebiet eingesetzt wurde. ${ }^{75}$

Nachdem der Erste Weltkrieg überstanden war, verbesserten sich die Arbeitsbedingungen am Institut nur vorübergehend. Zahlreiche Dokumente aus der Zeit der Weimarer Republik belegen, dass die finanziellen Nöte im Jahre 1923 mit dem Erreichen des Höhepunktes der Inflation in Deutschland enorm waren. Bereits im Jahre 1922 berichtete Reichenbach von einer „ungeheueren Preissteigerung“, ${ }^{76}$ die die finanzielle Lage des Instituts bedenklich machte. Im besagten Jahr war der dem Institut bewilligte Jahresetat von 29800 Mark bereits im September aufgebraucht. Hierfür waren laut Reichenbach zum einen die Preissteigerungen und zum anderen nicht beglichene Rechnungen aus dem Vorjahr verantwortlich.

Die Preise betrugen, so geht aus dem Schreiben hervor, über das Hundertfache der Preise zu Friedenszeiten. Für Brennmaterialien betrug der Preis sogar fast das Dreihundertfache und die Lage spitzte sich im Jahre 1923 weiter $\mathrm{zu} .^{77}$

Auch nachdem die Spitze der Inflation erreicht war, gestaltete sich die Lage äußerst prekär. Im Jahre 1924 befand sich das Institut schon im März in einem derartig finanziellen Engpass, dass die Zahlung der Gehälter an die Angestellten nicht sicher gewährleistet werden konnte. In dieser Situation wendete sich Reichenbach bittend an den Kurator der Universität, da wie Reichenbach anmerkte, dessen Wort bei der Bitte um Zuschüsse beim Ministerium schwerer wog. $^{78}$

Die Kriegsjahre und die Zeit der enormen wirtschaftlichen Engpässe spiegeln sich in der wissenschaftlichen Arbeit Reichenbachs wider. Die meisten seiner Veröffentlichungen sind vor Beginn des ersten Weltkrieges erschienen. Einen nochmaligen Anstieg an Veröffentlichungen kann man in der Zeit zwischen Weltkrieg und Inflation erkennen. Gegen Ende seiner beruflichen Laufbahn nimmt die Zahl der von Reichenbach verfassten Aufsätze erneut ab.

Ob dies persönliche Gründe hatte, oder auf die anhaltenden wirtschaftlichen Probleme zurückzuführen ist, ist nur zu vermuten. Zweifellos hatte das Institut nach wie vor mit der finanziellen Lage zu kämpfen. Dies wird unter anderem durch die Tatsache belegt, dass sich

\footnotetext{
Vgl. GUA Personalakte Reichenbach, Schreiben vom 08.1925

76 Vgl. GUA Institut für Medizinische Chemie und Hygiene, Schreiben vom 19.09.1922

77 Vgl. GUA Institut für Medizinische Chemie und Hygiene, Schreiben vom 19.09.1922

78 Vgl. GUA Institut für Medizinische Chemie und Hygiene, Schreiben vom 06.03.1924
} 
trotz der anhaltenden Bemühungen Reichenbachs, die mangelhaften räumlichen Bedingungen des Instituts zu verbessern, daran bis zum Ende seiner Laufbahn nichts änderte. ${ }^{79}$

Aufgrund der geringen wirtschaftlichen Unterstützung finanzierte Reichenbach sogar die Verlegung von elektrischen Leitungen aus eigenen Mitteln. ${ }^{80}$

Auch bei der Lektüre der Institutsakten stößt man immer wieder auf Schreiben, die die finanziell klamme Situation belegen. So kann man beispielsweise aus einem Schriftwechsel, der 1932 zwischen dem Direktor Reichenbach und dem Kurator der Universität Göttingen geführt wurde, ersehen, dass das Untersuchungsamt des Hygienischen Institutes kurz vor der Schließung stand, da die Mittel zur Aufrechterhaltung des Betriebs nicht mehr zur Verfügung gestellt werden konnten. ${ }^{81}$

Die Schließung konnte nur abgewendet werden, weil Reichenbach durch verschiedene Maßnahmen erreichte, dass sich das Institut selbstständig trug. Beispielsweise besetzte er eine frei gewordene Stelle nicht neu, sondern trug die Mehrbelastung selber. ${ }^{82}$ Reichenbach erwirkte aber nicht nur Einsparungen, die das Institut retten sollten. Er setzte auch Mehreinnahmen durch. Fortan mussten die Kliniken für bakteriologische Untersuchungen selber aufkommen. Bis dahin war ein großer Teil dieser Untersuchungen für die Krankenhausabteilungen kostenlos gewesen. ${ }^{83}$

Wie dringend eine bauliche Veränderung der Institutsräume gewesen wäre, die aus Mangel an finanziellen Möglichkeiten ausblieb, veranschaulicht eine Beschreibung derselben durch Reichenbachs Nachfolger Franz Schütz.

„Derartig primitive Einrichtungen - vom Geruch her ganz zu schweigen - haben wir nur unter den finstersten Verhältnissen unseres Vormarschs in Polen angetroffen. Man kann natürlich auch auf diese Art und Weise behelfsmäßig desinfizieren, und daher ist vielleicht unser Institut für alle Zivil- und Militärärzte eine geeignete Ausbildungsstätte gewesen, in der sie lernten, wie man sich mit den bescheidensten Mitteln einrichten kann. “84

Zum Ende der Amtszeit Reichenbachs war Deutschland vom politischen Gedankengut der Nationalsozialisten geprägt. Über die Gesinnung Reichenbachs ist wenig in Erfahrung zu bringen.

\footnotetext{
Vgl. Rieberer (1990) S. 58 f und Hartung (1963) S. 22

Vgl. Rieberer (1990) S. 58

Vgl. GUA Institut für Medizinische Chemie und Hygiene, Schreiben vom 12.01.1932

Vgl. GUA Institut für Medizinische Chemie und Hygiene, Bericht vom 07.06.1933

Vgl. GUA Institut für Medizinische Chemie und Hygiene, Schreiben vom 12.01.1932 und vom 13.05.1932

Schütz (1941) S. 39
} 
Klar ist nur, dass er bis zum Ende seiner beruflichen Tätigkeit nicht der NSDAP beigetreten ist. Dies geht aus Anschreiben hervor, in denen der Minister für Inneres die Mitgliedschaft der Beamten zur Partei abfragte. ${ }^{85}$

Auch distanzierte sich Reichenbach als Hygieniker (vgl. S. 9 dieser Arbeit) von der Rassenhygiene, die seiner Meinung nach nicht zum Aufgabengebiet der klassischen Hygiene gerechnet werden könne. ${ }^{86}$

Außer den genannten Quellen, die nahe legen, dass Reichenbach dem Lager der Nationalsozialisten nicht nahe stand, gibt es keine weiteren Hinweise, die etwas über die politische Gesinnung Reichenbachs aussagen.

85 Vgl. GUA Personalakte Reichenbach, Schreiben von Aug. 1935

86 Vgl. Reichenbach (1926) S. 31 


\section{Das wissenschaftliche Werk Reichenbachs im Kontext der Zeit}

Reichenbach war in seiner über zwanzigjährigen, leitenden Tätigkeit sowohl allgemeinhygienisch als auch bakteriologisch tätig. Seine Arbeiten behandelten ein breites Spektrum der Hygiene. Reichenbach machte Veröffentlichungen auf dem Gebiet der Trinkwasserhygiene, der er sich besonders verschrieben hatte. Er legte für den Regierungsbezirk Hildesheim eine Kartothek an, basierend auf den Daten der von ihm durchgeführten Wasseruntersuchungen. Ein weiteres Gebiet seiner Forschungen war die Beleuchtungshygiene, zudem beschäftigte er sich eingehend mit dem Thema der Desinfektion. Auch die Kleidungshygiene und bakteriologische Themen wurden von ihm behandelt. Auf dem Gebiet der Bakteriologie veröffentlichte er unter anderem Arbeiten zur Tuberkulose, ging der Frage der Vererbung bei Einzellern nach und nahm eine Einteilung der Krankheitserreger vor.

Betrachtet man die Forschungsgebiete Reichenbachs, kann man feststellen, dass er sich mit den Kernfragen der Hygiene beschäftigte. Seine Forschungsarbeiten lagen im Strom der Zeit. Richtet man aus heutiger Sicht sein Augenmerk auf die großen Erfolge der damaligen Zeit, stellt man fest, dass die Errungenschaften in kleineren Teilgebieten der Hygiene erzielt wurden. Sie lagen mehr im Bereich der Immunologie und Serologie.

Im Bereich der Immunologie konnte man schon Ende des 19. Jahrhunderts Erfolge verzeichnen. So entdeckte Robert Koch beispielsweise den Tuberkuloseerreger, und Louis Pasteur $(* 1822$ - †1895) gelang 1885 die erste erfolgreiche Impfung gegen Tollwut. Ein weiterer wichtiger Erfolg war der von Emil Adolf von Behring $(* 1854$ - †1917), der erfolgreich ein Antiserum gegen Diphtherie verabreichte. 1901 wurde von Behring, der zeitweise Ordinarius für Hygiene in Marburg war, für seine Forschungserfolge mit dem damals erstmals verliehenen Nobelpreis für Medizin ausgezeichnet.

Auch in den folgenden Jahren wurden bahnbrechende Erfolge verzeichnet. Es wäre beispielsweise die Entdeckung der keimtötenden Wirkung des Schimmelpilzes der Gattung Penicillium durch Alexander Flemming (*1881 - †1955) im Jahre 1928 zu nennen. 


\section{Institutsgeschichte}

An dieser Stelle folgt ein kurzer Überblick über die geschichtliche Entwicklung des Hygieneinstituts in Göttingen. Diese Übersicht soll die zu Reichenbach gegebene Darstellung ergänzen.

Gegründet wurde das Hygieneinstitut 1883 von Carl Flügge (*1847 - †1923). Flügge kam 1881 nach Göttingen, wo er zu Anfang unter Georg Meißner (*1829 - †1905) am Physiologischeninstitut eine eigene Abteilung für medizinische Chemie und Hygiene einrichtete. ${ }^{87}$ Im Jahre 1883 wurde die Abteilung zum eigenständigen Institut, dem ersten Hygieneinstitut Preußens. Flügge war sowohl Schüler Pettenkofers als auch Kochs und ist somit ein Beispiel für die Annäherung der beiden unterschiedlichen Lager der Hygiene, dem bakteriologischen Lager nach Koch und dem allgemein hygienischen Lager nach Pettenkofer. Trotzdem lag der Forschungsschwerpunkt Flügges im Bereich der Bakteriologie. Unter seiner Leitung am Institut wurden herausragende Leistungen erzielt, wie die Isolierung und Kultivierung des Tetanusbazillus. ${ }^{88}$

Gustav Wolfhügel (*1854 - †1899) war ab 1887 der Nachfolger von Flügge und ebenfalls Schüler Pettenkofers $\left(* 1818\right.$ - †1901) und Kochs $\left(* 1843\right.$ - †1910). ${ }^{89}$ Er leitete das Göttinger Institut bis 1899. Eine seiner Leistungen war es, nach langen Bemühungen den Umzug des Instituts in größere Räumlichkeiten durchzusetzen. Das Institut war von nun an im ehemaligen Ernst-August-Hospital in der Geiststraße untergebracht. $^{90}$ Der Forschungsschwerpunkt unter Wolfhügel lag im Bereich der Beleuchtungshygiene und dem Desinfektionswesen. Mit diesen Themen wurde auch der unter Wolfhügel tätige Assistent Reichenbach betraut. Wolfhügel selber hatte während seiner leitenden Tätigkeit in Göttingen keine wissenschaftlichen Arbeiten veröffentlicht. ${ }^{91}$

Die Nachfolge Wolfhügels trat 1899 Erwin von Esmarch (*1855 - †1912) an, welcher das Institut bis 1911 leitete. Auch Esmarch war ein Schüler von Koch und reihte sich somit in die Liste seiner Vorgänger ein. ${ }^{92}$ Seine Forschungsarbeit umfasste das gesamte Spektrum der Hygiene. Esmarch war bakteriologisch tätig, beschäftigte sich aber auch mit der Serologie und der Virologie. Darüber hinaus deckten seine Arbeiten die Bereiche der allgemeinen Hygiene ab. Unter Esmarch gelang 1902 der Nachweis, dass ein Zusatz von Formaldehyd die

\footnotetext{
Vgl. Rieberer (1990) S. $11 \mathrm{f}$.

Vgl. Rieberer (1990) S. 22

Vgl. Rieberer (1990) S. 28

Vgl. Rieberer (1990) S. 29

Vgl. Rieberer (1990) S. 37

Vgl. Rieberer (1990) S. 46
} 
Desinfektionseigenschaften von Wasserdampf erheblich steigern kann. Auch gelang es Esmarch, eine Methode zu entwickeln, mit der eine quantitative Bestimmung des Bakterium Coli- Gehalts im Wasser möglich war, die unter dem Namen „Göttinger Verfahren“ bekannt wurde. ${ }^{93}$ Darüber hinaus setzte er Umbaumaßnahmen am Institut durch.

Reichenbach wurde 1911, nachdem er zwei Jahre lang in Bonn als außerordentlicher Professor gearbeitet hatte, in Göttingen Ordinarius am Hygieneinstitut, welches er bis 1934 leitete.

Seine Nachfolge trat Franz Schütz $(* 1887$ - †1955) im Jahre 1934 an. Franz Schütz wurde als Nachfolger Reichenbachs berufen, obwohl er nicht auf der Fakultäts- Liste aufgeführt war. Sein Ruf nach Göttingen könnte durch seine Mitgliedschaft in der NSDAP begünstigt worden sein, der er am 01.04.1933 beigetreten ist. ${ }^{94}$ Im Jahre 1945 wurde er nach einer Anklage des Entnazifizierungsausschusses vom Lehrdienst suspendiert, kehrte jedoch im Jahre 1950 an den Lehrstuhl zurück, den er dann bis zu seinem Tode im Jahre 1955 inne hatte. ${ }^{95}$

Schütz konnte während seiner ersten Amtszeit in Göttingen den Umzug in neue Räumlichkeiten durchsetzen ${ }^{96}$ und erwirkte zudem eine Namensänderung von „Institut für medizinische Chemie und Hygiene“ in „Hygienisches Institut“. Mit der Namensänderung wurde man der Tatsache gerecht, dass schon seit Jahren kein Unterricht mehr für medizinische Chemie gegeben wurde. ${ }^{97} \mathrm{Da}$ die Realisierung des Umzuges viel Zeit in Anspruch nahm, lag der größere Teil seiner wissenschaftlichen Tätigkeit in seiner zweiten Amtszeit von 1950 bis 1955. Schwerpunktmäßig beschäftigte er sich mit den Themen der Blutgruppenforschung, der Bakteriologie, der Epidemiologie und der Wasserhygiene. ${ }^{98}$

Theodor J. Bürgers (*1881 - †1954) leitete das Hygieneinstitut von 1945 - 1950, dem Jahr seiner Emeritierung. In seiner wissenschaftlichen Arbeit setzte er sich eingehend mit der Bakteriologie auseinander, wobei seine Schwerpunkte bei der Diphtherie und der Tuberkulosebehandlung lagen. Aber auch die Epidemiologie, die Wohnungshygiene sowie die Städteplanung waren Themen, die er behandelte. ${ }^{99}$

Wie oben erwähnt, trat nachdem Bürgers in den Ruhestand ging, Franz Schütz nochmals die Leitung des Instituts an. Er wurde durch Henning Brandis abgelöst, der bis 1967 am Institut tätig war. Reiner Thomssen folgte im Jahre 1968, er war der letzte Institutsleiter, der den gesamten Lehrstuhl für Hygiene innehatte. 1973 kam es zu einer Teilung in einen Lehrstuhl

\footnotetext{
93 Vgl. Rieberer (1990) S. 46 f.

94 Vgl. Rieberer (1990) S. 68

95 Vgl. Rieberer (1990) S. 72 f.

96 Vgl. Zimmermann (2009) S. 87

97 Vgl. Rieberer (1990) S. $76 \mathrm{f}$.

98 Vgl. Rieberer (1990) S. 83

99 Vgl. Rieberer (1990) S. 118
} 
für medizinische Mikrobiologie und einen weiteren Lehrstuhl für Allgemeine Hygiene. 1975 wurde aus dem Bereich der Allgemeinen Hygiene nochmals der Bereich Arbeits- und Sozialmedizin abgespalten. ${ }^{100}$

Betrachtet man die Arbeitsschwerpunkte der einzelnen Institutsleiter in der damaligen Zeit, fällt auf, dass diejenigen, die sich in ihrer Amtszeit vermehrt für neue Räumlichkeiten stark machten, weniger Forschungsarbeit leisteten als diejenigen, die sich um solche Belange nicht kümmern mussten. Dies war so bei Gustav Wolfhügel, der keine wissenschaftliche Veröffentlichung in seiner Göttinger Zeit machte, dafür aber einen Institutsumzug herbeiführte. Auch bei Franz Schütz kann man erkennen, dass er in seiner ersten Amtszeit vorrangig mit der Umsetzung des Umzuges beschäftigt war, während er in seiner zweiten Amtszeit deutlich mehr Forschungsarbeit aufweisen konnte.

Reichenbachs Bemühungen, bauliche Änderungen zu ermöglichen blieben erfolglos. Dies ist sicher durch die ungünstigen zeitlichen Umstände bedingt. Trotz dieser Umstände kann Reichenbach eine Reihe an Veröffentlichungen vorweisen.

100 Vgl. Rieberer (1990) S. 133 
7. Das wissenschaftliche Werk Reichenbachs 


\subsection{Bakterien in Luft, Wasser, Erdboden und Milch ${ }^{101}$}

Im vorliegenden Werk Hans Reichenbachs haben wir es mit einer Abhandlung über Theoretisches zu Bakterien in unterschiedlicher Umgebung zu tun. Die Arbeit beginnt mit dem Kapitel „Bakterien in der Luft“. Die Arbeit ist ein Beispiel für die Auseinandersetzung Reichenbachs mit bakteriologischen Fragen.

\section{Bakterien in der Luft}

Reichenbach beschrieb, dass Bakterien nur auf zwei Wegen in die Luft gelangen konnten; entweder trocken, meist an Staub gebunden, oder in Verbindung mit Wassertropfen. ${ }^{102}$ Damit Bakterien an Staub gebunden in der Luft schweben konnten, mussten sie zu einem bestimmten Grad ausgetrocknet sein.

Ob Bakterien getrocknet in der Luft vorkommen, hängt also von zwei Faktoren ab:

o wie resistent sie gegenüber dem Austrocknen sind,

o ob es ausreichende Luftbewegungen gibt, die die Bakterien zum Schweben bringen.

Die durch Versuche verifizierten Überlegungen lassen den Schluss zu, welche Bakterien bei normaler Luftströmung im Innenraum überhaupt über den Luftweg verbreitet werden können. Hierzu gehören z.B. die Tuberkelbacillen, Staphylokokken und Thyphus.

Choleravibrionen, Pestbazillen und Influenzabazillen sterben dagegen immer ab, bevor sie in der Luft zum Schweben kommen. Eine Verbreitung dieser Erreger ist somit bei Luftströmungen, wie sie in geschlossenen Räumen vorkommen, nicht möglich.

Im Freien, wo höhere Luftströmungen herrschen, kommen laut Reichenbach die oben genannten Erreger nicht dauerhaft vor, da sie sich außerhalb des Organismus nicht vermehren können.

„Eine Infektion durch Staub im Freien wird deshalb zu den allergrößten Seltenheiten gehören. “103

$\mathrm{Zu}$ unterscheiden sind von den an Staub haftenden Bakterien die, die an Wassertröpfchen gebunden in die Luft gelangen, z.B. beim Husten, Niesen oder Sprechen. Diese in der Luft befindlichen Keime können auch schon bei geringster Luftbewegung im Schwebezustand verbleiben, und mitunter größere Entfernungen überwinden. Da in diesem Fall keine Schädigung durch Austrocknung vorliegt, kann man an Wassertopfen gebundene Keime in

\footnotetext{
101 Vgl. Reichenbach (1919)

102 Vgl. Reichenbach (1919) S. 395

103 Reichenbach (1919) S. 396
} 
der Luft finden, die in getrockneter Form nicht in der Luft vorkommen. Zudem ist, wie Versuche gezeigt haben, die Infektiosität der an Wasser gebundenen Keime deutlich höher. ${ }^{104}$ Im Freien kann man ein anderes Spektrum an Keimen beobachten, als es in Innenräumen vorkommt. Die Hauptgruppen bestehen aus Stäbchen, Kokken und Schimmelpilzen. Der Keimgehalt der Luft im Freien variiert stark, je nach den äußeren Bedingungen. Am größten ist die Keimbelastung bei Trockenheit und Wind, aber auch bei Nebel liegen viele Keime in der Luft vor. ${ }^{105}$

\section{Bakterien im Wasser}

Nach Reichenbach gäbe es aus medizinischer Sicht im Wasser drei Bakteriengruppen die von Bedeutung wären. ${ }^{106}$ Man unterschied die, die dauerhaft im Wasser lebten von solchen, die nur temporär im Wasser vorkämen. Die dritte Gruppe stellten die pathogenen Bakterien, welche aus medizinischer Sicht besonders interessant wären.

\section{Die Bedeutung der im Wasser vorkommenden pathogenen Bakterien und die von ihnen verursachten Infektionskrankheiten}

Die meisten durch Wasser übertragenen Infektionskrankheiten sind MagenDarmerkrankungen. In unseren Breitengraden spielt dabei der Thyphus eine entscheidende Rolle. Eine weitere, nicht ganz so häufig vorkommende Erkrankung aus diesem Bereich ist die Cholera. Von Bedeutung ist, so Reichenbach, dass alle humanpathogenen Keime nicht dauerhaft im Wasser leben können und sich dort auch nur bedingt vermehren. ${ }^{107}$

Aus hygienischer Sicht interessant und somit Gegenstand vieler Forschungsarbeiten war die Frage, wie lange sich pathogene Organismen im Wasser halten können. Zahlreiche Untersuchungen zeigen, dass das Überleben der Keime stark von äußeren Einflüssen abhängig ist und somit eine verbindliche Aussage kaum zu treffen ist. ${ }^{108}$ Die Aufgabe der Hygiene ist es, zu verhindern, dass Keime ins Wasser (z.B. Brunnen) gelangen können und sich von dort ausbreiten.

$\begin{array}{ll}104 & \text { Vgl. Reichenbach (1919) S. } 396 \\ 105 & \text { Vgl. Reichenbach (1919) S. } 397 \\ 106 & \text { Vgl. Reichenbach (1919) S. } 398 \\ 107 & \text { Vgl. Reichenbach (1919) S. } 399 \\ 108 & \text { Vgl. Reichenbach (1919) S. } 400\end{array}$ 


\section{Zu der Bedeutung der nichtpathogenen Keime im Wasser}

Man hoffe, durch die Analyse der nicht pathogenen Keime im Wasser, z.B. von Wasserversorgungsanlagen, Rückschlüsse auf die Qualität des Wassers machen zu können, beziehungsweise beurteilen zu können, ob es oberflächliche Zuflüsse zu der Anlage gab, über die potentiell auch Krankheitserreger eingeschleppt werden könnten.

Es war bekannt, dass das Grundwasser an sich keimfrei ist. In der Praxis waren jedoch die Brunnen mit Keimen belastet, da durch die Erbauung der Anlagen Keime ins Grundwasser gelangen konnten.

Klar war, dass über den reinen Keimgehalt des Wassers kein Rückschluss auf den Grad der Verunreinigung eines Brunnens gemacht werden konnte, da vermutlich durch den im Brunnen vorhandenen Sauerstoffmangel die Keimzahl recht konstant blieb und sich nicht explosionsartig vermehrte. ${ }^{109}$

Um eine Differenzierung machen zu können, wäre es interessant gewesen zu beurteilen, ob die sich im Wasser befindlichen Keime echte Wasserbakterien waren die von Anfang an in der Anlage zu finden waren, oder ob die Keime durch späteren Zufluss hineingelangen konnten und es sich somit nicht um typische Wasserkeime handelte. Diese Überlegung war jedoch in der Praxis schwer umzusetzen und setzte einen großen Erfahrungswert des Untersuchers voraus. Reichenbach kommentierte wie folgt:

„In Wirklichkeit existiert eine solch scharfe Grenze nicht. Die eigentlichen Wasserbakterien sind zum Teil auch im Boden vorhanden, und können mit oberflächlichen Zuflüssen immer von nеuет in das Grundwasser gespült werden; andererseits kann ein Teil der wasserfremden Saprophyten unter günstigen Bedingungen solange im Wasser sich halten, dass ihr Vorhandensein jedenfalls nicht mehr als Beweis für eine frische Verunreinigung angesehen werden kann. “110

\section{Zu den eigentlichen Wasserbakterien}

Die Wasserbakterien waren zu Reichenbachs Zeit noch weitgehend unerforscht, was er in dem vorliegenden Aufsatz auch bemängelte.

„Eine allgemein anerkannte Systematik der Wasserbakterien ist nicht vorhanden. “111

Bekannt waren bestimmte Charakteristika der Bakterien, wie z.B. die besonderen Ansprüche an den Nährboden und die vergleichbar niedrige Temperatur zum Heranziehen der Kulturen.

109 Vgl. Reichenbach (1919) S. 402

110 Reichenbach (1919) S. 403

111 Reichenbach (1919) S. 403 


\section{Die vorübergehend im Wasser lebenden Saphrophyten}

Die Angaben über die Zahl der vorübergehend im Wasser zu findenden Bakterienarten variiert sehr stark. Es gab Autoren, die maximal 40 Arten beschrieben während andere von über 180 Arten sprachen. ${ }^{112}$ Reichenbach beschreibt als häufigen Ursprungsort der transient im Wasser vorkommenden Bakterien die oberen Schichten des Erdbodens.

Als besonders geeigneten Indikator für die Verunreinigung von Wasser hält er das Bakterium coli. ${ }^{113}$ Das Bakterium hat den Vorteil, dass es leicht zu identifizieren ist und auf keinen Fall dauerhaft im Wasser leben kann. Findet man es also in Wasserproben vor, kann man sicher sein, dass eine Verunreinigung stattgefunden hat. Es muss aber beachtet werden, dass coli zum einen häufig im Erdreich vorkommt und zum anderen, einmal ins Wasser gelangt, sich hier lange halten kann. Somit ist nicht zwingend eine direkte Kontamination mit Fäkalien und auch keine frische Verunreinigung nötig, um das Bakterium im Wasser nachzuweisen.

\section{Die Bakterienflora der natürlichen Wasservorräte}

Je nach Art des Gewässers unterscheidet sich die Zusammensetzung der Bakterienflora. ${ }^{114}$ Die bakterielle Zusammensetzung des Grundwassers ist zum einen dadurch gekennzeichnet, dass das Grundwasser keine Berührung mit der Erdoberfläche hat, zum anderen sind die Eigenschaften der Bakterien wichtig. So können sich im Grundwasser längerfristig nur Wasserbakterien halten, da sie, einmal hineingelangt, bestehen können.

Im Gegensatz dazu kommt es bei Verunreinigung des Grundwassers mit Bakterien, die nicht zu den Wasserbakterien gehören, zu einer vorübergehenden Besiedlung und dann zu einem baldigen Absterben der Keime.

Je ausgeprägter die Verunreinigung ist, desto größer ist der Anteil an nur vorübergehend im Wasser lebenden Bakterien. Interessant ist, dass das Bakterium coli immer in Gewässern zu finden ist, die mit der Erdoberfläche in Verbindung gekommen sind. $^{115}$ So kann beispielsweise durch den Bau einer Wasseranlage auch das Grundwasser mit Oberflächenmaterial in Verbindung kommen und die entsprechenden Bakterien beherbergen. Solche Bakterien sind dann jedoch nur vorübergehend nachweisbar.

In stehenden Gewässern und Flüssen kommen auch Bakterien vor, die nicht zu den Wasserbakterien gehören und beispielsweise durch Kontakt mit der Erdoberfläche in das Wasser gelangt sind. Aber auch hier kann man eine Selbstreinigung der Gewässer

\footnotetext{
Vgl. Reichenbach (1919) S. 404

Vgl. Reichenbach (1919) S. 404

Vgl. Reichenbach (1919) S. 405

Vgl. Reichenbach (1919) S. 406
} 
beobachten. Gerät ein Gewässer z.B. durch das Einleiten von Abwässern aus dem Gleichgewicht, stellt sich nach einer Zeit das physiologische Gleichgewicht wieder ein. ${ }^{116}$ Hierfür sind folgende Tatsachen verantwortlich:

o die Verdünnung durch den Zufluss an keimarmem Gewässer,

o die bakterienabtötende Wirkung des Lichts,

o die Sedimentierung,

o die Fresstätigkeit der Protozoen

o und das für Nichtwasserbakterien ungeeignete Nährmedium.

Laut Reichenbach sei bei oberflächlichen Gewässern im Gegensatz zum Grundwasser immer die Gefahr vorhanden, dass es zu einer Verunreinigung mit pathogenen Bakterien käme. Daher dürfe Oberflächenwasser nicht zur Wasserversorgung genutzt werden, es sei denn es lägen ideale Bedingungen vor, wie das bei einer Talsperre der Fall wäre.

\section{Bakterien im Erdboden}

Auch im Erdreich unterscheidet man zwischen dauernd und nur vorübergehend dort lebenden Bakterien. Laut Reichenbach ist die Quelle der meisten Bakterien im Erdboden der Dünger. ${ }^{117}$ Der größte Teil der Keime findet sich in der oberflächlichen Erdschicht, während in einigen Metern Tiefe kaum noch Keime vorkommen.

Als die typischerweise im Boden vorkommenden Bakterien betrachtet man die Gruppe der nitrifizierenden Bakterien, die eine Oxidation von Ammoniak hin zu Salpetersäure bewirken. Positiv für die Landwirtschaft ist die Fähigkeit einiger Bakteriengruppen zu werten, den atmosphärischen Stickstoff $\mathrm{zu}$ assimilieren und der Pflanze zugänglich zu machen. ${ }^{118}$ Weiterhin kommen aerobe und anaerobe Keime im Boden vor, die am Abbau organischer Substanzen beteiligt sind. Zu nennen wären unter anderen: Bacillus mycoides und Bacillus subtilis sowie mesentericus, welche alle aerob sind.

\section{Pathogene Bakterien im Erdboden}

Eine Reihe von pathogenen Erregern kommt im Boden vor. In gedüngter Erde findet man regelmäßig das Tetanus-Bakterium, während man es nur selten im unbehandelten Erdreich ausmachen kann. Weiter findet man häufig die Erreger des Gasbrandes, welche, wie auch die meisten andern pathogenen Bakterien im Boden, ihren Ursprung im Darm von Mensch und

116 Vgl. Reichenbach (1919) S. 406

117 Vgl. Reichenbach (1919) S. 407

118 Vgl. Reichenbach (1919) S. 408 f. 
Nutztier haben und über den Dünger in das Erdreich gelangen. Reichenbach nimmt an, dass eine Vermehrung der pathogenen Erreger im Boden möglich, aber selten ist. ${ }^{119}$

Weiterhin gelangen über beerdigte Leichen Erreger wie Typhus, Cholera und Ruhr in das Erdreich.

\section{Bakterien in der Milch}

Die Milch bietet einer Vielzahl von Bakterien ausgesprochen gute Lebensbedingungen. Eine Bakteriengruppe jedoch wird besonders regelmäßig in der Mich gefunden und zwar die der Milchsäurebakterien. Diese Bakterien verursachen die Milchsäuregärung, also die Zersetzung von Milchzucker unter Bildung von Säure. ${ }^{120} \mathrm{Zu}$ den Milchsäurebakterien gehören: Streptococcus lacticus, Bacillus acidi lactici, lange Milchsäurebazillen und Säurelabbildner, eine Gruppe Labferment produzierender Bakterien. Da diese jedoch nicht alle Milchzucker umsetzen, zählen sie nicht klassischerweise zu den Milchsäurebakterien.

Weiterhin findet man in der Milch die anaeroben Erreger der Buttersäuregärung, welche den Milchzucker in Buttersäure und Kohlensäure, sowie Wasserstoff aufspalten. Die Buttersäuregärung tritt nach abgelaufener Milchsäuregärung und nur unter anaeroben Bedingungen ein. $^{121}$

Auch fände man laut Reichenbach in der Milch Sporen von Kartoffel- und Heubazillen, die eine Peptonisierung des Kaseins bewirken und so zu dem bitteren Geschmack verdorbener Milch führen. Sie hätten zwar keinen Einfluss auf den Milchzucker, besäßen jedoch eine giftige Potenz. Zu beachten sei, dass die Sporen der beschriebenen Bakterien äußerst hitzestabil seien und somit auch durch mehrstündiges Erhitzen auf $100^{\circ}$ Celsius nicht unschädlich gemacht werden könnten.

\section{Der Milchfehler}

Der Milchfehler beschreibt Veränderungen der Milch, durch für gewöhnlich nicht in ihr vorkommende Erreger. Zu nennen wäre beispielhaft die Verfärbung der Milch, durch Bacillus cyanogenes. $^{122}$

\footnotetext{
119 Vgl. Reichenbach (1919) S. 411

120 Vgl. Reichenbach (1919) S. 412

121 Vgl. Reichenbach (1919) S. 414

122 Vgl. Reichenbach (1919) S. 415
} 


\section{Pathogene Bakterien der Milch}

Die Milch ist Überträger verschiedener Infektionskrankheiten. Man unterscheidet zum einen Bakterien, die über das erkrankte Tier in die Milch gelangten von solchen, die durch nachträgliche Kontamination zur Verunreinigung führten.

Zu den über das Milchtier verursachten Infektionskrankheiten gehörte laut Reichenbach an erster Stelle der Tuberkelbazillus. ${ }^{123}$ Eine weitere über das Tier hervorgerufene Infektion ist die Maul- und Klauenseuche, die sich jedoch nur selten auf den Menschen überträgt.

An Erregern, die die Milch nachträglich infizieren, ist ein wichtiger Vertreter der Typhusbazillus, wobei aufgrund der langen Inkubationszeit der direkte Erregernachweis in der Milch nur selten gelingt. Zur Kontamination kommt es durch die Hände des Personals, das an der Milchgewinnung und Verarbeitung beteiligt ist. Weitere, nachträglich die Milch verunreinigenden Keime sind Ruhr, Cholera, Diphtherie und Scharlach.

Um einer Infektion durch Milch vorzubeugen, sollte diese nur nach ausreichender Erhitzung verzehrt werden, wobei die Erhitzung auf $63^{\circ}$ Celsius für dreißig Minuten für die gängigen Keime ausreichend ist. ${ }^{124}$ 


\subsection{Die Vererbung erworbener Eigenschaften bei einzelligen Lebewesen $^{125}$}

In der vorliegenden Rede beleuchtet Reichenbach die Vererbung bei Einzellern. Er geht auf die zu beachtenden Begrifflichkeiten ein und macht den Unterschied zwischen Einzellern und höheren Lebewesen deutlich. Er zeigt auf, weshalb er der Auffassung ist, dass man aus Beobachtungen, die bei der Vererbung bei Einzellern gewonnen werden, nur eingeschränkt Rückschlüsse auf die Vererbung höherer Lebewesen machen kann.

Als einen Vorteil der Einzeller nennt Reichenbach die kurze Generationszeit.

„[...]Wir können doch mit einiger Sicherheit darauf rechnen, dass eine 24 stündige Kultur etwa 30 Generationen alt ist. 30 Generationen! Das würde für den Menschen 1000 Jahre, für die Maus immerhin noch 6 Jahre, und für die meisten Pflanzen 30 Jahre bedeuten. “126

Folglich kann man bei Einzellern Vererbungen über mehrere Generationen leichter nachvollziehen.

„Es könnte also danach scheinen, als ob die Bakterien geradezu prädestiniert seien für Vererbungsexperimente. Aber die kurze Generationsdauer hat doch auch einen großen Nachteil: sie kann die Deutung mancher Versuchsresultate sehr erschweren. “127

Ein Problem ist, dass man die einzelnen Generationen nicht voneinander trennen kann und somit nicht beurteilen kann, wann sich eine Veränderung manifestiert hat. Außerdem ist es nicht möglich zu erkennen, ob die Veränderung plötzlich von Generation zu Generation entsteht, oder ob sie sich langsam ausprägte hat. Weiterhin ist es nicht möglich zu beurteilen, ob die Veränderungen kontinuierlich weitergegeben werden oder ob auch Generationen übersprungen werden. Problematisch ist, dass bei den Einzellern nur die Kultur beurteilt werden kann.

„Da tritt an die Stelle des Individuums die Kultur, d. h. eine ungeheuere Anzahl von Einzelindividuen, die zwar alle in nahem verwandtschaftlichem Verhältnis miteinander stehen, deren genauere Genealogie uns aber unbekannt ist. “ 128

Man versuchte dies zu optimieren, indem man die zu betrachtende Zelle isolierte und mit dieser isolierten Zelle eine neue Kultur anlegte. Die so neu entstandene Kultur bezeichnete man als Kolonie. Eine Kolonie bildet sich nur aus einer einzelnen Zelle, nämlich der Zelle,

\footnotetext{
Vgl. Reichenbach (1913)

Reichenbach (1913) S. 325

Reichenbach (1913) S. 325

Reichenbach (1913) S. 326
} 
die man beobachten will. Trotzdem blieb der Umstand, dass auch die Kolonie durchaus Veränderungen erfahren kann, die die Ursprungszelle nicht hat, bestehen.

Ein weiterer Punkt, in dem sich die Einzeller von höheren Lebewesen deutlich unterscheiden, ist die asexuelle Vermehrung durch Zweiteilung.

Bei den höheren Lebewesen wird eine Veränderung, die nicht die Keimzelle betrifft, nicht auf weitere Generationen übertragen. Anders bei den Einzellern. Hier muss jede Veränderung, die die Zelle durchläuft, aufgrund der Zweiteilung auf die Tochterzelle übertragen werden.

Für seine weiteren Überlegungen bezeichnete Reichenbach nur die Veränderungen als vererbt, die auch nach Wegfallen der zu der Veränderung führenden äußeren Bedingung Bestand hätten. Diesen Umstand nenne man Transformation.

Im Gegensatz zu den tatsächlich vererbten Eigenschaften stehen so genannte Modifikationen, die durch Umweltfaktoren verursacht werden und nicht dauernd erblich fixiert sind.

Bei der Modifikation wird somit eine Veränderung so lange weitergegeben, wie die auslösende Eigenschaft auf die Zelle einwirkt. Beim Wegfallen der Stimulation wird die Eigenschaft nicht mehr übertragen.

Eine Anpassung auf äußere Reize kann sowohl zu einer Transformation als auch zu einer Modifikation führen. Reichenbach erklärte den Unterschied wie folgend beschrieben.

Er vermutete in den Einzellern eine Differenzierung in Vegetatives und „Keimplasma““29. Zu einer Modifikation käme es laut Reichenbach dann, wenn nur das vegetative Plasma durch die Veränderung betroffen wäre. Durch die Zweiteilung würde die Veränderung auf die nächste Generation weitergegeben. Es wäre aber ein Fortbestehen der äußeren Stimulation notwendig, um die Veränderung aufrecht zu halten.

„Ein Einfluss dagegen, der so stark ist, dass er das Keimplasma verändert, würde zu einer erblichen Fixierung auch nach dem Aufhören des Einflusses führen. “130

In diesem Falle hätten wir es laut Reichenbach mit einer Transformation zutun.

Von einer Mutation spricht man, wenn eine Veränderung ohne erkennbaren Grund von einer Generation zur nächsten plötzlich auftritt.

„Es scheint mir aber sehr zweifelhaft, ob wir überhaupt berechtigt sind, den Begriff der Mutation ohne weiteres von den höheren Organismen auf die Einzelligen und auf die Fortpflanzung durch Zweiteilung zu übertragen. ${ }^{131}$

Reichenbach warf diese Frage auf, da, wie er festhielt, durch die Zweiteilung der Zelle keine Eigenschaft weitergegeben werden konnte, die nicht schon zuvor in der Zelle vorhanden war.

129 Vgl. Reichenbach (1913) S. 331

130 Reichenbach (1913) S. 332

131 Reichenbach (1913) S. 332 
Kam es durch äußere Einflüsse zu der Veränderung, wäre man wieder bei der Definition der Transformation gewesen. Diese verlief jedoch schleichend. Somit konnte man laut Reichenbach bei Einzellern nur dann von einer Mutation sprechen, wenn die Veränderung schlagartig auftrat. Dies war jedoch aufgrund der kurzen Generationszeit äußerst schwierig nachzuweisen.

Als alternative Beweisführung dafür, dass es sich bei einem Prozess um eine Mutation handelte, schlug Reichenbach vor, nur solche Veränderungen zu beobachten, die nicht im Sinne einer Anpassung auf äußere Umstände verstanden werden konnten.

\section{Anpassung}

Als Beispiel für eine Anpassung nannte Reichenbach das langsame sich Gewöhnen von Bakterien an immer höhere Giftdosen. Wurden Bakterien auf einem Nährboden ausgesetzt, der mit einer bestimmten Dosis eines giftigen Agens versehen worden war, konnte beobachtet werden, dass kein Wachstum stattfand und die Kultur einging.

Übertrug man die Bakterien jedoch auf ein Nährmedium mit einer Giftdosis, die sie gerade noch gedeihen ließ, konnte die Kultur nach und nach höheren Dosen ausgesetzten werden und wuchs schließlich auch bei einer hohen Giftmenge, die die Anfangsdosis um ein Vielfaches überstieg. Die ursprüngliche Bakterienkultur hätte diese Enddosis somit nicht vertragen, und hatte sich erst im Laufe des Versuches an das Gift gewöhnen können. Hierzu resümierend Reichenbach:

„Das ist eine Anpassung, denn die Gifttoleranz ist hervorgerufen durch das Gift selbst, die neu erworbene Eigenschaft ist gewissermaßen zielbewusst auf die hervorrufende Ursache gerichtet. "132

Man konnte in einem weiteren Schritt untersuchen, ob es sich bei der Anpassung um einen Prozess der Modifikation oder aber der Transformation handelt.

Zu diesem Zweck wurde der Stamm für mehrere Generationen auf giftfreiem Nährmedium gehalten und es wurde beobachtet, ob die Kultur, wenn man sie viele Generationen später erneut auf ein mit Gift angereichertes Medium brachte, ihre Resistenz behalten hatte oder nicht. In den durchgeführten Versuchen handelte es sich um Transformationen, denn die Bakterien hielten ihre Resistenz bei.

Den Verdacht, es könnte sich um eine Auslese und nicht tatsächlich um eine Anpassung handeln, begegnete Reichenbach mit dem Argument, dass die Kulturen ja zunächst hohen Dosen an Gift ausgesetzte waren und es dabei zu keinerlei Wachstum kam. Wären vereinzelte

132 Reichenbach (1913) S. 333 
Keime mit Resistenz vorhanden gewesen, hätten sie von Anfang an dem Gift trotzen können.

\section{Mutation}

Kam es bei dem beschriebenen Giftversuch dazu, dass die Bakterien die Fähigkeit zur Umsetzung bestimmter Zuckerarten dazu gewannen oder verloren, handelte es sich nicht um eine Anpassung an das Gift. Man würde bei diesem Beispiel eine Mutation annehmen.

Ein weiteres Problem bei der Beurteilung der Vererbung war es, zu bewerten ob man bei den Versuchen nicht lediglich eine selektive Reinzüchtung erwirkte. Gerade bei Versuchen mit Einzellern, bei denen immer eine ganze Population betrachtet wurde, konnte es sein, dass einzelne Zellen der Population das neu aufgetretene Merkmal schon besessen hatten und sich nur durch Selektion durchsetzen konnten und nicht, wie es schien, die ganze Population das Merkmal durch Vererbung neuer Eigenschaften angenommen hatte.

Diesem Dilemma versuchte man zu entgehen, indem man, wie oben beschrieben, Bakterienkolonien anzüchtete, also eine reine Linie entstehen ließ. Alternativ konnte nachgewiesen werden, dass in der Ausgangskultur keine Zellen vorhanden waren, die das Merkmal schon besessen hatten.

\section{Modifikation}

Ein Beispiel für eine Modifikation: Man brachte einem einzelligen Lebewesen (in dem beschriebenen Fall Infusorien) eine Verletzung bei, „die die Lebensfähigkeit nicht merklich herabsetzt “ ${ }^{133}$ Kam es vor Abheilung der Verletzung zur Teilung, wurde die betroffene Stelle auf die Tochterzelle übertragen. In den folgenden Generationen kam es bei einer Modifikation zur Ausheilung der verletzten Stelle. Bei den Einzellern musste eine Weitergabe eintreten, da der verletzte Teil selber direkt auf die Nachkommen überging.

Ein vom Ansatz her ähnlicher Versuch, der in der Vergangenheit an Mäusen durchgeführt worden war, denen man systematisch die Schwänze abnahm, konnte keine vergleichbaren Resultate bringen.

„Dieses Mausexperiment ist [...] niemals geglückt, und konnte nach unseren heutigen Anschauungen auch nicht glücken, weil die Verstümmelung die Keimzelle nicht beeinflusst. “134

Diese Versuche zeigten, dass es einen deutlichen Unterschied in der Vererbung von Einzellern im Vergleich zu höheren Lebewesen gibt.

133 Reichenbach (1913) S. 337

134 Reichenbach (1913) S. 338 
Ein Weiteres Beispiel für eine Modifikation war die rot blühende chinesische Primel. Hielt man diese bei hohen Temperaturen, konnte sie in eine weiße Primel überführt werden. Sobald man die Primel wieder kühleren Temperaturen aussetzte, färbte sie sich wieder rot. Die Veränderung bestand also nur solange, wie auch der äußere, verursachende Einfluss.

\section{Transformation}

Interessant sei bei dem im vorhergehenden Absatz beschriebenem Fall der chinesischen Primel, „dass es durch sehr lange Einwirkung der Brüttemperatur schließlich gelingt, weiße Rassen zu erhalten, die nicht mehr in die Roten zurückschlagen. “135

Hier läge keine Modifikation mehr vor, sondern eine Transformation. Diese könne nach Reichenbach dadurch verursacht sein, dass durch die längere Bebrütungszeit nicht nur das vegetative-, sondern auch das Keimplasma verändert worden wäre. Ein weiterer Fall zu dem Thema ist im folgendem beschrieben:

„Ein sicheres Beispiel für eine Transformation, und zwar eins der ältesten und am besten studierten, ist der Verlust der Sporenbildung. “136

Die Versuche hierzu wurden fast ausschließlich an Milzbrandbazillen durchgeführt, die während der Versuche durch hohe Temperaturen besonderem Stress ausgesetzt worden waren. Durch die hohen Temperaturen verloren sie die Fähigkeit der Sporenbildung. Der Verlust blieb auch fortbestehen, als man die Bazillen in günstige Verhältnisse zurückbrachte. Das galt für Hunderte von beobachteten Generationen.

\section{Bedeutung der sexuellen und asexuellen Vermehrung}

Ein interessanter Versuch, der den großen Unterschied zwischen sexueller und asexueller Vermehrung verdeutlichte, war der mit Trypanosomen.

Das besondere an Trypanosomen ist, dass sie sich nur in bestimmten Insekten geschlechtlich fortpflanzen, während sie sich sonst durch Zweiteilung vermehren. Paul Ehrlich (*1854 $† 1915)$, der den Versuch durchführte, setzte in seinem Versuch Mäuse, die er mit Trypanosomen infiziert hatte, Arsen aus. Nachdem die Mäuse verstorben waren, konnte er zeigen, dass die Trypanosomen eine hohe Resistenz gegen das Arsen gewonnen hatten. Die Resistenz der Trypanosomen hielt auch noch über viele Generationen an, als die erneut mit Trypanosomen beimpften Mäuse keinem Arsen mehr ausgesetzt wurden.

\footnotetext{
135 Reichenbach (1913) S. 339
}

136 Reichenbach (1913) S. 340 
Die Resistenz dem Arsen gegenüber verschwand schlagartig, als die Trypanosomen sich in Insekten injiziert, geschlechtlich fortpflanzen konnten. Reichenbach kommentiert den Versuch folgendermaßen:

„Die gewaltige theoretische Bedeutung dieser Beobachtung liegt darin, dass sie uns aufs deutlichste den Unterschied zwischen der Vererbung bei Zweiteilung und bei geschlechtlicher Fortpflanzung vor Augen führt; Sie ist eine erneute dringende Mahnung, nicht aus Beobachtungen, die an ungeschlechtlich sich fortpflanzenden Lebewesen gewonnen wurden, irgendwelche Schlüsse auf das Verhalten bei geschlechtlicher Fortpflanzung zu ziehen. “137

\section{Weitere Betrachtungen zur Anpassung}

Das Phänomen der Anpassung konnte auch in Bezug auf Nährstoffe beobachtet werden. Einzelne Bakterienarten wurden befähigt, bestimmte Zucker durch die Bildung von Fermenten zu zersetzen. Für diese Eigenschaft waren Bakterien sehr konstant.

So berichtete Reichenbach, dass er selber einen Stamm des Bakterium coli besaß, der seit 16 Jahren nicht mehr mit Milchzucker in Berührung gekommen war. Trotzdem hatte er seine Fähigkeit für dessen Zersetzung nicht eingebüßt.

„Es erregte deshalb berechtigtes Aufsehen, als vor einigen Jahren Neißer mit der Beschreibung eines Bakteriums hervortrat, das ursprünglich nicht imstande war, Milchzucker zu zersetzen, das diese Fähigkeit aber sehr bald [...] erlangte, wenn man es mit Milchzucker in Berührung brachte. “138

Wie intensive Nachforschungen, auch unter der Leitung Reichenbachs ergaben, handelte es sich bei diesem Phänomen nicht wie ursprünglich angenommen um eine Mutation, sondern um einen Prozess der Anpassung. ${ }^{139}$

Gegen die Theorie der Mutation sprach die Tatsache, dass sich die Eigenschaft nicht schlagartig ausbildete, sondern dass sie langsam über mehrere Generationen zunahm. Auch die Tatsache, dass das Erwerben der Fähigkeit zum Zersetzen von Milchzucker in direktem Zusammenhang dazu stand, dass die Bakterien dieser Zuckerart ausgesetzt wurden, sprach für eine Anpassung. In dem beschriebenen Fall handelte es sich genauer genommen um eine Transformation, da die Bakterien die beschriebene Eigenschaft nicht mehr verloren hatten.

Eine für die Medizin wichtige Frage war die, ob mit der Anpassung an andere Verhältnisse, im beschriebenen Fall die Anpassung an eine höhere Temperatur, die Entstehung pathogener Keime aus nicht pathogenen Bakterien ermöglicht werden konnte.

Reichenbach (1913) S. 344

138 Reichenbach (1913) S. 345

139 Vgl. Reichenbach (1913) S. 345 
Reichenbach berichtete von einem Fall, der vor längerer Zeit für Aufsehen gesorgt hatte und der genau diese Behauptung aufstellte. Hierbei handelte es sich nicht um Einzeller, sondern um Schimmelpilze. Behauptet wurde, dass der gewöhnliche Schimmelpiz „Penicillium glaucum“, wenn er bei Körpertemperatur gezüchtet wurde, im Tierversuch pathogene Eigenschaften zeigte.

Es stellte sich jedoch heraus, dass in dem Versuch keine Reinkultur verwendet worden war, sondern eine Mischkultur aus „Penicillium glaucum“ und dem pathogenen „Aspergillus fumigatus“. Es zeigte sich, dass bei niedrigen Temperaturen das „Penicillium glaucum“ wuchs, während bei Körpertemperatur der „Aspergillus fumigatus“ wucherte.

Auch spätere, mit Bakterien durchgeführte Versuche konnten keine Veränderung der Pathogenität unter verschiedenen äußeren Bedingungen zeigen.

\section{Fazit}

Am Ende seines Vortrages resümiert Reichenbach:

„Wenn wir die Resultate kurz zusammenfassen, so haben wir gesehen, dass ganz zweifellos bei den Einzelligen Lebewesen und speziell bei den Bakterien neben zahlreichen Modifikationen auch sichere Transformationen vorkommen. Die Frage nach der Vererbung erworbener Eigenschaften bei Einzelligen ist also unbedingt zu bejahen. Ich glaube aber, nicht besonders betonen zu müssen, dass ich nicht zu denjenigen gehöre, welche geneigt sind, aus diesem Nachweis einen Analogieschluss auf das Verhalten höherer Organismen zu ziehen. Die geschlechtliche Fortpflanzung und die Vermehrung durch Zweiteilung sind so Grundverschiedene Vorgänge, dass irgendwelche Schlüsse von einem Vorgang auf den anderen nicht gezogen werden dürfen. “140

140 Reichenbach (1913) S. 350 f. 


\subsection{Die desinfizierenden Bestandteile der Seifen ${ }^{141}$}

„Die desinfizierende Kraft der Seifen ist, seitdem sie zuerst durch R. Koch (*1843 - †1910) festgestellt wurde, der Gegenstand sehr zahlreicher Untersuchungen gewesen. “142

Die Ergebnisse dieser Untersuchungen waren sehr variabel und reichten von der Behauptung der guten Desinfektionseigenschaft bis hin zur These, dass die Seifen gar keinen desinfizierenden Nutzen hätten. Die Fülle an unterschiedlichen Resultaten und deren Abweichungen voneinander, lassen darauf schließen, dass hier nicht nur Unterschiede in der Methodik der Versuche zu den unterschiedlichen Ergebnissen führten.

Reichenbach lehnte es ab, weitere Versuche mit Seifen anzustellen und somit neue widersprüchliche Resultate zu erlangen und forderte:

„Vielmehr muss unbedingt erst die Vorfrage erledigt werden, auf welchen Bestandteilen die bei vielen Seifen beobachtete, nicht unbeträchtliche Desinfektionswirkung beruht: dann haben wir die Hoffnung, eine Seife von möglichst großem und vor allen Dingen von konstantem Desinfektionswert herzustellen[...]. “143

Somit untersuchte Reichenbach in der vorliegenden Arbeit, die einzelnen Bestandteile der Seifen und unterteilte sie in drei Gruppen: die der fettsauren Salze, die des überschüssige Alkali und die der übrigen Zusätze.

\section{Die fettsauren Salze}

Für gewöhnlich wurden die Salze der höheren Fettsäuren als Seifen bezeichnet. Hierzu gehörten insbesondere die Kali- und Natronsalze. Von besonderem praktischem Interesse waren Stearin-, Palmitin- und Laurinsäure. ${ }^{144}$ Ungesättigte Fettsäuren kamen in Seifen vor allem in Form von Ölsäure, Erucasäure, Linolsäure, Linolensäure und Isolinolensäure vor.

Zu Anfang untersuchte Reichenbach die desinfizierende Wirkung der Kalisalze. Hierbei war ihm die Reinheit der verwendeten Proben und deren genaue Neutralisation wichtig, da er vermutete, dass es schon bei geringen Abweichungen hin zum saueren oder alkalischen einen Einfluss auf die desinfizierende Wirkung gab. Da Reichenbach die im Handel erhältlichen Präparate in dieser Beziehung als „nicht genügend“ betrachtete, fertigte er die Salze selber an. ${ }^{145}$

\footnotetext{
141 Vgl. Reichenbach (1908)

142 Reichenbach (1908) S. 296

143 Reichenbach (1908) S. 297

144 Vgl. Reichenbach (1908) S. 298

145 Vgl. Reichenbach (1908) S. 298
} 
Nach einer Anzahl von Vorversuchen kam er letztlich zu folgender Vorgehensweise. Reichenbach löste die Salze zunächst in absolutem Alkohol, dann brachte er die Lösung zum Sieden und versetzte sie mit Phenolphthalein und ein wenig Kalilauge, um eine schwache alkalische Reaktion hervorzurufen. Nun fügte er zur Neutralisation eine kleine Menge an Säure hinzu. In einem weiteren Schritt entzog er über eine Pumpe dem Kristallbrei die Flüssigkeit, um das gewonnene Produkt dann in Äther zu waschen, wodurch etwaige Reste an Fettsäure und Phenolphthalein entfernt wurden.

„Man enthält auf diese Weise Präparate, die vollständig neutral sind und auch nicht, wie die meisten Handelspräparate Bikarbonat enthalten. “146

Mit dem so gewonnen Salzen stellte Reichenbach eine Versuchsreihe zur desinfizierenden Wirkung der Salze an, wobei er sich zu Beginn auf die Wirkung im Bezug auf das Bakterium coli beschränkte. ${ }^{147}$

In seinem Versuchsaufbau fügte er den einzelnen Salzlösungen Bakterien hinzu. Nach 5, 10, 20, 40, 60 und 120 Minuten entnahm Reichenbach Proben die er einzeln in Gelatine Nährböden mischte. Nach 5 Tagen wurden die herangewachsenen Kolonien gezählt.

Um die Vergleichbarkeit der einzelnen Salze zu gewährleisten, waren die verwendeten Lösungen äquimolar in ihrer Konzentration und bewegten sich zwischen 1/25 und 1/80.

Bei Betrachtung der Ergebnisse der Salze der gesättigten Fettsäuren erzielte Palmitat die beste Wirkung. So tötet die Lösung mit einem Konzentrationsverhältnis von 1/40 Bakterium coli schon nach weniger als 5 Minuten ab. Zum Vergleich kam es bei einprozentiger Karbolsäure nicht einmal nach einer Einwirkungszeit von zwanzig Minuten zum Absterben der Bakterien. $^{148}$

Verglich man die einzelnen Salze und deren Wirkung, zeigte sich ein Zusammenhang zwischen desinfizierender Wirkung und der Molekülgröße. So nahm, das Stearat ausgenommen, die Desinfektionsleistung mit der Molekülgröße ab.

Die Versuche zeigten, dass die Kalisalze der gesättigten Fettsäuren, welche Bestandteil der Seife waren, desinfizierende Eigenschaften hatten.

Bei den Salzen der ungesättigten Fettsäuren war das nicht der Fall. Diese Versuche zeigten nur eine schwache desinfizierende Wirkung.

„Die Salze der ungesättigten kommen also an und für sich bei der Desinfektionswirkung der Seifen nicht in betracht. “149

\footnotetext{
146 Reichenbach (1908) S. 299

147 Vgl. Reichenbach (1908) S. 299

148 Vgl. Reichenbach (1908) S. 301

149 Reichenbach (1908) S. 304
} 
Ein Teil der unterschiedlichen Ergebnisse, die in der Literatur zu den desinfizierenden Eigenschaften der Seifen gemacht wurden Säuren, konnten so Reichenbach, schon mit dieser Differenz erklärt werden. Da die Autoren der Versuche lediglich die Gesamtmenge und nicht die Art der Fettsäuren berücksichtigt hatten, ist der Nachweis im Nachhinein jedoch nicht möglich.

Die Tatsache, dass die gewöhnlich im Handel zu erstehenden Schmierseifen, die aus ungesättigten Fettsäuren zusammengesetzt waren, desinfizierende Wirkung hatten, lässt den Schluss zu, dass diese Seifen entweder noch einen zusätzlichen beträchtlichen Anteil an gesättigten Fettsäuren hatten, oder das andere Bestandteile für diese Wirkung verantwortlich waren.

\section{Der Gehalt an Alkali}

Der Einfluss des Alkaligehalts auf die desinfizierende Wirkung der Seife war umstritten. ${ }^{150}$ In seinem Aufsatz führte Reichenbach verschiedenen Hygieniker und deren Meinungen zu dem Thema auf. So berichtete er von Koch $(* 1843-\dagger 1910)$, der die Ansicht vertrat, dass der Alkaligehalt in der Seife zu gering sei, als dass die desinfizierende Wirkung von ihm ausgehen könnte. Auch andere Autoren kamen laut Reichenbach zu dieser Auffassung. Im Gegensatz dazu gab es Forscher, die annahmen, dass der Alkaligehalt der Seife alleine für die desinfizierende Komponente der Seife verantwortlich wäre. ${ }^{151}$

Reichenbach selber verfolgte einen anderen Ansatz. Er ging davon aus, dass die Spaltung der Seife unter dem Einfluss von Wasser zu einer Änderung führte, die mitverantwortlich für die desinfizierende Eigenschaft ist. Wie allgemein anerkannt, nahm auch Reichenbach an, dass Alkalisalze in wässriger Lösung hydrolytisch aufgespaltet vorliegen, und zwar in fettsaures Salz und freies Alkali. Werden die Temperaturen erhöht entstehen freie Fettsäure und freies Alkali. Somit kommt in jeder wässrigen Seifenlösung freies Alkalihydrat vor. Neben dem hydrolytisch abgespaltenen Alkali existiert immer eine kleine Menge an freiem Alkali, welches auch im wasserfreiem Zustand in der Seife zu finden ist und auf Produktionsprozesse zurückgeführt werden kann. Reichenbach sprach hier von überschüssigem Alkali. Eine Differenzierung zwischen beiden sei in wässriger Seifenlösung quantitativ nicht möglich. Man könne jedoch durch Titration einer Seifen- Alkohollösung den Anteil an freiem Alkali bestimmen. ${ }^{152}$

150 Vgl. Reichenbach (1908) S. 305

151 Vgl. Reichenbach (1908) S. 305

152 Vgl. Reichenbach (1908) S. 307 
Dieses Verfahren wandte Reichenbach für eine Reihe von käuflichen Schmierseifen an. Er stellte fest, dass alle Seifen einen erheblichen Anteil an überschüssigem Alkali, größtenteils aus Karbonat bestehend, hatten. Auffällig war laut Reichenbach, dass der Gehalt an freiem Alkali im Verhältnis zu der Desinfektionsleistung der Seife stand. Dies bedeutete, je höher der Alkaligehalt war, desto größer war die desinfizierende Wirkung der Seife. Dabei war jedoch der Alkaligehalt so gering, dass er nicht alleine für diese Eigenschaft verantwortlich sein konnte. ${ }^{153}$

Schwierigkeiten machte die quantitative Bestimmung des hydrolytisch abgespaltenen Alkali. Die Vermutung lag nahe, dass durch die hydrolytische Spaltung beträchtliche Mengen an Alkali frei wurden und diese maßgeblich zu der desinfizierenden Wirkung der Seife führten. Mit dieser Annahme betrachtete Reichenbach die Versuche, die er zu den fettsauren Salzen angestellt hatte erneut.

Bekannt war, so Reichenbach, dass mit der Größe der Moleküle der Fettsäuren der Grad der Dissoziation zunimmt und somit mehr hydrolytisch gespaltenes Alkali vorliegt. ${ }^{154}$ Dies steht im Einklang mit der Tatsache, dass bei den von Reichenbach durchgeführten Versuchen mit fettsauren Salzen, die Salze mit größerer Molekülgröße eine stärker desinfizierende Wirkung aufwiesen.

Man wusste, dass der Grad der Dissoziation bei den Salzen der gesättigten Fettsäuren größer war, als dies bei den ungesättigten Fettsäuren der Fall ist, da bei ihnen eine ausgeprägte Hydrolyse stattfindet. Dies führte ebenfalls zu einem höheren Anteil an gespaltenem Alkali. Diese Tatsache deckte sich also mit den Versuchsergebnissen in denen sich zeigte, dass die Seifen mit gesättigten Fettsäuren im Gegensatz zu den anderen, desinfizierende Eigenschaften haben. Weiterhin war auffällig, dass bei Salzen mit höheren Fettsäuren die Wirkung der desinfizierenden Eigenschaften mit steigender Verdünnung nur sehr langsam abnahm. ${ }^{155}$

Dies war darauf zurück zu führen, dass zwar mit steigender Verdünnung die absolute Menge des Alkalis abnahm, dass aber prozentual der Anteil an gespaltenem Salz durch die Zunahme der Hydrolyse bei höherer Verdünnung stieg. Somit wurde durch die relative Zunahme des Alkalis die Schwächung durch die Verdünnung teilweise kompensiert, was zu der nur langsamen Abnahme der Desinfektionseigenschaften führte.

Einen weiteren Hinweis in diese Richtung bot das Verhalten der Eladinsäure. Diese in der Natur nicht vorkommende Fettsäure, bildete insofern eine Ausnahme, da sie, obwohl sie zu

153 Vgl. Reichenbach (1908) S. 307

154 Vgl. Reichenbach (1908) S. 308

155 Vgl. Reichenbach (1908) S. 310 
den ungesättigten Fettsäuren zählte, stark dissoziierte und somit erhebliche desinfizierende Wirkung hatte.

„Wir können also die Resultate all dieser Überlegungen dahingehend zusammenfassen, dass höchstwahrscheinlich die Hydrolyse an dem Zustandekommen der desinfizierenden Wirkung der Salze der gesättigten Fettsäuren erheblich beteiligt ist. “156

Es war aber zu bedenken, dass die Alkaliwirkung nicht alleine für die Beobachtungen verantwortlich sein konnte. So hatten beispielsweise auch ungesättigte Fettsäuren, die bekanntlich nicht dissozieren, in höherer Konzentration eine desinfizierende Wirkung.

Weiterhin zeigten Versuche, dass die Desinfektionskraft einer Seifenlösung mit bestimmter Alkalimenge wesentlich größer war, als die Desinfektionskraft einer gleich großen Menge an Alkali. Reichenbach erläuterte die Unregelmäßigkeiten bei der Wirksamkeit der Seifen so: „Die Erklärung beruht, kurz zusammengefasst, darauf, dass Alkali und fettsaure Salze bei gemeinsamer Einwirkung eine gegenseitige Erhöhung ihrer Desinfektionskraft bewirken, und zwar eine stärkere Erhöhung, als sie durch die selbe Menge in einer gleich starken Lösung desselben Mittels hervorgebracht worden wären. “157

Es war nun nicht möglich, diese Annahme experimentell an einer Seifenlösung zu bestätigen, da im wässrigen Zustand immer eine hydrolytische Spaltung stattfindet und somit beide Substanzen gleichzeitig vorliegen. Ausweichend machte Reichenbach an ölsauren Salzen Versuche, da sich diese nicht in dem Maße spalten. ${ }^{158}$

In diesen Versuchen zeigte sich, dass die Oleate, welche für sich genommen kaum desinfizierende Eigenschaft haben, in Verbindung mit Kaliumhydrat stark desinfizierend wirkten. Deutlich ausgeprägter, als dies der Fall gewesen wäre, hätte man die Kaliumkonzentration für sich alleine genommen verdoppelt. Zur Verdeutlichung konnte man den Versuch auch anders aufbauen.

Man ersetzte die Hälfte einer Kaliumhydratlösung durch eine für sich betrachtet unwirksame Oleatlösung. Es kam nicht, wie vielleicht vermutet, zu einer Minderung der Desinfektionskraft, sondern selbige wurde deutlich gesteigert.

„Diese Beobachtung, die zunächst an den Oleaten gemacht ist, werden wir ohne Bedenken auf die Salze der gesättigten Fettsäuren übertragen dürfen. Denn wenn schon die an sich unwirksamen Oleate eine so energische Erhöhung der Desinfektionskraft bewirken, lässt sich

Reichenbach (1908) S. 311

Reichenbach (1908) S. 314

Vgl. Reichenbach (1908) S. 312 
annehmen, dass dies bei den Salzen der gesättigten Säuren, die für sich allein schon desinfizierende Wirkung besitzen, in mindestens dem gleichen Maße der Fall ist. “159

\section{Zusätze}

Als Zusätze fasste Reichenbach Bestandteile wie Stärke, Natron und Kreide zusammen, denen er aller Wahrscheinlichkeit nach keine desinfizierenden Eigenschaften zuschrieb. ${ }^{160}$ Zwei Zusätze betrachtete er jedoch genauer, da hier eine Beeinflussung der desinfizierenden Eigenschaften nicht ausgeschlossen war.

Zum einen ist er der Behauptung nachgegangen, die desinfizierende Wirkung der Seife sei einzig den Geruchstoffen, hier vor allem dem Terpinoel zuzuschreiben. Dieser Behauptung widersprach Reichenbach vehement, stellte jedoch in Versuchen tatsächlich eine desinfizierende Wirkung von Terpinoel fest. Somit räumte er diesem Geruchsstoff zumindest eine Desinfektionssteigernde Wirkung ein. ${ }^{161}$

Zudem untersuchte er einen häufig verwendeten Zusatz, nämlich das Harz. Harze finden sich häufig in Seifen, da sie die Schaumbildung fördern. Die Versuche, die Reichenbach zu den Harzen machte, zeigten zwar eine schwache desinfizierende Wirkung, jedoch war keine große Einflussnahme durch die Harze anzunehmen. ${ }^{162}$

159 Reichenbach (1908) S. 314

160 Vgl. Reichenbach (1908) S. 315

161 Vgl. Reichenbach (1908) S. 315

162 Vgl. Reichenbach (1908) S. 316 


\subsection{Die Leistung der Formaldehyd-Desinfektion ${ }^{163}$}

Der vorliegende Artikel Reichenbachs beschäftigt sich mit der Wohnungsdesinfektion mittels Formaldehyd. Diese Art der Desinfektion fand, dank der Arbeiten von C. Flügge (*1847 †1932), unter dem Namen „Breslauer Verfahren“ weite Verbreitung. Flügge, sowie Reichenbach betonte, konnte nachweisen, dass seine vereinfachte Methode anwenderfreundlich und wirkungsvoll war. ${ }^{164}$

Folgende Punkte waren hierfür maßgeblich:

Erstens gelang es Flügge, die gefürchtete Polymerisation durch Verwendung einer verdünnten Formaldehydlösung zu verhindern und den übeln Geruch des Formaldehyds durch spätere Neutralisation mit Ammoniak zu eliminieren. Zweitens konnte er auf eine Reihe von in Breslau durchgeführte Versuche verweisen, die der Methode hohe Zuverlässigkeit bescheinigten. Das „Breslauer Verfahren“ fand in den nächsten Jahren durch zahlreiche Nachprüfungen Bestätigung. ${ }^{165}$

Reichenbach ging der Frage nach ob aktuelle wissenschaftliche Veröffentlichungen, die der Methode schlechte Resultate nachsagten, Berechtigung hatten. Besonders zu berücksichtigen war hierbei die Frage, ob es modernere Verfahren gab, die den Desinfektionserfolg genauer beurteilen konnten und diesen berechtigt in Frage stellten. Unter diesem Gesichtspunkt betrachtete er in dem vorliegenden Aufsatz Arbeiten, die die Zuverlässigkeit der Formaldehyddesinfektion in Frage stellten.

\section{Reichenbach zur Arbeit von Sprengler ${ }^{166}$}

Sprengler stellte die Behauptung auf, dass die Formaldehyd-Desinfektion gegenüber den Tuberkulosebakterien unwirksam wäre, wenn sich diese im Sputum befänden. ${ }^{167}$

Im Gegensatz zu der damals gängigen Methode, den Erfolgsnachweis der Desinfektion im Tierversuch zu erbringen, führte Sprengler den Erregernachweis im Kulturverfahren durch.

In der Vergangenheit zeigten die Tierversuche, welche an Meerschweinchen durchgeführt wurden, dass nach Formaldehyd-Desinfektion des Erregermaterials eine Infektion des Versuchstiers nicht mehr zu erwarten ist.

Da Meerschweinchen für Tuberkulose anfällig sind, ging man davon aus, dass ein Ausbleiben der Infektion als ausreichender Nachweis der Unschädlichkeit der Bakterien zu werten sei.

\footnotetext{
163 Vgl. Reichenbach (1905b)

164 Vgl. Reichenbach (1905b) S. $451 \mathrm{f}$.

165 Vgl. Reichenbach (1905b) S. 452

166 Vgl. Reichenbach nahm Bezug auf: vgl. Sprengler (1903)

167 Vgl. Reichenbach (1905b) S. 453
} 
Reichenbach bemängelte an den Versuchen von Sprengler, das dieser parallel zu dem kulturellen Nachweis keine Tierversuche durchgeführt hatte. Da somit bis dato kein direkter Vergleich der beiden Verfahren stattgefunden hatte, stellte Reichenbach fest:

„Eine Nachprüfung hätte deshalb zunächst den Beweis zu liefern, dass ein formaldehydbehandeltes Sputum, das ein Meerschweinchen nicht mehr zu schädigen vermag, beim Kulturverfahren noch lebensfähige Tuberkelbazillen enthalten kann. “168

Geht man davon aus, dass kein Fehler im Versuchsverlauf zu den unterschiedlichen Ergebnissen geführt hatte, kann man annehmen, dass der Nachweis mit Kultur empfindlicher ist als der mittels Tierversuch. Für die Praxis der Formaldehyd-Desinfektion hatte dies aber, so Reichenbach, keine Konsequenz, was er wie folgend erklärte:

„Es ist nicht anzunehmen, dass ein Tuberkelbacillus, der das so sehr empfindliche Meerschweinchen bei günstiger Art der Application nicht mehr zu schädigen vermag, dem viel weniger disponierten Menschen irgendwie gefährlich werde kann. “169

Dieser Überlegung zufolge musste man, so Reichenbach, an dem Desinfektionsverfahren keine Änderung vornehmen.

Darüber hinaus merkte er an, dass in der Bedienungsanleitung des Breslauerapparates schon seit Jahren darauf hingewiesen wurde, dass große Sputumflecken zusätzlich zu der Formaldehyd-Desinfektion mit starker Sublimatlösung behandelt werden müssten.

\section{Reichenbach zur Arbeit von Römer ${ }^{170}$}

Auch Römer hatte Kritik an der Formaldehyd-Desinfektion lautend gemacht.

Im Gegensatz zu der gebräuchlichen Versuchsanordnung mit Tuberkelbelastetem Sputum verwendete er eine Tuberkulosekultur im Reagenzglas als Testobjekt für die FormaldehydDesinfektion. Reichenbach kritisierte an dieser Vorgehensweise, dass sie nicht mit den Bedingungen, die in der Praxis vorkamen, vergleichbar war und unverhältnismäßig schwere Anforderungen an das Verfahren stellte.

Somit konnte auch bei diesem Versuch kein Rückschluss auf den praktischen Wert der Desinfektionsmethode gezogen werden. ${ }^{171}$

\footnotetext{
168 Reichenbach (1905b) S. 454

169 Reichenbach (1905b) S. 455

170 Vgl. Reichenbach nahm Bezug auf: vgl. Römer (1903)

171 Vgl. Reichenbach (1905b) S. 455
} 


\section{Reichenbach zur Arbeit von Engels ${ }^{172}$}

Bei den von Engels mit dem „Schneider Apparat“ angestellten Versuchen, verglich dieser seine Ergebnisse mit denen, die nach dem „Breslauer Verfahren“ ermittelt wurden und stellte somit beide Methoden gegenüber. ${ }^{173}$ Bei den Versuchen von Engels kamen jedoch weniger befriedigende Ergebnisse zustande, was Reichenbach auf die Unterlegenheit des „Schneiderschen Apparates“ zurückführte.

Weiterhin bemängelte Reichenbach das Vorgehen von Engels grundlegend. So hatte dieser die Ergebnisse, die er erzielte in der Gesamtheit mit Ergebnissen verglichen, die nach dem „Breslauer Verfahren“ erstellt wurden. ${ }^{174}$ So gesehen kamen ähnliche Prozentzahlen bei den unterschiedlichen Verfahren zustande, was Engels dazu veranlasste, von einer Gleichwertigkeit der beiden Methoden zu sprechen.

Bei genauerer Beurteilung der Tabellen sah man aber, so Reichenbach, dass die übereinstimmenden Ergebnisse nur bei leichter $\mathrm{zu}$ eliminierenden Bakterien vorlagen. Differenzen traten hingegen bei schwer abzutötenden Testobjekten, wie Milzbrandsporen und Staphylokokken auf. Somit konnte man keineswegs behaupten, dass die Verfahren gleichwertig waren, da sie sich in Bezug auf die schwer zu eliminierenden Bakterien unterschieden. Man konnte also von einer deutlichen Überlegenheit der durch Flügge etablierten Methode sprechen. Ein Infragestellen der Zuverlässigkeit der FormaldehydDesinfektion allgemein war somit für Reichenbach nicht zulässig.

\section{Weitere Kritikpunkte}

Reichenbach räumte jedoch ein, dass zwei Einwände gegen die Formaldehyd-Desinfektion ihre Berechtigung haben. Zum einen war durch das „Breslauer Verfahren“ das Einleiten von Ammoniak in das desinfizierte Zimmer, oder das direkte Abspülen von Testobjekten zur gängigen Praxis geworden. Wie sich aber gezeigt hatte, konnte sich dies negativ auf den Desinfektionserfolg auswirken. ${ }^{175}$

Zum anderen wurde von Werner darauf hingewiesen, dass er in einer Reihe von Versuchen feststellen konnte, dass nach Formaldehyd-Desinfektion bei einer Bebrütungszeit der desinfizierten Milzbranderreger von 20 bis 30 Tagen, regelmäßig eine Auskeimung der Sporen zu beobachten war. Die von Werner gewählte Bebrütungszeit ging dabei deutlich über die damals gängigen 5 bis 8 Tage hinaus.

172 Vgl. Reichenbach nahm Bezug auf: vgl. Engels (1902)

173 Vgl. Reichenbach (1905b) S. 457

174 Vgl. Reichenbach (1905b) S. 457

175 Vgl. Reichenbach (1905b) S. 458 


\section{Dazu Reichenbach:}

„Hiernach trage ich kein Bedenken, ohne Weiteres die Möglichkeit zuzugeben, dass von den meisten Untersuchern und auch von mir selbst in manchen Fällen Milzbrand Sporen für abgetötet gehalten sind, die unter günstigen Bedingungen sich noch als lebensfähig erwiesen hätten. “176

Reichenbach räumte ein, dass es somit für die Formaldehyd-Desinfektion eine Einschränkung für Milzbranderreger gab. Dies hatte jedoch für die Praxis kaum Relevanz:

„Bei der Desinfektion menschlicher Wohnungen wird es sich nur in seltenen Ausnahmefällen um die Unschädlichmachung von Milzbranderregern handeln. ${ }^{177}$

Für die gängigen Keime gab es somit keine Einschränkung. Zudem wies Reichenbach darauf hin, dass man zwar unter Idealbedingungen aus den desinfizierten Milzbrandsporen neue Kulturen züchten konnte. Tierversuche mit den behandelten Milzbranderregern zeigten jedoch, dass diese keine Pathogenität mehr hatten. Somit folgerte Reichenbach, dass es bis dato keine begründete Ablehnung gegenüber dem „Breslauer Verfahren“ zur Wohnungsdesinfektion gab.

Im letzten Teil des Artikels ging Reichenbach auf Einwände ein, die gegen den „Breslauer Apparat“ erhoben wurden.

So wurden z.B. schwere Sicherheitsmängel von Lewaschew ${ }^{178}$ beanstandet, der von einer Explosion des „Breslauer Apparats“ berichtete und somit ein Sicherheitsrohr am Kessel für unerlässlich hielt. Wie Reichenbach erläuterte, könne ein Sicherheitsrohr für „ängstliche Gemüter" durchaus Verwendung finden, bei sachgerechter Anwendung wäre dies aber seiner Meinung nach nicht nötig. ${ }^{179}$ Man müsste, so Reichenbach, beachten, dass die alten noch verlöteten Kessel nicht leer kochten, da es in diesem Falle zu einer Schädigung der Lötnaht kommen könnte. Weiterhin sollte man dafür Sorge tragen, dass die abführenden Schläuche nicht knickten. Wenn diese Punkte beherzigt würden sah Reichenbach kein erhöhtes Risiko, zumal bei den neuen gefalzten Kesseln eine Explosion kaum möglich wäre.

Mayer und Wolpert ${ }^{180}$ beanstandeten, dass bei ihren Versuchen der „Breslauer Apparat“ regelmäßig Feuer gefangen hatte und teilweise meterhoch in Flammen stand. ${ }^{181}$

\footnotetext{
Reichenbach (1905b) S. 460

Reichenbach (1905b) S. 460

78 Vgl. Reichenbach nahm Bezug auf: vgl. Lewaschew (1904)

179 Reichenbach (1905b) S. 463

180 Vgl. Reichenbach nahm Bezug auf: vgl. Mayer und Wolpert (1902)

181 Vgl. Reichenbach (1905b) S. 465
} 
Auf diese Vorwürfen eingehend studierte Reichenbach die Versuchsbeschreibung der beiden, und bemerkt ein Missachten der Bedienungsanleitung. So hatten Mayer und Wolpert in ihren Versuchen eine zu große Menge an Spiritus in zu hoher Prozentzahl verwendet, was zu den beschriebenen Ereignissen geführt haben musste.

Aus unzähligen eigenen Versuchen konnte Reichenbach berichten, nie Ähnliches erlebt zu haben, auch wurde von anderen Anwendern bis dato kein ähnliches Problem beschrieben.

Proskauer und Elsner ${ }^{182}$ zwei Sachverständige aus dem Desinfektionswesen von Berlin entschieden sich, wie Reichenbach berichtete, wegen beobachteter Mängel gegen den „Breslauer Apparat““ und Verwendeten eine eigene Konstruktion „Berolina““. ${ }^{183}$

Diese Beiden beanstandeten an dem „Breslauer Apparat“ dass er zum einen bei der Desinfektion eine zu hohe Feuchtigkeit entwickelte und somit Möbel, Wände, Boden und Kleidungsstücke sehr feucht waren, ja teilweise sogar Beschädigungen aufwiesen.

Zum anderen stellten sie fest, dass der Apparat für große Flüssigkeitsmengen nicht genügend erprobt war. So kam es, laut den Autoren, durch die zu hoch angegebene Spiritusmenge mehrfach zum Leerkochen des Kessels, so dass an verschiedenen Stellen Lötnähte schmolzen. Reichenbach bemerkt in seinen Nachforschungen, dass die von den Autoren verwendete Tabelle tatsächlich fehlerhaft war. Die Spiritusmenge war somit zu hoch was das Leerkochen des Apparates durchaus erklären konnte.

Was nach Reichenbach zu urteilen jedoch nicht nachvollziehbar war, war folgende Tatsache. Der Apparat „Berolina“ sollte durch seine Konstruktion den Misstand der hohen Feuchtigkeit in den zu desinfizierenden Räumen vermeiden. Vom Prinzip her arbeitete der Apparat ähnlich wie der „Breslauer Apparat“. Dass für einen gleich großen Raum mehr Spiritus verwendet wurde als beim „Breslauer Apparat“, ließ darauf schließen, dass mehr Wasserdampf erzeugt wurde. Eine verminderte Feuchtigkeitsentwicklung war somit unwahrscheinlich.

\section{Ausführung zur benötigten Formaldehydmenge}

Abschließend machte Reichenbach noch Angaben zu der nötigen, zu verwendenden Formaldehydmenge. ${ }^{184}$

Flügge forderte allgemein für jede Anwendung 5 Gramm Formaldehyd pro Kubikmeter zu desinfizierenden Raum und eine Einwirkzeit von 3,5 Stunden. ${ }^{185}$

\footnotetext{
182 Vgl. Reichenbach nahm Bezug auf: vgl. Proskauer und Elsner (1903)

183 Vgl. Reichenbach (1905b) S. 466

184 Vgl. Reichenbach (1905b) S. 468

185 Vgl. Reichenbach (1905b) S. 468
} 
Abweichend stellte Werner die Forderung auf, bei 5 Gramm Formaldehyd eine Einwirkzeit von 7 Stunden einzuhalten. Reichenbach konnte dies nicht nachvollziehen, da Werner in eigenen Versuchen mit 2,5 Gramm Formaldehyd und 7 Stunden Einwirkzeit erfolgreiche Ergebnisse erbrachte. Diese Angabe würde aber einer Einwirkzeit von 3,5 Stunden mit 5 Gramm Formaldehyd entsprechen. ${ }^{186}$

Proskauer und Elsner forderten bei einer Desinfektion über 3,5 Stunden grundsätzlich 8 Gramm Formaldehyd zu verwenden. Sie begründeten die deutlich höhere Formaldehydmenge damit, so auch unter ungünstigen Umständen eine ausreichende Desinfektion zu erreichen. Reichenbach hielt eine allgemeine Erhöhung der Formaldehydmenge für wenige Ausnahmefälle nicht für ökonomisch. Besser sei es, eine jeweilige Anpassung an die Umstände vorzunehmen. ${ }^{187}$

Situationen, die eine Erhöhung der Dosis rechtfertigen, waren neben niedriger Temperatur Schwierigkeiten bei der Abdichtung des zu desinfizierenden Raumes. Auch sehr vollgestellte Räume konnten, so Reichenbach Probleme bringen. 


\subsection{Die Tageslichtmessung in Schulen ${ }^{188}$}

In dem vorliegenden Artikel, wird das Verfahren der Helligkeitsbestimmung am Arbeitsplatz, mit photographischem Papier beurteilt. Diese Möglichkeit der Helligkeitsbestimmung fand seinerzeit große Beachtung, da sie als einfach zu handhabende und preisgünstige Alternative zu den aufwändigen photometrischen Verfahren galt. ${ }^{189}$

Reichenbach näherte sich dem Thema erst theoretisch, um seine Bedenken dann mit eigenen Versuchen zu untermauern.

\section{Erläuterungen zur Lichtbestimmung mittels Photopapier}

Die Helligkeitsbestimmung mittels Photopapier macht sich die Eigenschaft zu Nutze, dass sich Photopapier unter Lichteinfluss schwarz färbt. Der Grad der Schwarzfärbung sollte Auskunft über die Intensität des Lichtes geben.

Folgend werden die vier, damals gängigen Vorgehensweisen zur Lichtbestimmung mittels Photopapier vorgestellt, auf die sich Reichenbach bezog. ${ }^{190}$

1) Mittels Photometer wird ein Platz bestimmt, der eine Lichtstärke von $50 \mathrm{MK}$ aufweist. In einem weiteren Schritt legt man ein Photopapier aus, welches dem zuvor gemessenen Licht eine vorgegebene Zeit ausgesetzt ist. Das so geschwärzte Papier, dient in den Folgeversuchen dieser Versuchsreihe als Normalpapier.

Die weiteren Arbeitsplätze können nun mit Photopapier ausgelegt werden und je nach dessen Schwärzung sieht man, ob der Platz dunkler oder heller als der Arbeitsplatz ist, an dem das Normalpapier erstellt wurde.

2) Man benutzt zum Vergleich ein einmalig für alle Folgeversuche angefertigtes Normalpapier, welches bei einer Bestrahlung von 50 MK für 60 min. erstellt wurde.

3) Es wird die Zeit bestimmt, welche benötigt wird, um das Photopapier entsprechend der Färbung des Normalpapiers einzufärben.

4) Man misst die Zeit, die benötigt wird, auf dem Photopapier gerade eine Einfärbung zu erlangen. Dann bestimmt man zusätzlich die Zeit, die zum Erreichen der Schwärzung des zu vergleichenden Normalpapiers benötigt wird.

\footnotetext{
Vgl. Reichenbach (1904)

Vgl. Reichenbach (1904) S. 231

190 Vgl. Reichenbach (1904) S. 232 f.
} 


\section{Einwände, die Reichenbach dem Verfahren entgegenbrachte}

Reichenbach bezeichnete die beschriebenen Vorgehensweisen als kritisch, da nicht berücksichtigte Komplikationen bei diesem Verfahren der Lichtbestimmung auftreten könnten.

Er gäbe zu bedenken, dass das Maximum der Empfindlichkeit für Licht, beim Auge und beim Photopapier in unterschiedlichen Bereichen des Spektrums läge. ${ }^{191}$

Es gäbe chemische Strahlen, die primär zu einer Einfärbung des Photopapiers führten, dem menschlichen Auge jedoch nicht als hell erschienen und es gäbe optische Strahlen, die zwar den Eindruck von Helligkeit erzeugten, aber kaum zu einer Reaktion des Indikatorpapiers führten.

Gerade bei der Betrachtung der Arbeitsplatzhelligkeit, für die das Vorgehen gedacht war, kam verkomplizierend hinzu, dass das von den Wänden reflektierte Licht photographisch nur wenig wirksam war, aber maßgebend an der Helligkeit des Innenraums beteiligt war. ${ }^{192}$

Reichenbach führte aus, dass selbst wenn man das reflektierte Licht vernachlässigen könnte, das Verfahren nicht geeignet wäre, da das Verhältnis von optischer zu chemischer Lichtqualität auch bei direktem Sonnenlicht und wolkenlosem Himmel nicht konstant wäre.

„Die gleiche Papierschwärzung kann je nach der wechselnden Qualität des Lichtes ganz verschiedenen Geraden der optischen Helligkeit entsprechen. “193

\section{Zu den Versuchen von Reichenbach}

Versuchsaufbau: Die Versuche fanden in zwei unterschiedlichen Räumen statt (siehe unten). Mittels Photometer wurde erst ein Platz mit einer Helligkeit von annähernd 50 MK ermittelt. In einem weiteren Schritt wurde über die Versuchsdauer von einer Stunde Photopapier an einem photometrisch gemessenen Platz ausgelegt, um dessen Schwärzung beurteilen zu können. Im Verlauf dieser Stunde wurde nach jeweils fünf Minuten der MK Wert mittels Photometer kontrolliert.

Es zeigte sich, dass trotz wolkenlosem Himmel, also idealen Versuchsbedingungen, die Helligkeit stark schwankte. Somit wurde das Mittel aus dreizehn Messungen als durchschnittliche Beleuchtung angesehen. ${ }^{194}$

\footnotetext{
191 Vgl. Reichenbach (1904) S. 232

192 Vgl. Reichenbach (1904) S. 233

193 Reichenbach (1904) S. 232

194 Vgl. Reichenbach (1904) S. 235
} 


\section{Erste Versuchsreihe}

Es wurden vier Versuche in einem Zimmer mit schwarz gestrichenen Wänden durchgeführt. Die Schwarzfärbung der Wände sollte Lichtrefflektionen vermeiden, so dass nur direktes Himmelslicht auf das Photopapier einwirken konnte.

Da, je nach Bewölkungsgrad, die Schwärzung sehr unterschiedlich ausfiel, wurden zum Vergleich je zwei Versuche bei wolkenlosem und bei bewölktem Himmel durchgeführt. Bei wolkenlosem Himmel kam es im Gegensatz zum bewölkten Himmel zu einer deutlicheren Schwarzfärbung. Dies, obwohl bei beiden Versuchen die photometrisch gemessene Helligkeit $50 \mathrm{MK}$ betrug.

Ein fünfter Versuch wurde bei wolkenlosem Himmel in einem Hörsaal durchgeführt. Die hier gemessenen $50 \mathrm{MK}$ wurden zu einem Großteil durch reflektierendes Licht erzeugt. Trotz wolkenlosem Himmel wurde das Photopapier nur schwach angefärbt, was auf den hohen Anteil an reflektiertem Licht zurückzuführen war. ${ }^{195}$

\section{Zweite Versuchsreihe}

In der zweiten Versuchsanordnung beschäftigte sich Reichenbach mit der Frage, ob an einzelnen Plätzen in einem Raum das Verhältnis von optischen zu chemischen Strahlen konstant war, oder ob es schon innerhalb eines Raumes Schwankungen zwischen beiden Strahlenarten gab. ${ }^{196}$

Für die Erstellung eines Normalpapiers, welches als Referenz für die Folgeversuche diente, wäre Voraussetzung, dass das Verhältnis zwischen optischen und chemischen Strahlen in einem Raum konstant wäre. Nur dann könnte das Normapapier als Vergleichsgrundlage für die anderen Plätze in dem Versuchsraum dienen.

Als Versuchsraum diente ein 64 qm großer Hörsaal mit hellem Anstrich. Es waren je zwei Fenster nach Norden und zwei kleinere Fenster nach Osten hin ausgerichtet. Es wurden sechs Plätze des Raumes untersucht, die jeweils viermal photometrisch kontrolliert wurden.

Die schon mit bloßem Auge leicht zu identifizierenden dunkleren Plätze waren auch photometrisch gemessen schwächer ausgeleuchtet. Die Schwärzung des Photopapiers war jedoch an den helleren Plätzen geringer, als an den photometrisch gemessen dunkelsten Plätzen. Dies besagte, dass die Schwarzfärbung weniger von der Gesamthelligkeit als vielmehr von der Menge direktem Himmelslicht abhing. Der Versuch belegte, dass das Verhältnis von optischen und chemischen Strahlen in einem Raum nicht konstant ist.

195 Vgl. Reichenbach (1904) S. 235 f.

196 Vgl. Reichenbach (1904) S. 237 


\section{Reichenbach zieht folgendes Fazit}

„Wir sehen, dass ein direktes Verhältnis zwischen Lichtintensität und Papier Veränderung nicht existiert, dass es also nicht möglich ist aus der Schwärzung des Papiers Schluss auf die absolute Lichtstärke zu ziehen. “197

Aber selbst wenn es gelingen würde, mit dem Photopapier die genaue Helligkeit zu bestimmen, formulierte Reichenbach Zweifel an dem tatsächlichen Nutzen des Verfahrens:

„Ich möchte dem noch hinzufügen, dass das Verfahren, selbst wenn es wirklich eine Lichtmessung gestatte, immer noch die Nachteile haben würde, dass es Durchschnitts Werte für einen längeren Zeitraum angibt. Welchen praktischen Wert soll es haben, zu wissen, dass ein Arbeitsplatz eine Stunde lang eine mittlere Helligkeit von 20 MK aufweist, wenn es während der Hälfte der Zeit10 und während der andere $30 \mathrm{MK}$ gehabt hat. zum Arbeiten ist der Platz ungenügend, trotz der durchschnittlich ausreichenden Helligkeit. ${ }^{198}$

Abschließend empfiehlt Reichenbach, unter ungünstigen Bedingungen, so z.B. an trüben Tagen und in späten Nachmittagsstunden, die unzureichende Beleuchtung mittels Photometer oder Raumwinkelmessung zu belegen. ${ }^{199}$ 


\subsection{Zur Frage der Tageslichtmessung ${ }^{200}$}

Der Artikel beschäftigt sich mit der Tageslichtmessung in Schulen. Reichenbach beschrieb die Problematik der gängigen Methode und zeigte einen, in seinen Augen effizienteren Weg auf.

In der Hygiene war zur Ermittlung der Helligkeit das Weber Photometer weit verbreitet und auch zur Bestimmung der ausreichenden Beleuchtung von Klassenzimmern wurde es eingesetzt. Einzig und alleine wegen seines hohen Anschaffungspreises wurde es, laut Reichenbach, nicht flächendeckend verwendet. ${ }^{201}$

Der Nachteil des Photometers lag, so Reichenbach, darin, dass die ermittelten Ergebnisse immer Momentaufnahmen waren. Hatte man einen Wert gemessen, der unter dem geforderten Mindestwert von 26 MK lag, wusste man, dass der Platz im Klassenraum nicht ausreichend beleuchtet war. Anders verhielt es sich, wenn der gefundene Wert oberhalb der $26 \mathrm{MK}$ lag. In letzterem Fall konnte man lediglich sagen, dass zu dem Zeitpunkt der Bestimmung der Platz ausreichend hell war. Das hieß aber noch nicht, dass das Klassenzimmer auch in den Wintermonaten durchweg ausreichend Licht bot, wenn die Beleuchtungsmessung an einem hellen sommerlichen Tag erfolgt war.

Ein möglicher Ausweg wäre gewesen, den Zeitpunkt der Messung zu einem ungünstigsten Termin z.B.an einem trüben Dezembernachmittag zu machen. Die Forderung, wenn eine Messung nicht im Winter möglich wäre, sie an einem Sommertag mit blauem Himmel durchzuführen und unter diesen Bedingungen das Fünffache des Minimalwerts zu verlangen, lehnte Reichenbach als zu ungenau ab. ${ }^{202}$

Reichenbach verfolgte den Ansatz, für die Bestimmung der Lichtverhältnisse in einem Klassenraum, die Größe und den Neigungswinkel des zu beleuchtenden Himmelstückes selber zu messen. ${ }^{203}$ Dies war mit einem Raumwinkelmesser möglich. Der Raumwinkel als solcher machte über die Lichtverhältnisse im Klassenraum noch keine Aussage. Er gab jedoch an, wie groß das Himmelsstück war, welches den Raum beleuchtete. Um eine Aussage über die Lichtverhältnisse des Klassenzimmers zu machen, musste zusätzlich empirisch ermittelt werden, wie stark die entsprechende Leuchtkraft eines solchen Himmelsabschnittes war.

\footnotetext{
200 Vgl. Reichenbach (1905a)

201 Vgl. Reichenbach (1905a) S. 325

202 Vgl. Reichenbach (1905a) S. 326

203 Vgl. Reichenbach (1905a) S. 327
} 
Zur Vereinfachung der Methode sollte der kleinste mögliche Raumwinkel ermittelt werden, der auch unter ungünstigen Verhältnissen noch für genügend Helligkeit sorgte. Somit wüsste man, dass jeder Raum der einen größeren Raumwinkel besäße ausreichend beleuchtet wäre.

Zu berücksichtigen war, dass die Beleuchtungsverhältnisse am Arbeitsplatz nicht nur von der Größe des Himmelsstückes abhängig waren, sondern auch von dem, von Decken und Wänden reflektierten Licht. Die Helligkeit des Arbeitsplatzes war somit nicht einfach der Größe des Raumwinkels proportional, der zu fordernde Öffnungswinkel musste angepasst werden. ${ }^{204}$ Problematisch an der praktischen Durchführung der Raumwinkelmessung war, dass das Verfahren sehr zeitaufwendig war. Beleuchteten den zu messenden Platz mehrere, möglicherweise sogar stark seitlich liegende Fenster, war die Messung noch schwieriger.

Verschiedene Versuche, das Messinstrument zu vereinfachen, waren damals nicht erfolgreich gewesen.

Eine Überlegung jedoch das Verfahren zu vereinfachen, kam von Gottschlich ${ }^{205}$. Er machte darauf aufmerksam, dass es in den meisten Fällen ausreichend wäre, nur den Höhenwinkel, auch Öffnungswinkel genannt und nicht den aufwendigeren Raumwinkel zu messen. ${ }^{206}$

Der Ansatz beruhte auf der Erfahrung, dass für gewöhnlich die Breitenausdehnung des Himmelstücks nicht limitierend wirkte. Eine von Gottschlich durchgeführte Versuchsreihe ergab, dass die Minimalgröße des Öffnungswinkels $4^{\circ}$ nicht unterschreiten darf.

Sein Verfahren ergänzend, hatte Gottschlich einen Spiegelapparat entwickelt, mit dessen Hilfe man in kurzer Zeit sowohl den Öffnungswinkel als auch den Elevationswinkel bestimmen konnte. ${ }^{207}$

Sicherlich brachte die vorgestellte, vereinfachte Methode eine größere Ungenauigkeit mit sich.

„Man muss aber hier, wie bei allen abgekürzten und darum weniger genauen Methoden abwägen: auf der einen Seite steht der Nachteil der geringeren Genauigkeit, - auf der anderen der Vorteil der größeren Bequemlichkeit und rascheren Ausführung; je nach dem Verhältnis dieser beiden Faktoren zu einander und je nach der Bedeutung, welche man jedem von ihnen beilegt, wird das Urteil über die abgekürzte Methode verschieden ausfallen müssen. Solche Entscheidung lässt sich deshalb auch nicht allgemein treffen: sie wird von den Umständen des einzelnen Falles [...] abhängen. “208

\footnotetext{
204 Vgl. Reichenbach (1905a) S. 328

205 Vgl. Reichenbach nahm Bezug auf: Gotschlich (1904)

206 Vgl. Reichenbach (1905a) S. 329 f.

207 Vgl. Reichenbach (1905a) S. 330

208 Reichenbach (1905a) S. 331
} 
Dem Öffnungswinkel größere Bedeutung beizumessen als dem Breitenwinkel, schien theoretisch betrachtet sinnvoll zu sein. So ist der Öffnungswinkel durch äußere Einflüsse, wie gegenüberliegende Gebäude, Mauern und Bäume stärkeren Schwankungen unterlegen als der Breitenwinkel der in erster Linie baulich bestimmt ist. Letzterer ist am stärksten abhängig von der Fensterbreite und von der Entfernung des einzelnen Platzes vom Fenster. ${ }^{209}$ Darüber hinaus wirken sich kleine Veränderungen im Breitenwinkel weniger stark auf die Beleuchtung aus als entsprechende Änderung im Öffnungswinkel.

Wie sich bei genauerer Betrachtung des Verfahrens von Gottschlich zeigte, waren bei Beachtung seiner Mindestforderungen nicht immer ausreichende Beleuchtungsverhältnisse gegeben. Reichenbach konnte bei eingehender Analyse feststellen, dass der Fehler darin lag, dass Gottschlich bei seinem Verfahren der Einfachheit halber, wie Reichenbach vermutete, auf die Anpassung des Elevationswinkels verzichtete. ${ }^{210}$ Diesen Punkt kommentierte Reichenbach wie folgt:

„Ich muss aber gestehen, dass es mir überhaupt nicht rationell erscheint, den Einfluss der Veränderung des Elevationswinkels so ganz außer Acht zu lassen wie es Gottschlich getan hat. “211

Reichenbach empfahl zusätzlich zum Öffnungswinkel, den Elevationswinkel zu berücksichtigen, der durch den Winkel gebildet wurde, welcher die Mitte des Himmelsstückes mit der Horizontale bildete. Der Elevationswinkel musste durch eine Reduktion des Öffnungswinkels, den man einer Tabelle entnehmen konnte, angepasst werden. Hierdurch war es möglich das vereinfachte Verfahren recht genau zu halten. ${ }^{212}$

Unter Berücksichtigung der Veränderung des Elevationswinkels, ermittelte Reichenbach einen mindest einzuhaltenden reduzierten Öffnungswinkel von $3^{\circ}$, ein Wert der geringgradig von dem durch Gottschlich ermittelten Wert abwich.

Am Ende seines Aufsatzes, wies Reichenbach darauf hin, dass zu den beschriebenen Ausführungen noch genauere Versuche fehlten, die das Gesagte untermauern würden.

$\begin{array}{ll}209 & \text { Vgl. Reichenbach (1905a) S. } 331 \\ 210 & \text { Vgl. Reichenbach (1905a) S. } 334 \\ 211 & \text { Reichenbach (1905a) S. } 333 \\ 212 & \text { Vgl. Reichenbach (1905a) S. } 334\end{array}$ 


\section{7. Über den Einfluss der Farbe künstlicher Lichtquellen auf die Sehschärfe ${ }^{213}$}

Reichenbach ging im vorliegenden Artikel der Frage nach, ob Lampen mit unterschiedlicher spektraler Farbzusammensetzung, aber gleicher Helligkeit, Unterschiede in der Sehschärfe bedingen.

Die modernen Lichtquellen der damaligen Zeit entwickelten häufig eine höhere Temperatur des Leuchtkörpers, als dies bei älteren Lampen der Fall war. Hierdurch wurde eine stärkere Leuchtkraft verursacht. Die Temperaturerhöhung führte aber auch zur Änderung der spektralen Zusammensetzung des Lichts. Bei älteren Lampen überwiegen die Farben rot und gelb, während die neueren Lampen einen größeren Anteil an Grün- und Blautönen aufweisen. Beispiele für Lampen mit eher rot- gelbem Farbenspektrum sind die Petroleumlampe, der Gas-Argandbrenner und die elektrische Glühlampe. Die elektrische Bogenlampe, das Auerlicht, sowie die Nernstlampe gehören dagegen zum Spektrum der moderneren Lampen.

Zur Begriffklärung sei erläutert, dass Reichenbach von gleicher optischer Helligkeit sprach, wenn zwei verschiedene Lichtquellen dem Auge gleich hell erscheinen. Eine übereinstimmende Sehschärfenhelligkeit liegt hingegen dann vor, wenn zwei verschiedene Lichtquellen die Unterscheidung feiner Einzelheiten auf einer von ihnen beleuchteten Fläche gleich gut ermöglichen. ${ }^{214}$

Die Kernfrage des Artikels lautete:

„Können zwei praktisch verwendete Lichtquellen verschiedener Farbe, aber gleicher optischer Helligkeit, verschieden in der Sehschärfenhelligkeit sein?“215

$\mathrm{Zu}$ dieser Fragestellung gab es noch keine praktischen Versuche, jedoch haben sich auch zuvor schon Forscher mit der Frage der Sehschärfe beschäftigt. ${ }^{216}$ Reichenbach ging an dieser Stelle des Artikels auf Autoren und deren Arbeiten zu dem Thema ein, die wie folgt zusammengefasst werden:

Der erste, der sich laut Reichenbach mit diesem Thema befasste war H. Cohn, der schon 1879 Versuche auf dem Gebiet der Sehschärfenhelligkeit anstellte. ${ }^{217}$ Die von ihm gemachten Untersuchungen, ermittelten zwar die Sehschärfe unterschiedlicher Leuchtquellen, berücksichtigten aber keine weiteren Aspekte, wie z.B. die optische Helligkeit der einzelnen Lampen zueinander.

213 Vgl. Reichenbach (1902)

214 Vgl. Reichenbach (1902) S. 258

215 Reichenbach (1902) S. 258

216 Vgl. Reichenbach (1902) S. 260

217 Vgl. Reichenbach (1902) S. 258 
Weiterhin berichtet Reichenbach von den Autoren Mace de Lepinay und Nicati aus Frankreich, die feststellen konnten, dass sich bis zu einer Wellenlänge von 517, Helligkeit und Sehschärfe gleich verhalten. ${ }^{218}$ Über den genannten Bereich der Wellenlänge hinaus jedoch bleibt die Sehschärfe zum blauen Bereich hin hinter der Helligkeit zurück. Die beiden Forscher folgerten daraus, dass bei Leuchtkörpern, die mehr blaues, also kurzwelliges Licht aufwiesen die Sehschärfe weniger gut ist, als bei Leuchtkörpern mit langwelligem Licht. Diese Überlegungen waren jedoch theoretischer Natur. Praktische, vergleichende Versuche haben die beiden Franzosen nicht durchgeführt.

Uhthoff, ein weiterer Autor auf den Reichenbach einging, macht zwar Versuche zu der Sehschärfe verschiedener Spektralfarben des Lichtes, nahm diese aber nicht bei gleicher optischer Helligkeit der Leuchtquellen vor. ${ }^{219}$ Aus diesem Grunde sind seine Ergebnisse in denen er beschreibt, dass die Sehschärfe für gelbe Lichtquellen am größten ist, mit Vorsicht zu betrachten.

\section{Zu den Versuchen von Reichenbach}

Reichenbach beschreibt in dem vorliegenden Artikel seine Versuchsreihe, in der die Sehschärfe für verschiedene Spektren in Bezug zur optischen Helligkeit ermittelt wurde.

Schwierigkeiten machte die Photometrie der Lichtquellen. So musste ein Messinstrument verwendet werden, welches sich nur an der optischen Helligkeit der Lichtquelle orientierte.

„Das für hygienische Zwecke sonst unentbehrliche, und gerade für die Vergleichung ungleichfarbiger Lichtquellen vorzüglich geeignete Webersche Photometer ist natürlich hierfür nicht brauchbar, da es von vornherein die Lichtquelle auf Grund ihrer Sehschärfenhelligkeit vergleicht. “220

Reichenbach entschied sich dazu, den direkten Vergleich der Versuchslampen über die gleiche optische Helligkeit herzustellen.

Hierzu verwendete er einen speziellen Photometeraufsatz, den so genannten LummerBrodhun Aufsatz, bei dem die zu vergleichenden Lichtquellen jeweils eine mattweiße Fläche beleuchten. Die Lichtstärke wird dadurch bestimmt, dass man die Aufsätze solange gegeneinander verschiebt, bis die beiden weißen Felder gleich hell erscheinen. Die Lichtstärke wird dann über die Entfernung der Lichtquelle zu der jeweiligen weißen Fläche berechnet.

218 Vgl. Reichenbach (1902) S. 259

219 Vgl. Reichenbach (1902) S. 259

220 Reichenbach (1902) S. 260 
Bei der Versuchsdurchführung zeigte sich, dass verschiedene Beobachter zu unterschiedlichen Ergebnissen kamen. Da die Differenzen jedoch gering waren, konnten sie das Verfahren nicht in Frage stellen. Reichenbach wies aber darauf hin, dass der photometrische Vergleich ungleichfarbiger Lichtquellen immer subjektiv ist. ${ }^{221}$

Bei der Versuchsdurchführung ist für die Helligkeitsbestimmung der Mittelwert zweier Messreihen ausgewählt worden, die durch unterschiedliche Beobachter erstellt wurden. Die praktischen Schwierigkeiten waren somit zu lösen, was Reichenbach folgendermaßen beschrieb:

„Es stellten sich also der praktischen Ausführung der heterochromatischen Photometrie gewisse Schwierigkeiten entgegen, die aber, wenn man auf äusserste Genauigkeit verzichtet, nicht unüberwindbar sind. “ 222

Es blieben aber theoretische Zweifel, ob die Photometrie verschiedenfarbiger Lichtquellen möglich ist. Unter dem Namen Purkinje- Phänomen ist folgender Umstand bekannt. ${ }^{223}$ Zwei farblich verschiedene Lichtquellen z.B. rot und blau, mit gleicher optischer Helligkeit, werden nicht mehr als gleich hell wahrgenommen, wenn sie um die objektiv gleiche Lichtintensität verändert werden. Somit würde das gefundene Verhältnis immer nur für die spezielle Lichtstärke zutreffen.

In der Praxis erwies sich das Phänomen jedoch als weniger störend, da es in dem Maße nur für stark unterschiedliche Farbspektren zutrifft, die zu untersuchenden Lampen in ihrem Spektrum aber weniger weit auseinander lagen. Darüber hinaus tritt das Purkinje- Phänomen vor allem bei schwacher Lichtintensität auf. Die in der Praxis zum Lesen nötige, und somit im Versuch gewählte Lichtstärke, lag deutlich über diesen Werten.

Die Bestimmung der Sehschärfe wurde wie folgt vorgenommen. Der Proband las im Takt eines Metronoms Zahlentafeln. Die zu lesende Zahlenreihe befand sich bei den Versuchen immer in Augenhöhe genau in der Mitte des Gesichtsfeldes. Es war immer nur eine Zahlenreihe zu sehen während die anderen verdeckt blieben. Die Tafeln waren so angebracht, dass ein fehlerfreies Lesen gerade nicht mehr möglich war. Die Anzahl der gemachten Fehler ließ eine vergleichende Aussage über die Sehschärfenverhältnisse zu.

Im Vorfeld zu der eigentlichen Versuchsreihe wurde zwecks Überprüfung der angewandten Methode und um ein Gefühl für die Beziehung zwischen Fehlerzahl und Beleuchtungsintensität zu erlangen, mit einer Glühlampe bei unterschiedlicher Helligkeit Leseproben genommen. Hier zeigte sich, dass eine Verminderung der Lichtstärke um 10,5 \%

221 Vgl. Reichenbach (1902) S. 261

222 Reichenbach (1902) S. 262

223 Vgl. Reichenbach (1902) S. 262 f. 
zu einer Erhöhung der Fehlerzahl um 40,8\% führte. Eine Schwächung der Lichtstärke um 21,7\% führte gar zu einer Fehlerzunahme von 81,6\%. Wählte man hingegen nur kleinere Unterschiede in der Lichthelligkeit, waren die Abweichungen weniger eindeutig.

Bei der anschließenden Versuchsreihe, waren die zu untersuchenden Lampen nebeneinander auf einer Photometerbank angebracht. Am Ende der Bank befand sich außerdem eine herkömmliche Glühlampe, die bei einer Spannung von genau 110 Volt leuchtete. Diese diente als Normallampe. Mit dieser Lampe wurden die zu untersuchenden Leuchtkörper auf oben beschriebene Weise abgeglichen und somit auf gleiche optische Helligkeit gebracht.

In der ersten Versuchsanordnung verglich Reichenbach die Nernstlampe mit der Kohlenfadenglühlampe.

Um die Sehschärfenhelligkeit zu prüfen, wurde jeweils abwechselnd eine Zahlenreihe mit einer der beiden Lampen gelesen. Um einer Ermüdung der Augen vorzubeugen wurden nie mehr als 5 Reihen gelesen. Der Versuch zeigte, dass mit der Nernstlampe bei gleicher Helligkeit 55,4\% mehr Lesefehler gemacht wurden als mit der Fadenglühlampe.

Der nächste Versuch wurde mit Auerbrenner und Glühlampe durchgeführt. Der Versuchsaufbau blieb wie zuvor beschriebenen. Der Versuch zeigte, dass sich der Auerbrenner ähnlich der Nernstlampe verhielt. Im Verhältnis zur Glühlampe wurden 61\% mehr Fehler bei der Leseprobe gemacht.

Der nachfolgende Versuch zwischen Auerbrenner und Nernstlampe (zwei modernen Lampen) bestätigte die vorherigen Versuche. Im direkten Vergleich der beiden Lampen zueinander, wurden nahezu gleich viele Zahlen falsch gelesen.

Eine weitere Verifizierung der Resultate erhoffte sich Reichenbach durch eine vergleichende Messung der Lichtquellen, die mit der Lummer- Brodhun- Vorrichtung auf gleiche optische Helligkeit gebracht wurden. Die vergleichende Nachmessung erfolgte durch das Weber Photometer.

Da das Photometer, wie erwähnt, die Sehschärfe misst, müsste bei einer Nachmessung mit diesem die Nernstlampe und der Auerbrenner eine geringere Lichtintensität ergeben als die Glühlampe, obwohl sie gleiche optische Helligkeit haben. Die Messung konnte die bisherigen Ergebnisse bestätigen.

Zusammenfassend hält Reichenbach fest:

„Es ergibt sich also als definitives Resultat, dass Nernst- und Auerlampe einer Glühlampe von gleicher optischer Helligkeit so weit an optischer Sehschärfenhelligkeit nachstehen, wie einer Verminderung der optischen Helligkeit um 12 bis 14 Procent entspricht. “224

224 Reichenbach (1902) S. 270 
Das schlechtere Abschneiden der beiden Lampen in der Versuchsreihe kann aber durch die deutliche, wirtschaftliche Überlegenheit dieser Lampen gegenüber der Glühlampe kompensiert werden. So nutzt die Nernstlampe die Energie fast doppelt so gut aus wie die Glühlampe. Hierzu Reichenbach:

„Die wirtschaftliche Überlegenheit der beiden Lampen ist also so bedeutend, dass die etwas geringere Sehschärfenhelligkeit dagegen nicht in Betracht kommt. ${ }^{225}$

225 Reichenbach (1902) S. 270 


\section{8. Über Wärmestrahlung von Leuchtflammen ${ }^{226}$}

Aus hygienischer Sicht war bei der Beurteilung moderner Leuchtkörper die Betrachtung der Wärmentwicklung von besonderer Relevanz. ${ }^{227}$

Mit diesem Thema hatte sich zuvor schon M. Rubner $\left(1854\right.$ - 1932) ${ }^{228}$ eingehend beschäftigt. Reichenbach griff das Thema auf und ergänzte es einerseits, andererseits modifizierte er die Untersuchungstechnik. Er nahm in seiner Darstellung Bezug auf die Arbeit von M. Rubner.

\section{Methodik}

Die Messung der Wärmestrahlung erfolgte mit einer Thermosäule, die aus 70 AntimonWismut-Elementen zusammengesetzt war. Die Säule war mit einer Messvorrichtung, einem Galvanometer, ausgestattet. Das Galvanometer verfügte über eine a-statische Nadel, von der man die Wärmestrahlung ablesen konnte. Wie sich zeigte, waren die sich ändernden magnetischen Einflüsse der Erde, auf die Nadel umso größer, je a-statischer die Nadel war. Dem trug Reichenbach Rechnung, indem er aus zwei, durch einen Commutator verursachten gegensätzlichen Ablenkungen der Nadel den Mittelwert bildete und ihn in die Rechnung einbezog.

Aufgrund theoretischer Vorteile begann Hans Reichenbach die Versuchsreihe mit einem an der Thermosäule befestigten Auffangtrichter. ${ }^{229}$ Eine vergleichbare Vorrichtung war auch von M. Rubner bei seinen Versuchen verwendet worden.

Vorteilhaft an einem solchen Auffangtrichter war zum einen, dass die Wirksamkeit der Thermosäule um ca. das Sechsfache gesteigert werden konnte. Außerdem hielt sie Luftströmungen fern, die zu einer Verfälschung der Ergebnisse hätten führen können. Bei der Arbeit mit dem Auffangtrichter ergaben sich aber praktische Schwierigkeiten, die letztlich dazu führten, dass Reichenbach auf dessen Verwendung verzichtete.

Ein Problem der Anwendung war, dass der Abstand der Leuchtquelle zur Thermosäule nicht eindeutig ermittelt werden konnte. ${ }^{230}$ Wählte man nämlich die Vorderseite der Säule als Begrenzung, wurden nur die Strahlen berücksichtigt, die direkt auf die Säule trafen. Alle Strahlen, die durch Reflektion des Auffangtrichters verursacht, die Thermosäule trafen, fanden keine adäquate Berücksichtigung und verfälschten das Ergebnis. Wählte man die vordere Öffnung des Auffangtrichters, war dies nur dann richtig, falls sich alle in dem

226 Vgl. Reichenbach (1898)

227 Vgl. Reichenbach (1898) S. 315

228 Reichenbach nahm Bezug auf: Rubner (1895)

229 Vgl. Reichenbach (1998) S. 316

230 Vgl. Reichenbach (1998) S. 317 
Trichter reflektierenden Strahlen auch auf der Thermosäule getroffen hätten. Der Fehler wurde umso größer, je näher die Leuchtquelle an der Thermosäule stand.

Ein weiteres Übel war, dass die vom Trichter reflektierten Strahlen zu einer Vergrößerung des Einfallswinkels führten. Allgemein war die Wirkung der einfallenden Strahlen dem Kosinus des Einfallswinkels proportional. Der Kosinus nahm aber mit steigendem Einfallswinkel stetig ab und somit führte die durch den Trichter verursachte Zunahme des Einfallswinkels zwangsläufig zu einem Fehler. Erschwerend traten Mehrfachrefflektionen auf, die jeweils zu einer erneuten Vergrößerung des Einfallswinkels führten. Im Gegensatz dazu hatten Änderungen beim Einfallswinkel ohne Verwendung des Trichters eine kaum merkliche Auswirkung auf den Einfluss der Strahlen auf die Thermoelemente.

Ein geringerer Anteil der Strahlen ging weiterhin dadurch verloren, dass die Trichterwand einen Teil der Strahlen nicht reflektierte, sondern absorbierte.

Aus diesen Gründen kam es zu einer Differenz zwischen errechnetem und tatsächlichem Nutzen des Auffangtrichters. Darüber hinaus, führte die Summe der genannten Unwägbarkeiten dazu, dass die Beobachtungen bei Verwendung des Auffangtrichters fehleranfällig waren.

Theoretischen Überlegungen zufolge hätte der verwendete Trichter eine Verstärkung der Strahlen um das Vierzehnfache erreichen müssen, während bei den Versuchen nur eine Steigerung um das Sechsfache erzielt werden konnte.

Durch die oben beschriebenen Umstände konnten, laut Reichenbach, bei Verwendung eines Auffangtrichters nur Wärmequellen untereinander verglichen werden, die die gleiche Entfernung zum Trichter hatten und die eine vergleichbare Flächenausdehnung besaßen. ${ }^{231}$ Anderenfalls wäre es bei veränderter Entfernung und/oder verändertem Einfallswinkel der Strahlen zu einer Veränderung des Kosinus und somit zu einer abgeschwächten Wirkung der Strahlen auf die Thermosäule gekommen. Um dem gerecht zu werden, ging Reichenbach in seinen anfänglichen Experimenten wie folgt vor:

„Ich habe deshalb in den ersten Versuchen, wo ich noch mit Auffangtrichter arbeitete, wenn es sich um die Vergleichung mehrere, in verschiedener Entfernung aufgestellter Lichtquellen handelt, die Reduction auf eine einheitliche Entfernung in der Art vorgenommen, dass ich für eine Anzahl von Entfernungen, 0,5, 1,0, 1,5 und 2,0 m die Werte feststellte und mit den gefundenen Verhältniszahlen die abgelesenen Ausschläge multiplicierte. “232

\footnotetext{
231 Vgl. Reichenbach (1898) S. 319
}

232 Reichenbach (1898) S. 320 
Auch Rubner kam in seiner Arbeit zu dem Ergebnis, dass errechnete und in den Versuchen ermittelte Werte nicht übereinstimmten. ${ }^{233}$ Er zog jedoch einen anderen Schluss, der aus Sicht von Reichenbach nicht zulässig war.

Bei seinen Versuchen verwendet Rubner einmal eine 120 mm große Argandflamme, in einer weiteren Versuchsanordnung eine $60 \mathrm{~mm}$ hohe Argandflamme. Während bei beiden Versuchsanordnungen die Flamme einmal 127,3 cm und einmal 63,7 cm von der Thermosäule entfernt stand, stimmten für die beiden Messungen bei einer Flammenhöhe von $120 \mathrm{~mm}$ theoretische und praktische Werte nicht überein. Anders verhielt es sich bei dem Versuch mit $60 \mathrm{~mm}$ hoher Flamme und gleicher Versuchsanordnung. Hier deckten sich der theoretische und der praktische Wert. Rubner folgerte, dass dieses Phänomen durch den veränderten Einfallswinkel kommen musste und der damit verbundenen Änderung des Kosinus.

Nach den Berechnungen von Reichenbach würde der Fehler aber nur 3\% betragen haben und nicht wie im Falle Rubners 11\%. Reichenbach nahm an, dass die Summe der oben genannten Fehlerquellen zu der Differenz zwischen theoretischen und praktischen Ergebnissen geführt hatte. Beim zweiten Versuch kam es, so Reichenbachs Überlegung, nur durch zufälliges gegenseitiges Aufheben der Fehler zu dem übereinstimmenden Ergebnis.

In seinen Versuchsreihen verwendete Reichenbach eine Vorrichtung, die zeigen sollte, dass nicht ein Fehler der Apparate zu der Verfälschung der Ergebnisse führte. ${ }^{234}$ Hierzu verwendete er einen Pappschirm, der mit zwei ungleichgroßen Löchern versehen war, die durch Klappen verschlossen werden konnten. Hinter dem Schirm wurde die Wärmequelle angebracht, vor dem Schirm die Thermosäule.

Nun fertigte Reichenbach unterschiedliche Versuchsreihen an. Einmal arbeitete er mit verschlossenen Klappen, dann, indem er zunächst eine Klappe, danach beide Klappen öffnete. Mittels dieser Versuchsanordnung, konnte er nachweisen, dass der Ausschlag des Galvanometers wirklich der Wärmemenge, die auf die Thermosäule fiel, proportional war.

Da Reichenbach bei den weiteren Versuchen auf den Auffangtrichter verzichtete, musste er Änderungen in der Versuchsanordnung vornehmen. ${ }^{235}$ So zeigte sich zum Beispiel, dass schon kleinste Luftströmungen zu einem Ausschlagen der Nadel führten, wenn man ohne Trichter arbeitete.

Um diesen Misstand zu beheben, konzipierte Reichenbach einen Kasten, in den die Thermosäule eingesetzt wurde. Diese Konstruktion mit einer Seitenlänge von $10 \mathrm{~cm}$ war

\footnotetext{
233 Vgl. Reichenbach (1898) S. 319

234 Vgl. Reichenbach (1898) S. 321

235 Vgl. Reichenbach (1898) S. 322 f.
} 
doppelwandig gebaut. Um eine Erwärmung zu vermeiden, wurde zwischen das Außen- und das Innenblech Wasser eingefüllt. In der Vorderwand des Kastens war eine Öffnung, die mit einer ebenfalls doppelwandigen Klappe versehen war. Mithilfe dieses Kastens konnte man effizient Luftströmungen von der Thermosäule abhalten.

Bei der folgenden Versuchsreihe verwendete Reichenbach Leuchtquellen mit unterschiedlicher Flächenausdehnung (Platinspirale, Amylacetatlampe und Argandbrenner). Hierdurch prüfte er, ob bei Weglassen des Auffangtrichters die errechneten und die praktisch ermittelten Ergebnisse, auch bei Leuchtmitteln verschiedener Flächenausdehnung, übereinstimmten. Wie sich zeigte war dies der Fall. Reichenbach hielt fest, dass die Säule nun dem Gesetz der Quadrate der Entfernung folgte. ${ }^{236}$

In einem weiteren Schritt widmete er sich der Eichung des Gerätes. Hierzu benötigte er eine Fläche von bestimmter Größe und Temperatur, die ein bekanntes Strahlungsvermögen besaß. Für die praktische Umsetzung bediente sich Reichenbach einer Arbeit von Dr. Kurlbaum, der die Strahlung eines schwarzen Körpers bestimmt hatte. ${ }^{237}$

Kurlbaum stellte, wie Reichenbach in seiner Arbeit ausführte, eine schwarze Fläche mit bekannter Temperatur her, indem er die geschwärzte Innenfläche eines Holzylinders benutzte. An der Vorderseite des Zylinders befand sich eine Öffnung, die die Größe der strahlenden Fläche definierte. Diese Fläche konnte durch Einleiten von Dampf in einen Mantelraum auf eine bestimmte Temperatur gebracht werden. Der Wärmeverlust durch die Öffnung war vernachlässigbar. In Bezug auf die Thermosäule waren Größe und Entfernung der Öffnung des Zylinders mit einer schwarzen Fläche gleicher Größe und Entfernung vergleichbar.

Die Thermosäule mit der beschriebenen schwarzen Fläche zu eichen, ist nur dann zulässig, wenn sie für die zu untersuchenden Strahlen und für die Strahlen der schwarzen Fläche das gleiche Absorptionsvermögen hatte. ${ }^{238}$ Reichenbach ging davon aus, dass man eine Korrekturrechnung vornehmen musste. Hierzu lagen aber noch keine Untersuchungen vor.

Aufgrund der Tatsache, dass die Eichungsmethode mit Hilfe des schwarzen Körpers aufwendig war, bemühte sich Reichenbach eine alternative Lösung zu finden, mit der er die Thermosäule jederzeit mit wenig Aufwand überprüfen konnte. ${ }^{239}$

Er stellte Versuche mit der Hefnerlampe an, da sie dafür bekannt war, eine besonders konstante Lichtstärke zu haben. Die Hoffnung, dass damit auch die abgehende Wärme konstant wäre, erwies sich jedoch als unzutreffend. Zwar waren über viele Messungen hinweg

236 Vgl. Reichenbach (1898) S. 323

237 Vgl. Reichenbach (1898) S. 325

238 Vgl. Reichenbach (1998) S. 328

239 Vgl. Reichenbach (1898) S. 329 
gute Ergebnisse erzielt worden, aber es gab auch immer wieder starke Abweichungen. Wie sich zeigte, war hierfür die Luftbeschaffenheit, insbesondere der Gehalt an Kohlensäure mit verantwortlich.

Die von Reichenbach durchgeführten Versuche zeigen einen deutlichen Zusammenhang zwischen steigendem Kohlensäuregehalt und einem geringeren Ansprechen der Thermosäule. Es wurden jedoch keine Untersuchungen durchgeführt, die hätten zeigen können, ob die Kohlensäure eine Veränderung in der Beschaffenheit der Flamme verursachte, oder ob z.B. Wärme absorbiert wurde

Als Wert, mit dem man theoretisch arbeiten könne, gab Reichenbach einen Kohlensäuregehalt in der Raumluft von über einem Promille an. Er räumte aber eine gewisse Unsicherheit für diese Methode ein, und empfahl sie nur als mögliche vergleichende Ergänzung zu der aufwendigen Eichung mit schwarzer Fläche.

\section{Beobachtungen}

Schon seit längerer Zeit beschäftigte sich Reichenbach mit der Strahlenmessung. Seine ersten Versuche stellte er mit einer Petroleumlampe an. ${ }^{240}$ Diese Arbeiten waren noch in relativen Werten zu einer „Amylacetatlampe“ angegeben, da er zum damaligen Zeitpunkt die Eichung der Thermosäule noch nicht vorgenommen hatte. Nun, mit der neuen Versuchsanordnung, wiederholte er zumindest zwei Versuchsreihen. Zum einen die mit der Lampen „IntensivBlitz“ und zum anderen die mit einer Normallampe.

Da die erzielten Werte mit den Resultaten der früheren Versuche gut übereinstimmten, gab er auch die Werte der anderen Versuche in Normalzahlen an. Er wies jedoch darauf hin, dass diese nur als Annäherungswerte dienen konnten.

Vergleichend zur Petroleumlampe, stellte Reichenbach Untersuchungen mit mehreren Beleuchtungsvorrichtungen an. ${ }^{241}$ Einmal benutzt er den „Argandbrenner“, der, bevor er durch das „Auersche Glühlicht“ verdrängt wurde, nach der Petroleumlampe die größte Verbreitung besaß. Außerdem benutzte er das „Auerlicht“, der Spiritus- Glühlampe „Phöbus“ und die „Moderateurlampe“.

Bei den Versuchen mit dem „Argandbrenner“ verwendete Reichenbach zwei verschiedene Brenner ähnlicher Konstruktion. Beide besaßen einen Specksteinkopf und 32 Löcher. Sie unterschieden sich jedoch in der Wandstärke ihrer Zylinder.

Die Versuche zeigten, wie auch schon bei Rubner beschrieben, dass der „Argandbrenner“ bei unterschiedlicher Flammenhöhe in Strahlung und relativer Ausnutzung des Gasverbrauches

240 Vgl. Reichenbach (1898) S. 331

241 Vgl. Reichenbach (1898) S. 335 
wenig differiert. Weiterhin konnte gezeigt werden, dass die von dem „Arganbrenner“ ausgehende Strahlung höher war als die der Petroleum Lampe.

In diesem Punkt kam Rubner in seinen Versuchen zu einem anderen Ergebnis und beschrieb, dass die Petroleum Lampe doppelt so viel Wärme abgab. Hierzu merkte Reichenbach an, dass der genaue Grund für die unterschiedlichen Ergebnisse ohne Kenntnis des von Rubner verwendeten Brenners nicht möglich gewesen wäre. Aber er ging davon aus, dass die unterschiedliche Methodik der Versuche, so zum Beispiel das Verwenden des Auffangtrichters, zu den Differenzen geführt hatte. Abschließend formulierte er:

„Übrigens scheint es mir auch mit der Erfahrung des täglichen Lebens nicht überein zustimmen, dass ein Argandbrenner nur halb so viel Wärme ausstrahlen sollte, wie eine gleich helle Petroleumlampe. “242

Der „Auerbrenner“ war als Leuchtquelle populär, da er einen geringen Gasverbrauch und eine niedrige Wärmeproduktion aufwies. ${ }^{243}$ Reichenbach stellte mit dem „Auer`schen Glühlicht“ Versuche mit fünf verschiedenen Brennern an. Zwei verwendete Glühbrenner waren mit 200 Brennstunden älter als zwei neue Glühbrenner. Außerdem wurde ein kleiner, ebenfalls ungebrauchter Glühbrenner, das Modell „Juwel“ getestet.

Die Wärmestrahlung erwies sich bei allen verwendeten Modellen als gering. Die beiden neuen „Auerbrenner“ schnitten am besten ab. Vergleichbar und geringfügig schlechter waren die beiden gebrauchten „Auerbrenner“, sowie das kleinere Modell „Juwel“. Im Mittel betrug die Wärmestrahlung des „Auerbrenners“ nur 1/8 von der des „Argandbrenners.““244

Die Ergebnisse, die Rubner in seiner Arbeit ermittelte, sind noch günstiger, was Reichenbach darauf zurückführte, dass bei seinen Glühkörpern der Grün- Rotquotient kleiner war als bei den von Rubener verwendeten Glühkörpern.

Da sich Konstruktionen wie diese, mit Gas gespeisten „Auerglühlichter“, als sehr effizient erwiesen, versuchte man auch bei Konstruktionen, die mit flüssigen Brennstoff arbeiteten, das Prinzip des Glühkörpers anzuwenden. Als weiteres Leuchtmittel untersuchte Reichenbach die Spiritusglühlampe „Phöbus“. Sie galt als besonders effizient. ${ }^{245}$

Die Lampe benötigte, um auf Betriebstemperatur zu kommen, eine kleine Heizflamme. War die Betriebstemperatur erreicht, kam sie ohne aus. Auffällig war das sehr ruhige Licht, welches auch durch starken Luftzug kaum beeinflusst wurde. Die Lampe arbeitete

$\begin{array}{ll}242 & \text { Reichenbach (1898) S. } 337 \\ 243 & \text { Vgl. Reichenbach (1898) S. } 337 \\ 244 & \text { Vgl. Reichenbach (1898) S. } 338 \\ 245 & \text { Vgl. Reichenbach (1898) S. } 338\end{array}$ 
geruchsneutral. Nachteilig waren jedoch die hohen Betriebskosten und die Tatsache, dass es bis zu zwei Minuten dauerte, ehe die Lampe ihre volle Leuchtkraft entfaltete.

Vom hygienischen Standpunkt beschreibt Reichenbach die Lampe als günstig, bedauerte jedoch, dass sie aufgrund hoher Betriebskosten kaum Verbreitung finden würde. ${ }^{246}$

In weiteren Versuchen, die Reichenbach mit einem Petroleumglühlicht anstellte, zeigte sich, dass dieses aus hygienischer Sicht fast der Spiritusglühlampe gleichgestellt werden konnte. Die Kosten waren jedoch deutlich geringer. Bei sehr sorgfältiger Anwendung der Lampe wurde bei guter Leuchtleistung von ca. 60 Kerzen ein ruhiges Brennen ohne Blaken oder Rußen erzielt. Zur Schwierigkeit der Anwendung merkt Reichenbach an:

„Ich glaube nicht, dass es viele Hausfrauen oder gar Dienstmädchen gibt, die sich mit der schwer zu behandelnden Lampe befreunden werden. “247

Weiterhin stellte er Versuche mit der weniger modernen, aber noch immer beliebten „Moderateurlampe“ an. ${ }^{248}$ Diese Lampe hatte den Ruf, bei angenehmem Licht eine nur geringe Wärmeentwicklung zu haben. Wie sich zeigte, war die Wärmestrahlung aber nicht geringer als bei einer vergleichbaren Petroleumlampe.

Rubner hatte, um die gewonnenen Ergebnisse abzusichern, in Versuchen mit Menschen ermittelt, welche Wärmemenge gerade noch auf der menschlichen Gesichtshaut wahrgenommen wurde. Einen etwas höheren, als den ermittelten Wert, nämlich den von 0,05 Cal. fordert Rubner als Grenzwert für Beleuchtungskörper.

In einem Selbstversuch kam Reichenbach zu einem vergleichbaren Wert und somit übernahm er ihn.

„Im Folgenden will ich mich denn auch dieses Wertes bedienen, doch kann ich mich der Besorgnis nicht erwehren, dass ich selbst gegen strahlende Wärme besonders empfindlich bin und dass deshalb die Zahl reichlich niedrig gegriffen sein möchte. Einige Versuche, die ich vor kurzem an anderen Personen anstellte, ergaben größere Werte. Ich behalte mir vor, nähere Untersuchungen über diesen Gegenstand mit ausgedehnter Berücksichtigung individueller Eigentümlichkeiten vorzunehmen. “249

In der Praxis setzte sich der Anwendungsradius einer Lampe aus zwei Bereichen zusammen. Aus dem Bereich, dessen Wärmestrahlung den Grenzwert noch nicht überschreitet und dem

\footnotetext{
246 Vgl. Reichenbach (1898) S. 339

247 Reichenbach (1898) S. 340

248 Vgl. Reichenbach (1898) S. 341

249 Reichenbach (1898) S. 342
} 
Radius, in dem die gebotene Helligkeit noch ausreichend ist. Für die Strahlung berechnete sich der Bereich über die Formel:

$\mathrm{X}=$ Wurzel aus $\mathrm{S} / 0,87$

$\mathrm{S}=$ Gesamtwärmestrahlung

0,87 = Grenzwert (0,05 Cal. entspricht 0,87 mg x Cal. / Sec. X qcm)

Als ausreichend hell war ein Bereich zu bezeichnen, dessen MK Wert über 10 lag. $^{250} \mathrm{Zu}$ beachten war, dass in der Praxis die Lampen mit einer Kuppel ausgestattet waren. So verminderte sich die Strahlung um ca. 50\%, wenn sich die Lampe in einer Horizontalen mit dem Kopf des Betrachters befand. Bei Lampen, die höher angebracht waren, wich die Strahlung erheblich von der Horizontalen ab. Dadurch fielen nicht mehr alle Strahlen durch die Kuppel, was die Verhältnisse wesentlich erschwerte und somit gesondert untersucht werden musste.

Als Beispiel für eine auf Kopfhöhe angebrachte Lampe, sei die „Reichslampe“ aufgeführt. Ihr berechneter Strahlungsgrenzwert lag bei einem Radius von $71 \mathrm{~cm}$ um die Lampe, während sich eine ausreichende Helligkeit in einem Umkreis von $104 \mathrm{~cm}$ erstreckte. Die „Ausnutzbahre Zone“ der Lampe befand sich somit zwischen diesen beiden Bereichen.

Ein einfaches Mittel, um die Strahlung der Leuchtkörper zu verringern, war eine zwischengeschaltete Glasplatte. Ähnlich wie schon die Lampenkuppel konnte ein zusätzlicher Glaszylinder die Strahlung weiter reduzieren. Das Maß der Wärmeabsorption hing von der Stärke der verwendeten Glasplatte ab, von deren Platzierung sowie von der Wellenlänge der Wärmestahlen. Langwellige Strahlen wurden deutlich stärker absorbiert. ${ }^{251}$

Im Folgenden wird im Versuch geschildert, welche Wirkung eine eingefügte Glasplatte hervorruft. In einem Meter Abstand zu einer Thermosäule wurde eine „Argandlampe“ aufgestellt. Mittig zwischen Thermosäule und „Argandlampe“ befand sich eine Glasplatte mit einer Stärke von 2,5 mm. In dem Versuch wurde die absorbierende Eigenschaft der Wärmestrahlung bei unterschiedlicher Flammenhöhe verglichen. Wie sich zeigte, war bei kleiner Flammenhöhe die Absorbtionskraft der Scheibe deutlich höher als bei großer Flamme. Dies hatte folgenden Grund. Bei kleiner Flamme war der Anteil an Strahlen, der durch aufgeheizte Eisen und Glaselemente der Lampe ausging größer, als der Anteil der Strahlen der von der Flamme selber ausging. Diese Wärmestrahlen waren langwellig und wurden von der Glasplatte besser absorbiert als die Strahlen der Leuchtflamme. Aber auch bei hoher

\footnotetext{
250 Vgl. Reichenbach (1898) S. 342
}

251 Vgl. Reichenbach (1898) S. 344 f. 
Flamme war der Strahlenverlust im beschriebenen Versuch bei über 60\%, bei einer Flammenhöhe von $14 \mathrm{~cm}$, noch beträchtlich.

Somit stellte sich die Frage , warum die in der Praxis verwandten Überzylinder eine geringere Wirkung von nur ca. 30\% zeigten. Die Erklärung war, dass der Überzylinder selbst durch Leitung, Strahlung und Konvektion zu einer Wärmequelle wurde.

In der Folge betrachtete Reichenbach das Kapitel der Strahlung mathematisch, um eine Erklärung für das beobachtete geben zu können. Er fasste zusammen:

„Befindet sich zwischen einer Wärmequelle und einem bestrahlten Punkt ein Schirm, der einen Theil der Strahlen absorbiert und selbst wieder nach dem betreffenden Punkt ausstrahlt, so ist die von dem Schirm auf den Punkt ausgestrahlte Wärmemenge am geringsten, wenn sich der Schirm in der Mitte zwischen ihm und der Wärmequelle befindet, sie wächst, je mehr sich der Schirm der Wärmequelle oder dem bestrahlten Punkt nähert. “252

Die Praxis wich von dieser Regel erheblich ab und somit erklärt sich, weshalb die Wirkung der Zylinder hier soviel geringer war, als im Versuch ermittelt.

Es gab, wie Reichenbach zum Ende seines Artikels festhielt, aber auch Lampenschirme, die gute Ergebnisse in der Wärmedämmung boten. An dieser Stelle beschrieb Reichenbach zwei Modelle, die beide an derselben Lampe getestet wurden. Die Lampe war ein „Siemens`scher invertierter Regenerativbrenner J Nr. 7“, die der Beleuchtung eines Hörsaals diente. ${ }^{253}$

Aus räumlichen Gründen war die Flamme der Lampe nur $170 \mathrm{~cm}$ über der Tischhöhe angebracht, was eine deutliche Wärmebelästigung verursachte. Somit wurde die Lampe mit einer äußeren Glocke umgeben, die einen Abstand von $18 \mathrm{~cm}$ zur Flamme hatte. Am Boden der Glocke befand sich eine Öffnung mit einem Durchmesser von $11 \mathrm{~cm}$. Diese wurde von einer auf drei Füssen ruhenden Glasplatte bedeckt. Durch den zwischen Glocke und Glasplatte entstandenen Spalt fand eine Luftzirkulation ins Innere statt, so dass ein übermäßiges Erhitzen der Glocke verhindert wurde.

Messungen zeigten, dass mit dieser Konstruktion die Strahlung um 53\% vermindert werden konnte. Es zeigte sich jedoch auch ein Verlust an Leuchtkraft von 10\%. In Anbetracht der Tatsache, dass die untersuchte Lampe weiter entfernte Plätze ohnehin nur gerade bis über die geforderte Mindestgrenze von 10 MK ausleuchtete, war dies eher ungünstig. Aus diesem Grund wurde eine weitere Vorrichtung geprüft, von der man sich einen deutlich geringeren Lichtverlust versprach.

Reichenbach (1898) S. 346

253 Vgl. Reichenbach (1898) S. 347 
Man prüfte den von der Firma S. Elster konstruierten „Lamellen-Reflektor“. Wie sich zeigte, war die strahlungsvermindernde Wirkung von 60\%, senkrecht unter der Lampe gemessen, noch größer als bei der zuvor beschriebenen Glocke. Die Helligkeit konnte nur indirekt bestimmt werden, weil der Schirm so konzipiert war, dass nur reflektiertes oder durch Mattglas geführtes Licht nach außen drang. Bei der Messung zeigte sich, dass die Plätze in unmittelbarer Nähe zur Lampe eine starke Minderung der Helligkeit aufwiesen, während bei weiter weg liegenden Plätzen praktisch kein Helligkeitsverlust auftrat. Reichenbach beschrieb das als großen Vorteil.

Auch hob er hervor, dass das durch den Schirm verursachte diffuse Licht, welches das Auge nicht blendete und zudem scharfe Schlagschatten minderte, für die Hygiene des Auges von Vorteil war. $^{254}$

254 Vgl. Reichenbach (1898) S. 348 f. 


\subsection{Das Mikroskop und seine Nebenapparate ${ }^{255}$}

\section{Allgemeines zur Linse}

Eine Konvexlinse erzeugt von einem Gegenstand, der zwischen der doppelten und der einfachen Brennweite der Linse liegt, ein auf der anderen Seite der Linse gelegenes, vergrößertes auf dem Kopf stehendes reelles Bild. ${ }^{256}$

Das Bild wird umso größer, je näher sich der abzubildende Gegenstand der hinteren Brennebene nähert. Liegt er in der Brennebene, kommt kein Bild mehr zustande, da die von dem Gegenstand ausgehenden Strahlen die Linse parallel verlassen und sich theoretisch im Unendlichen treffen.

\section{Die Lupe und das einfache Mikroskop}

Man unterscheidet einfache und aus mehreren Linsen zusammengesetzte Mikroskope. Wobei das einfache Mikroskop als Lupe bezeichnet wird. Die Vergrößerung, welche eine Lupe erzeugen kann, wird angegeben im Verhältnis des Sehwinkels, der durch die Lupe wahrgenommen wird und zwar in Bezug zu dem Sehwinkel, den man mit bloßem Auge von einem Gegenstand hat, der $250 \mathrm{~mm}$ vom Auge entfernt gelegen ist. ${ }^{257}$ Eine Linse mit xmaliger Vergrößerung hat also einen $\mathrm{x}$-mal so großen Sehwinkel, mit der der Gegenstand wahrgenommen wird.

In der Praxis gibt es je nach Anforderung an die Linse verschiedenste Modelle. Während für einfache Lupen mit einer Vergrößerung bis um das fünffache einfache, plankonvexe Linsen ausreichen, benötigt man für stärkere Vergrößerungen aus mehreren Linsen zusammengesetzte Mikroskope.

\section{Das zusammengesetzte Mikroskop}

Das zusammengesetzte Mikroskop besteht aus Objektiv und Okular. Durch das Objektiv wird ein reelles, vergrößertes Bild geschaffen, welches aufgrund der Lupenfunktion des Okulars weiter vergrößert wird. Dabei ist die vergrößernde Komponente des Okulars, durch seine konstante Brennweite festgelegt, während die Größe des vom Objektiv gelieferten Bildes abhängig vom Abstand des Objektivs zum abzubildenden Gegenstand ist.

\footnotetext{
Vgl. Reichenbach (1929)

256 Vgl. Reichenbach (1929) S. 567

257 Vgl. Reichenbach (1929) S. 568
} 
Will man also die gesamt Vergrößerung des Mikroskops angeben, muss man sich der so genannten optischen Tubuslänge (=Delta) bedienen. ${ }^{258}$ Die optische Tubuslänge setzt sich aus der Entfernung der hinteren Brennebene des Objektivs bis zur vorderen Brennebene des Okulars zusammen.

Die gesamte Vergrößerung kann mit Hilfe folgender Formel errechnet werden:

Delta / f x 250 / f1

$\mathrm{f} \quad=$ Brennweite des Objektivs

f1 = Brennweite des Okulars

Auch diese Formel bezieht sich auf die weiter oben angegebene Entfernung von $250 \mathrm{~mm}$ zwischen Gegenstand und Auge des Betrachters.

\section{Die Objektive}

Jede Linse weist Fehler in ihren optischen Eigenschaften auf; hier die Wichtigsten: ${ }^{259}$

1) Die sphärische Aberration.

Sie beschreibt das Phänomen, das Lichtstrahlen, die weiter außen auf die Linse auftreffen, stärker gebrochen werden als Strahlen, die die Linse näher zur Mitte hin treffen. Somit trifft sich die Summe der Strahlen nicht in einem Punkt, sondern ergibt einen größeren Lichtfleck, der in seiner Mitte am hellsten ist und zum Rand hin dunkler wird.

Durch dieses Phänomen bedingt, kommt es zu einer größeren Schärfe des Bildes, wenn man den Rand der Linse abblendet, da die seitlich eintreffenden, nicht sauber gebrochenen Strahlen ausgeblendet werden. Außerdem kann man die sphärische Abberation durch Kombination mit einer Konkavlinse, die entgegen gesetzter Abberation ist, aber geringerer Brennweite hat, eliminieren.

2) Die Deckglasdicke.

Eine weitere Fehlerquelle ist eine vom Standardglas abweichende Deckglasdicke. Da das Deckglas den Strahlengang ebenfalls ablenkt, muss seine Stärke an das Mikroskop angepasst werden, was über eine Korrektionsfassung geschehen kann. Diese Fassung ermöglicht es, die Linsen im Objektiv gegeneinander zu verschieben und somit an das Deckglas anzupassen.

3) Die chromatische Aberration.

Als solche bezeichnet man die Tatsache, dass Licht unterschiedlicher Wellenlänge unterschiedlich stark gebrochen wird. So werden violette Strahlen stärker gebrochen

\footnotetext{
258 Vgl. Reichenbach (1929) S. 570
}

259 Vgl. Reichenbach (1929) S. 570 f. 
als rote Strahlen. Dort wo sich die Farben überlagern, entsteht weißes Licht, welches von einem bunten Saum umgeben wird.

Ein weiteres Phänomen, welches in engem Bezug steht, ist dass der chromatischen Differenz der Vergrößerung, die dadurch zustande kommt, dass die ungleichen Wellenlängen unterschiedlichen Lichts verschieden große Bilder erzeugen.

Die Korrektur der Farbfehler kann man durch die Kombination von Konvex- und Konkavlinse erreichen. Besitzt die Konkavlinse eine niedrige Brechungskraft, kann sie bei noch erhaltener Vergrößerung durch die Konvexlinse die Farbfehler, die oben beschrieben wurden, ausgleichen. Somit werden für den Bau von Mikroskopen meist zwei Linsen, die jeweils zwei- bis dreifach verkittet sind, benutzt. Für einfache Ansprüche reichen diese achromatischen Objektive aus. $^{260}$

Weitaus effektiver sind jedoch die so genannten Apochromate, die seit 1896 auf dem Markt erhältlich sind. ${ }^{261}$ Diese werden aus einer Kombination von Flussspat und Jenserglas gefertigt und haben kaum noch einen chromatischen Aberrationsfehler, was primär durch die optischen Eigenschaften des Flussspats bedingt ist. Zudem ist es bei den Apochromaten gelungen, die chromatische Differenz der Vergrößerung in allen Objektivstärken zu korrigieren.

\section{Die Okulare}

Das gebräuchlichste Okular, das so genannte Huygenssche Okular, besteht aus zwei einfachen, nicht achromatischen Linsen. ${ }^{262}$ Die weiter oben beschriebenen Farbfehler werden vermieden, indem die beiden Linsen in einem bestimmten Abstand zueinander angeordnet werden, nämlich dem arithmetischen Mittel ihrer Brennweite. Durch diese Anordnung der Linsen zueinander kommt es dazu, dass an der ersten Linse durch die stärkere Lichtbrechung der blauen Strahlen, diese die zweite Linse näher der Achse treffen als die roten Strahlen. Durch die sphärische Aberration werden die blauen Strahlen dann an der zweiten Linse weniger stark abgelenkt als die weiter peripher eintreffenden roten Strahlen. Durch diese Konstruktion verlassen sowohl rote als auch blaue Strahlen die zweite Linse unter dem gleichen Winkel. ${ }^{263}$

Die Krümmung des Gesichtsfeldes, welche durch das Objektiv verursacht wird, kann mit Hilfe von Spezialokularen ausgeglichen werden. Diese sind wie das Hygens'sche Okular

260 Vgl. Reichenbach (1929) S. 572

261 Vgl. Reichenbach (1929) S. 572

262 Vgl. Reichenbach (1929) S. 573

263 Vgl. Reichenbach (1929) S. 573 
gebaut, haben aber an Stelle der zweiten oberen einfachen Linse eine aus mehreren Linsen verkittete Linse.

„Die schwächeren Kompensationsokulare sind nach dem Huygensschen , die stärkeren nach dem Ramsdenschen Typus gebaut. “264

Das Ramsdensche Okular besteht aus zwei Linsen, die sich den konvexen Seiten zukehren. Die Linsen gleicher Brennweite sind um den Abstand der Brennweite der einzelnen Linse von einander entfernt und schaffen durch diese Anordnung die Achromasie.

\section{Auflösungsvermögen der Objektive}

Ein weiterer, äußerst wichtiger Punkt für die Bildqualität eines Mikroskops ist das Auflösungsvermögen. ${ }^{265}$

Für selbstleuchtende Objekte bzw. für die Dunkelfeldbeleuchtung hat man festgestellt, dass es bei der Abbildung von Objekten gewisse Beugungserscheinungen gibt, was zur Folge hat, dass ein Punkt nicht als Punkt, sondern als Lichtfleck als „Beugungsscheibchen“ wiedergegeben wird. Die Beugung findet an der kreisförmigen Apertourblende des Objektivs statt. Die Auflösung des einzelnen Punktes ist somit abhängig von der Größe der Beugungsscheibchen. Je kleiner die einzelnen Beugungsscheibchen sind, desto mehr entspricht die Abbildung dem tatsächlichen Objekt, umso schärfer wird es abgebildet. Bei von unten mit paralleler Lichtquelle durchleuchteten Objekten, z.B. einem aufgezeichneten Gitter, verhält es sich wie folgt. ${ }^{266}$

Die durch die Gitteröffnungen fallenden Strahlen werden in den Öffnungen nicht abgelenkt und treffen parallel auf die Optik. Die Strahlen, die auf die Gitterstreifen fallen werden an den Rändern abgelenkt und bilden einen Winkel zu den parallel verlaufenden Strahlen.

Für die Größe des Ablenkungswinkels besteht die Beziehung:

sin Alpha = m x Lambda / d (Legende siehe weiter unten).

Eine dem Gitter getreue Abbildung kommt nur dann zustande, wenn das Mikroskop bzw. das Objektiv tatsächlich alle Strahlen aufnehmen kann. Eine objektähnliche Wiedergabe ist möglich, sobald das erste Beugungsmaximum vom Objektiv aufgenommen wird.

In diesem Fall wird bei der gerade gezeigten Formel, $\mathrm{m}=$ eins.

Wenn nach d aufgelöst wird, erhält man die Formel:

d = Lambda / sin Alpha.

Reichenbach folgerte zu der kleinsten möglichen Gitterstreifenauflösung:

264 Reichenbach (1929) S. 574

265 Vgl. Reichenbach (1929) S. 574

266 Vgl. Reichenbach (1929) S. 575 
„[....]dass der von einem Objektiv aufzulösende kleinste Streifenabstand gleich dem Quotienten aus der Wellenlänge des Lichtes und dem Sinus des halben Öffnungswinkels des Objektivs sein muss. “267

Hierfür ist Voraussetzung, dass sich zwischen Objektiv und Objekt eine Luftschicht befindet. Ist anstelle von Luft ein anderes Medium vorhanden, muss dessen Brechungsexponent berücksichtigt werden. Nach dem Gesagten erhalten wir für das Auflösungsvermögen eines Objektivs folgende Formel:

$\mathrm{d}=$ Lambda / $\mathrm{n}$ x sin Alpha

$\mathrm{n}=$ der Brechungsindex der sich zwischen Frontlinse und Objekt befindlichen Flüssigkeit.

$\mathrm{n} x \sin$ Alpha wird von Abbe als die numerische Apertur des Objektivs bezeichnet, es ist also der Ausdruck für das Auflösungsvermögen des Objektivs.

Lambda $=$ die Wellenlänge.

$\mathrm{d}=$ der Abstand der Gitterstreifen, die so genannte Gitterkonstante.

$\mathrm{m}=$ die Ordnungszahl des Maximums; es kann nur eine ganze Zahl sein.

Abbe bezeichnete den Ausdruck $\mathrm{n} x$ sin Alpha als numerische Apertur, als Auflösungsvermögen des Objektivs. ${ }^{268}$

\section{Die förderliche Vergrößerung}

Das Auflösungsvermögen eines Objektivs ist ausschlaggebend dafür, welche Gesamtvergrößerung eines Mikroskops noch sinnvoll ist. Einzelheiten, die ein Objektiv nicht wiedergibt, werden auch bei noch so starker Vergrößerung nicht abgebildet und führen durch stärkere Vergrößerung somit nicht zu einer Verbesserung des Bildes. ${ }^{269}$

Das Auflösungsvermögen, also die Detailtreue, die ein Objektiv erreichen kann, ist abhängig von seiner numerischen Apertur. Die zweckmäßige Vergrößerung, welche ebenfalls abhängig von der numerischen Apertur ist, ist begrenzt durch die Vergrößerung, bei der das Auge noch bequem die einzelnen Details im Bild wahrnehmen kann. Bei stärkerer Vergrößerung würden die Einzelheiten nur mehr auseinander gezogen, es käme lediglich zu einer Abnahme der Bildqualität.

Die angulare Sehschärfe des Auges beträgt eine Minute. Das bedeutet, dass das Auge zwei parallele Linien bei einer Entfernung von 250 mm gerade dann noch als getrennt wahrnehmen

Reichenbach (1929) S. 575

268 Vgl. Reichenbach (1929) S. 576

269 Vgl. Reichenbach (1929) S. 579 
kann, wenn sie um 0,073 mm auseinander liegen. Die Vergrößerung des Objektivs muss also diesen Abstand erbringen, damit das Auge ihn noch als solchen wahrnimmt.

„Wir erhalten so für die Vergrößerung den Wert von 0,073 / d, und durch Einsetzen des Wertes für d bei gerader Beleuchtung 0,073 x sin Alpha / Lambda oder für Lambda =0,55, wenn wir alle Längen in $\mu \mu$ ausdrücken 73000 / 550 x n sin Alpha = 133 x sin Alpha. “270

Nach dieser Berechnung reicht eine Vergrößerung der numerischen Apertur auf das 133fache, um die im Bild enthaltenen Einzelheiten gerade zu erkennen.

Eine für die Praxis der Mikrobiologie zweckmäßige Vergrößerung liegt jedoch beim 600 700 fachen der Apertur. ${ }^{271}$

\section{Die Beleuchtung des Objektes und die Beleuchtungsapparate}

Bei den gängigen größeren Mikroskopen, welche mit durchfallendem Licht arbeiten, wird das Licht über einen Spiegel durch eine Öffnung im Objekttisch auf das zu mikroskopierende Objekt geleitet. ${ }^{272}$ Abhängig von der verwendeten Lichtquelle, wird ein Plan- oder ein Hohlspiegel benutzt. Der Planspiegel findet seine Anwendung bei Ausnutzung des Tageslichtes, während man den Hohlspiegel verwendet, wenn eine künstliche, kleine Lichtquelle benutzt wird.

Ist die durch den Spiegel hervorgerufene Beleuchtung zu klein bzw. zu schwach, bedient man sich eines so genannten Kondensors. Dieser wird vor allem bei starker Vergrößerung benötigt. Die gängigen Kondensoren werden aus zwei bis drei Linsen zusammengesetzt, dabei liegt die obere Linse im Objekttisch. ${ }^{273}$ Der Brennpunkt des Kondensors liegt im Objekt oberhalb des Objekttisches.

Um die Fläche der Lichtstrahlen, die Apertur regeln zu können befindet sich zwischen Spiegel und Kondensor eine Irisblende. Diese setzt man je nach zu mikroskopierendem Objekt verschieden ein. Objekte, die mit hoher Vergrößerung betrachtet werden erfordern eine hohe Apertur und werden bei voller Blendenöffnung betrachtet. Betrachtet man hingegen Objekte, z.B. Mikroorganismen mit hohen Brechungsunterschieden, so muss man zur Wahrung der Kontraste eine kleine Blendenöffnung wählen.

„Die günstigste Blendengröße muss von Fall zu Fall ausprobiert werden - als Annäherungsregel kann gelten, dass die Apertur der Beleuchtung etwa ein Drittel der Objektivapertur betragen soll. “ 274

\footnotetext{
270 Reichenbach (1929) S. 579

271 Vgl. Reichenbach (1929) S. 579

272 Vgl. Reichenbach (1929) S. 580

273 Vgl. Reichenbach (1929) S. 581

274 Reichenbach (1929) S. 583
} 
Somit vermeidet man auch ein $\mathrm{zu}$ starkes Abblenden, welches $\mathrm{zu}$ einem Verlust des Auflösungsvermögens führen würde.

\section{Die mechanische Ausführung des Mikroskops}

Der Bau der Mikroskope hat sich in letzter Zeit aufgrund von Neuerungen in der Mechanik verändert. Moderne Mikroskope werden nun mit Schlittenvorrichtung und Schwalbenschwanzführung gefertigt. ${ }^{275}$ Diese Änderungen stehen in Zusammenhang mit einer Verbesserung der Feinmechanik. Während früher der Tubus auf der Prismenführung mittels parallel zur Mikroskopachse stehender Mikrometerschraube verschoben wurde, ist die Schraube heute senkrecht angebracht, was zwar eine aufwendigere Konstruktion zur Folge hat, aber eine feinere Bewegung erlaubt.

Positiv ist auch, dass der Tubusträger nun nur beim Heben direkt mit der Stellschraube verbunden ist. Beim Absenken folgt er dem eigenen Gewicht und ist nicht mehr starr mit der Stellschraube verbunden. Das hat den Vorteil, dass das Objektiv beim Absenken gegen Widerstand nicht zu Schaden kommen kann, da es nur seinem geringen Eigengewicht ausgesetzt ist. Bei den früheren Ausführungen, bei denen die Mikrometerschraube großen Druck beim Absenken des Tubus verursachte, kam es regelmäßig zu Beschädigungen des Objektivs.

Reichenbach forderte in seiner Ausführung, dass standardmäßig neben der Möglichkeit der Feinjustierung auch eine Grobeinstellung zur Scharfstellung des Bildes gewährleistet sein müsste. ${ }^{276}$ Er merkte an, dass sonst ein mikrobiologisches Arbeiten nicht möglich sei.

Auch zur Beschaffenheit des Objekttisches machte er Angaben. Der Objekttisch sollte möglichst so groß sein, dass auch größere Gegenständen wie Petrischalen, Platz darauf hätten. Außerdem sollte er rund sein und eine Zentriervorrichtung haben. Die Objektführvorrichtung sollte möglichst abschraubbar sein, da sie zwar zur systematischen Durchsuchung des Präparats unentbehrlich war, für viele andere Arbeitsschritte jedoch hinderlich.

Zum Auswechseln der verschieden starken Objektive, stehen unterschiedliche Vorrichtungen zur Verfügung. ${ }^{277}$ Der häufig verwendete Revolver ist zwar praktisch, hat aber den Nachteil, dass beim Wechseln des Objektivs mit dem neuen Objektiv nicht exakt die Stelle anvisiert wird, die mit dem vorherigen Objektiv betrachtet wurde.

\footnotetext{
275 Vgl. Reichenbach (1929) S. 585

276 Vgl. Reichenbach (1929) S. 588

277 Vgl. Reichenbach (1929) S. 589
} 
Alternativ gibt es für Arbeiten, bei denen hohe Genauigkeit erforderlich ist Konstruktionen, die präzise arbeiten, jedoch umständlich in der Handhabung sind. Beispiele hierfür wären der Schlittenwechsler und der Zangenwechsler. Beide Vorrichtungen bestehen aus einem Zwischenstück, welches fest am Tubus montiert ist. An den jeweiligen Objektiven sind die Verbindungsstücke befestigt, die an das Zwischenstück gesetzt werden können. Die Verbindungsstücke sind justierbar und müssen einmalig im Vorfeld der mikroskopischen Arbeit angepasst werden.

\section{Die Lichtquelle}

Die beste Lichtquelle zum Mikroskopieren ist helles Tageslicht bei weiß bewölktem Himmel. ${ }^{278}$ Als künstliche Lichtquellen, die durch hohe Lichtgleichmäßigkeit mitunter geeigneter sind als Tageslicht, stehen verschiedene Varianten zur Verfügung.

Gängig sind solche mit elektronischer Lichtquelle. Als Beispiel hierfür wäre die Opallampe zu nennen, die 75 bis 100 Watt aufweist. Diese Lampe wird in 20 bis $30 \mathrm{~cm}$ Entfernung zum Mikroskop aufgestellt. Um eine höhere Gleichmäßigkeit des Lichts zu erlangen, kann man zwischen Lampe und Spiegel eine mit Kupferoxydammoniakwasser gefüllte, durchsichtige Flasche stellen. Durch das bläulich gefärbte Wasser ähnelt das Licht dem Tageslicht.

Steht kein Strom zur Verfügung, kann auch mit Gaslampen, Bogenlampen, Petroleumlampen oder Spirituslampen mikroskopiert werden.

\section{Binokulare und stereoskopische Mikroskope}

Das erste binokulare Mikroskop wurde 1852 vorgestellt. ${ }^{279}$ Da es sehr unvollkommen war, konnte es sich nicht durchsetzen. Man hatte durch das Einbringen von spiegelnden Prismen die Teilung des Strahlenbündels erreicht. Die Teilung fand nach Verlassen des Objektivs statt und verteilte die Strahlen auf die beiden Okulare. Man spricht in diesem Fall von einer geometrischen Teilung.

Ein anderer, effektiverer Ansatz ist der, dass man in den Strahlengang eine um den Winkel von $45^{\circ}$ versetzte Glasfläche einsetzt, welche das Licht teilweise durchlässt und teilweise reflektiert. ${ }^{280}$ Bei dieser Teilung der Strahlen sprach Reichenbach von physikalischer Teilung. Bei der geometrischen Teilung des Strahlengangs sind die beiden Bilder unterschiedlich, was zu einem stereoskopischen ${ }^{281}$ Eindruck führt, da beide Augen jeweils ein unterschiedliches

278 Vgl. Reichenbach (1929) S. $590 \mathrm{f}$

279 Vgl. Reichenbach (1929) S. 592

280 Vgl. Reichenbach (1929) S. 593

281 Stereoskopie: wie beim natürl. Sehen wird jedem Auge nur das ihm zugeordnete Bild vermittelt, es entsteht ein räumliches Bild 
Bild sehen. Im Gegensatz dazu entsteht bei der physikalischen Teilung kein stereoskopischer Eindruck; beide Augen bekommen dasselbe Bild präsentiert.

Tatsächlich kann man aus jedem binokularen Mikroskop ein stereoskopisches Mikroskop machen. Hierzu muss man die jeweilige Austrittspupille mit einer halbkreisförmigen Blende versehen, so dass das Auge nur jeweils ein Blickfeld betrachten kann.

Dasselbe Phänomen liegt vor, wenn der Abstand der Okularachse nicht mit dem Abstand der Augenachse übereinstimmt. ${ }^{282}$ Das Auge sieht in diesem Fall nur durch einen Teil der Austrittspupille hindurch und hat somit auch nur ein eingeschränktes Blickfeld. Ist der Okularabstand größer als der Augenabstand, sieht das Auge jeweils nur durch den inneren Teil der Austrittspupille und umgekehrt. Es entsteht ebenfalls ein stereoskopisches Bild.

Ein weiterer stereoskopischer Effekt der auftritt ist der, dass, wenn die Augenachse gleich der Okularachse ist, dem Auge verschieden gefärbte Objekte, die in einer Ebene liegen, tatsächlich auch als in einer Ebene liegend erscheinen. Kommt es jedoch bei nicht Übereinkommen der Augen / Okular Achse zu stereoskopischem Sehen, werden die in einer Ebene liegenden Farben nicht als in einer gemeinsamen Ebene liegend empfunden. Bei geringerem Abstand der Okularachse treten die roten, bei zu großem Abstand, die blau gefärbten Objekte vor. Somit muss man in der Praxis darauf achten, dass man die Lage gefärbter Objekte zueinander richtig einschätzt. ${ }^{283}$

\section{Die Bauart der binokularen und stereoskopischen Mikroskope}

Als gängige Bauart der binokularen Mikroskope setzte sich die der physikalischen Teilung durch. ${ }^{284}$ Die erste Firma, die einen binokularen Aufsatz baute, war die Firma Zeiss. Dieser Aufsatz konnte auf verschiedene Mikroskope aufgesetzt werden. Die physikalische Teilung erfolgte durch eine dünne Luftschicht. Diese Konstruktion wies jedoch Schwächen auf, da sie deutlich mehr Strahlen durchließ als sie reflektierte. Aus diesem Grund konnte sich der Aufsatz nicht durchsetzen.

Ausgereifter war eine Variante aus dem Hause Leitz. Allerdings musste man hier das ganze Mikroskop kaufen. Bei diesen Mikroskopen wurde eine halbdurchlässige Silberschicht eingebaut. Durch die Möglichkeit, die Stärke der Silberschicht zu variieren, konnte man bestimmen wie hoch der Anteil an reflektiertem, bzw. durchgelassenem Licht sein sollte. ${ }^{285}$

$\begin{array}{ll}282 & \text { Vgl. Reichenbach (1929) S. } 594 \\ 283 & \text { Vgl. Reichenbach (1929) S. } 594 \\ 284 & \text { Vgl. Reichenbach (1929) S. } 596 \\ 285 & \text { Vgl. Reichenbach (1929) S. } 597\end{array}$ 


\section{Konstruktionen mit geometrischer Teilung}

In der Anfangszeit des binokularen Mikroskops gab es nur die Konstruktionen mit geometrischer Teilung, welche später an Relevanz verloren und kaum noch gebaut wurden. Der Hauptgrund dafür, dass sich diese Konstruktion nicht durchsetzen konnte, war die Tatsache, dass bei stärkeren Objektiven der Objektivdurchmesser geringer ist. Bei den Mikroskopen mit geometrischer Teilung lagen die Teilungsprismen aber genau hier. Dies machte die Konstruktion für stärkere Mikroskope sehr schwierig. ${ }^{286}$

Es gab elegante Lösungsversuche. So wurde z.B. die Teilungslinie nicht in das Objektiv selber gelegt, sondern in ein eigens hierfür konstruiertes schwaches Hilfsobjektiv. Mit diesem Hilfsobjektiv wurde das von dem eigentlichen, starken Mikroskop entworfene Bild betrachtet. $^{287}$ Dieses Vorgehen verursachte mehrere Eigenheiten. Es kam zu einer Verkleinerung des Bildes und einer stark gewölbte Bildfläche. Außerdem kam es zu einer Bildaufrichtung und durch das Hilfsobjektiv wurde die Konstruktion unpraktisch in die Länge gezogen, was das Arbeiten im Sitzen erschwerte. Die Bildschärfe und die Plastik waren hingegen ausgezeichnet.

Eine weitere originelle Konstruktion steht gewissermaßen zwischen geometrischer und physikalischer Konstruktion. ${ }^{288}$ In diesem Fall wurde eine halbdurchlässige Silberschicht verwendet, welche jedoch im Gegensatz zu den physikalischen Mikroskopen nicht gleichmäßig dick war, sondern auf der rechten Seite wesentlich dicker als auf der linken. Das hatte zur Folge, dass auf der rechten Seite der Anteil an reflektierter Strahlung wesentlich größer war als auf der linken Seite, wo der Teil des durchgelassenen Lichtes höher war.

Je stärker man nun die Silberschicht machte, desto mehr arbeitete das Mikroskop in Richtung eines Mikroskops mit geometrischer Teilung und umgekehrt. Je kräftiger die rechte Silberschicht angelegt war, desto ausgeprägter war der stereoskopische Effekt.

\section{Zu stereoskopischen, geometrischen und binokularen Mikroskopen}

Die stereoskopischen Mikroskope haben Ihre Berechtigung überall dort, wo der räumliche Eindruck bei der Betrachtung des Präparates von Bedeutung ist. Am besten ist die räumliche Wirkung der stereoskopischen Mikroskope im Bereich der Dunkelfeldmikroskopie. Dies kommt durch die hier übliche große Apertur zustande, mit der bei der Dunkelfeldmikroskopie gearbeitet wird. Es gilt: je größer die Apertur ist, desto besser ist das stereoskopische

\footnotetext{
Vgl. Reichenbach (1929) S. 598

Vgl. Reichenbach (1929) S. 598

Vgl. Reichenbach (1929) S. 598 f.
} 
Sehen. ${ }^{289}$ Das stereoskopische Mikroskop ist nicht als Standardmikroskop zu benutzten, sein Einsatz ist für die beschriebenen Fälle reserviert, da in bestimmten Fällen das räumliche Sehen durchaus störend sein kann und die Bildqualität vergleichsweise schlecht ist. ${ }^{290}$

Bei den rein binokularen Instrumenten ohne stereoskopische Eigenschaften sind, abgesehen von dem hohen Anschaffungspreis, im Gegensatz zum monookularen Mikroskop, keine Nachteile zu finden. Umso mehr verwundert die Tatsache, dass die Verbreitung dieser Mikroskope noch so gering ist. Als besonders angenehm beschrieb Reichenbach, dass bei den binokularen Mikroskopen im Gegensatz zu den monookularen die Ermüdung der Augen sehr gering ist, was ein Mikroskopieren über mehrere Stunden hinweg ermöglicht. Auch die Bildqualität war deutlich besser, als diese mit den herkömmlichen Apparaten zu erreichen war.

Es gibt jedoch eine Ausnahme in der das Monookular dem Binokular überlegen ist. Wenn die Augen des Untersuchers in ihrer Sehstärke mehr als 5 Dioptrien divergieren, ist das Binokular ungeeignet. $^{291}$

\section{Stereoskopische Mikroskope mit zwei Objektiven}

Gute stereoskopische Bilder liefern die Geräte, die aus zwei eigenständigen Mikroskopen bestehen und deren optische Achse sich im zu betrachtenden Objekt schneidet. ${ }^{292}$ Der Winkel der beiden Mikroskope zueinander, muss dem Winkel der Augenachse des Betrachters zum Gegenstand entsprechen. Die Schwierigkeit liegt darin, dass der Augenabstand der Betrachter jeweils unterschiedlich groß sein kann. Dieser Umstand lässt sich durch das Einsetzen geeigneter Prismen ausgleichen. Was den Einsatz der Geräte einschränkt, ist die Tatsache, dass baulich bedingt nur eine maximale Vergrößerung von $12 \mathrm{X}$ erreicht werden kann. Der Mikrobiologe wird diese Geräte somit überwiegend für das Betrachten von Insekten und das Arbeiten mit Kolonien auf Kulturplatten verwenden. ${ }^{293}$

\section{Die Beobachtung im Dunkelfeld}

Beim gewöhnlichen Mikroskopiervorgang fällt das Licht durch das Objekt in das Objektiv. Bei der Dunkelfeldbeleuchtung hingegen ist der Strahlengang der Lichtquelle so gewählt, dass die Strahlen ungebrochen sämtlich am Objektiv vorbei ziehen würden. Nur die Lichtstrahlen, die durch das Objekt abgelenkt werden, treffen ins Objektiv.

289 Vgl. Reichenbach (1929) S. 600

290 Vgl. Reichenbach (1929) S. 600

291 Vgl. Reichenbach (1929) S. 602

292 Vgl. Reichenbach (1929) S. 602

293 Vgl. Reichenbach (1929) S. 603 f. 
Theoretisch könnte man dies erreichen, indem man die Lichtquelle mit einem so großen Winkel zum Objektiv hin einstellt, dass sämtliche Strahlen am Objektiv vorbeiziehen. Dies würde jedoch ein unbefriedigend dunkles Bild ergeben. In der Praxis erreicht man die Dunkelfeldbeleuchtung dadurch, dass man die Apertur des Kondensors größer hält als die Apertur des Objektivs. ${ }^{294}$

\section{Die Kondensoren für die Dunkelfeldbeleuchtung}

Wenn für die Fragestellung in der Dunkelfeldbeleuchtung schwache Objektive ausreichen, die somit eine geringe Apertur aufweisen, kann auch mit Kondensoren, die ebenfalls eine geringe Apertur haben, gearbeitet werden. Hier kann man in den meisten Fällen den „Abbe’schen Kondensor“ benutzen, der je nach Bauart eine Apertur von 1,2 bzw. von 1,4 hat. ${ }^{295}$

In der Folge werden die verschiedenen Kondensoren vorgestellt.

Der Paraboloidkondensor. ${ }^{296}$

Der Einsatz parabolischer Spiegel in der Dunkelfeldbeleuchtung setzte neue Maßstäbe. Die tatsächliche Verwendung der Spiegel war erst 50 Jahre nach den ersten Versuchen möglich, da in der Anfangszeit ein so vollkommener Schliff nicht erreichbar war.

Der Paraboloidkondensor hat die Eigenschaft, achsenparallel einfallende Strahlen in einem Brennpunkt zu bündeln. Er übertrifft den „Abbe’schen Kondensor“ in der Strahlenvereinigung deutlich und verursacht keinen Farbfehler. Somit ist er in hohem Maße für die Dunkelfeldbeleuchtung geeignet.

Der Spiegelkondensor . ${ }^{297}$

Dieser Kondensor ist ähnlich aufgebaut wie der Paraboloidkondensor, nur, dass hier keine Parabolische- sondern eine Kugelkalotte eingesetzt wird.

Die bizentrischen Kondensoren. ${ }^{298}$

Bei diesen Kondensoren kommen zwei spiegelnde Kugelflächen zur Anwendung. Es ist jeweils eine konkave und eine konvexe Spiegelfläche verbaut, wodurch Fehler der Lichtbrechung weitgehend aufgehoben werden.

Der Leuchtbildkondensor. ${ }^{299}$

Bei diesem Kondensor sieht man schwach angefärbte Mikroorganismen in einem Präparat besonders deutlich. Erstaunlicherweise erscheinen die Mikroorganismen nicht in der Färbung

\footnotetext{
294 Vgl. Reichenbach (1929) S. 605

295 Vgl. Reichenbach (1929) S. 605

296 Vgl. Reichenbach (1929) S. 607

297 Vgl. Reichenbach (1929) S. 608

298 Vgl. Reichenbach (1929) S. 608 - 610

299 Vgl. Reichenbach (1929) S. 610 f.
} 
der verwendeten Farbe, sondern in der Komplementärfarbe. Dieses Phänomen erklärt sich durch eine selektive Beugung. Bei der Methode, die ebenfalls zur Dunkelfeldbetrachtung gehört, wird zwischen Mikroskopspiegel und Lichtquelle eine Mattscheibe eingefügt. Häufig wird zusätzlich ein farbiger Filter, dessen Farbe dem Untergrund des Präparats entspricht, eingeschoben, um noch eindeutigere Bilder zu erlangen.

Dass diese Methode wenig Verbreitung fand, lag laut Reichenbach daran, dass nur Objektträger bestimmter Dicke verwendet werden konnten. Nicht für diese Mikroskopierart erstellte Präparate konnten somit nicht betrachtet werden.

„Dieser Übelstand in Verbindung mit gewissen Schwierigkeiten bei der Herstellung und Betrachtung der Präparate scheint der Ausbreitung der Methode abträglich zu sein. Andererseits muss aber anerkannt werden, dass die Betrachtung eines gut gefärbten, geeigneten Präparates ein ästhetischer Genuss allerersten Ranges ist. “300

Die Hell- Dunkelfeldkondensoren. ${ }^{301}$

Diese Apparate wurden konstruiert, um eine bestimmte Stelle im Präparat schnell und abwechselnd im Hell- und Dunkelfeld betrachten zu können. Dieses Vorgehen kann bei der Dunkelfeldbetrachtung sehr hilfreich sein. Die Hell- Dunkelfeldkondensoren sind somit auch nur für diesen Zweck geeignet und keineswegs als Universalgerät zu verwenden. Sie leisten im jeweiligen Bereich weniger als ein spezialisiertes Gerät.

\section{Die Beleuchtungsvorrichtung für das Dunkelfeld}

Die Wahl der Beleuchtung für die Dunkelfeldbetrachtung richtet sich nach der jeweiligen Fragestellung und damit verbunden, nach dem verwendeten Kondensor. ${ }^{302}$

Für Betrachtungen von Protozoen, welche mit dem „Abbe’schen Kondensor“ angestellt werden können, reicht zur Beleuchtung das Tageslicht. Ist für das zu betrachtende Objekt eine stärkere Vergrößerung nötig, wählt man zur Beleuchtung z.B. ein Gasglühlicht oder eine 75 Watt Lampe aus Opalglas. Die besten Ergebnisse lassen sich mit einer Bogenlampe erzielen. Es ist zu empfehlen, zwischen Lampe und Mikroskopspiegel eine Kollimatorlinse einzusetzen. Mit Hilfe einer solchen Linse treffen nahezu parallele Strahlen auf den Spiegel. ${ }^{303}$

\footnotetext{
300 Reichenbach (1929) S. 611

301 Vgl. Reichenbach (1929) S. 611

302 Vgl. Reichenbach (1929) S. 612

303 Vgl. Reichenbach (1929) S. 612
} 


\section{Die Technik der Dunkelfeldbeleuchtung}

Um gute Bildergebnisse zu erzielen, muss der Schnittpunkt der beleuchtenden Strahlen in das Objekt fallen; außerdem muss er genau in der Achse des Objektivs liegen. ${ }^{304}$ Die Objektträgerstärke ist somit von großer Relevanz. Bei abweichender Objektträgerstärke treffen sich die Strahlen nicht mehr im Objekt, was einen Verlust an Bildqualität zur Folge hat.

\section{Anwendung und Leistung der Dunkelfeldbeleuchtung}

Festzuhalten ist, dass durch die Dunkelfeldmikroskopie die Erkennbarkeit submikroskopischer Objekte nicht gesteigert werden kann. ${ }^{305}$

Möglich ist eine Sichtbarmachung kleinster Objekte, um sie z.B. zu zählen. Dies ist möglich, da die Sichtbarkeit nur von den im Objekt abgebeugten Strahlen abhängt und nicht von der Apertur des Objektivs. Theoretisch könnte man bei ausreichend intensiver Beleuchtung immer genug Strahlen ablenken, um auch noch so kleine Teilchen erkennbar zu machen. In der Praxis liegt die Grenze jedoch bei einer Teilchengröße von $16 \mu \mu$.

Da es sich aber nur um Sichtbarmachung und nicht um tatsächliche Abbildung handelt, kann nicht zwischen einfachem submikroskopischen Körper, und z.B.einem Parasit unterschieden werden. Man muss sich mit der Aussagekraft begnügen, die vorliegt, wenn Teilchen einer bestimmten Größe nicht vorhanden sind.

Nun ist der ultramikroskopische Bereich nicht der, in dem die Dunkelfeldmikroskopie ihre Hauptbedeutung hat. ${ }^{306}$ Die Bedeutung ist vielmehr an der Grenze der mikroskopischen Erkennbarkeit zu sehen. Das Wissen in der Spirochätenforschung oder die Erkenntnisse über die Bakteriengeißeln sind dank dieser Technik möglich geworden. Weiterhin können Differenzierungen im Bau der Bakterienzellen gemacht werden. So können Vakuolen, Membranen und Zelleinschlüsse studiert werden.

\section{Mikroskopisches Messen}

Für Längenmessungen unter dem Mikroskop bedient man sich eines vergleichenden Maßstabes, der sich in der Blendenebene des Okulars befindet. ${ }^{307} \mathrm{Um}$ mit einem solchen Maßstab vergleichsnahe Größen bestimmen zu können, muss immer die Objektivstärke berücksichtigt werden. Theoretisch ist es möglich, dem Okular eine skalierte Glasscheibe auf

$\begin{array}{ll}304 & \text { Vgl. Reichenbach (1929) S. } 613 \\ 305 & \text { Vgl. Reichenbach (1929) S. } 616 \\ 306 & \text { Vgl. Reichenbach (1929) S. } 616 \\ 307 & \text { Vgl. Reichenbach (1929) S. } 617\end{array}$ 
der Blende vorzulagern. Es ist jedoch zweckmäßig, ein spezielles Okular zu benutzen, mit welchem der Abstand zur Skalierung, der Refraktion des Auges angepasst werden kann. Es sollte also immer eine scharf eingestellte Skalierung die präzise Messung ermöglichen. Bei neueren Geräten ist die Skalierung beweglich eingebaut, sie kann über eine Mikrometerschraube genau an das zu messende Objekt angelegt werden.

Im Gegensatz zur Längenmessung, kann man Dickenmessungen vornehmen, indem man nacheinander erst die obere und dann die untere Grenze des Objekts scharf einstellt und dann die Verschiebung des Tubus abliest. Ist die Messung in einem Trockensystem erfolgt, muss der abgelesene Wert mit dem Brechungsexponenten $n$ des gemessenen Objekts multipliziert werden, bei Messungen mit Ölimmersion gilt es den Wert mit $n / 1,52$ zu multiplizieren. ${ }^{308}$

\section{Zählungen mikroskopischer Objekte}

Zur Zählung wird eine Glasscheibe, die mit Hilfsmarkierungen versehen ist, in der Blendenebene des Okulars angebracht. Besonders geeignet ist eine netzartige Unterteilung. Die einzelnen Linien stehen, etwa 10 pro Gesichtfeld, parallel zueinander, was das Auszählen der in dem Raster befindlichen Objekte sehr erleichtert. ${ }^{309}$

Eines der häufig zu zählenden Objekte in der Mikrobiologie sind Bakterienkulturen. Hier empfiehlt es sich das gesamte Gesichtfeld, welches in ein wie oben beschriebenes Raster unterteilt wird, auszuzählen. Beim Anlegen einer Kolonie ist stets darauf zu achten, dass die Kolonien nicht zu dicht wachsen, da dies ein Auszählen unmöglich macht. Weiterhin ist zu berücksichtigen, dass der Nährboden der Kulturplatte genau waagerecht steht.

Für Zählungen von in Flüssigkeit suspendierten Objekten ist es erforderlich, eine Schicht von genau definierter Dicke und Menge dieser Flüssigkeit herzustellen. Erst hierdurch weiß man, wie viele Teilchen in einer bestimmten Menge der Flüssigkeit vorhanden sind. Für das Auszählen der in Flüssigkeit gelösten Teilchen werden Zählkammern verwendet.

Es ist ratsam, die Teilung nicht in das Okular zu legen, sondern ein Raster direkt in den Boden der Zählkammer einzulassen. ${ }^{310}$

\footnotetext{
308 Vgl. Reichenbach (1929) S. 619

309 Vgl. Reichenbach (1929) S. 619

310 Vgl. Reichenbach (1929) S. 621
} 


\section{Untersuchungen im auffallenden Licht}

Die Hauptanwendung dieser Methode liegt außerhalb der Mikrobiologie. ${ }^{311}$ Ihr Schwerpunkt liegt im Bereich der Betrachtung von Metallen und Metalllegierungen. In der Mikrobiologie findet sie ihre Anwendung bei der Analyse der Oberflächen von Bakterien, Schimmelpilzkulturen und Insekten.

Die Mikroskopie im auffallenden Licht erfordert eine spezielle Vorrichtung am Mikroskop, den sogenannten Vertikalilluminator. Der Grund hierfür ist, dass die Lichtquelle bei starken Objektiven durch selbiges geleitet werden muss, um parallel zur optischen Achse auf das Objekt zu treffen. Diese aufwendige Bauweise ist nötig, da bei stärkeren Objektiven der Abstand des Objektivs zum Objekt so gering ist, dass man eine Lichtquelle nur seitlich anbringen könnte, was zu starker Schattenbildung auf dem Objekt führen würde.

Die Vertikalilluminatoren werden zwischen Mikroskoptubus und Objektiv eingeschraubt. Seitlich des Illuminators befindet sich ein in $45^{\circ}$ angebrachter Spiegel, über den eine außen befindliche Lichtquelle die Strahlen durch das Objektiv hindurch auf das Objekt wirft. Es stehen zwei verschiedene Modelle zur Verfügung. ${ }^{312}$

Beim ersten Modell wird die eine Hälfte des Objektivs zur Beleuchtung benutzt, die andere zur Beobachtung. Nachteil dieser Konstruktion ist, dass durch die Teilung des Objektivs die Bildqualität beeinträchtigt wird. Bei der zweiten Konstruktion dient eine dünne planparallele Glasplatte, die den ganzen Objektivdurchmesser einnimmt, als Spiegel. Durch die Scheibe sieht man beim Mikroskopieren hindurch, die Bildqualität wird nicht beeinflusst, jedoch ist das System lichtschwächer. Es ist zu beachten, dass die Fassungen der Objektive möglichst kurz gebaut sind, um die beschriebenen Spiegelvorrichtungen nahe an die Linse setzten zu können.

Bei auffallendem Licht würden die üblicherweise verwendeten Deckgläser starke Reflexionen verursachen, so dass man ohne sie arbeiten muss, was ebenfalls eine Anpassung der Objektive erfordert. Diese spezielle Objektivart ist nur für diese Art des Mikroskopierens verwendbar.

\section{Zeichenapparate}

Die Zeichenapparate ermöglichen eine genaue Wiedergabe der Lage und Größe einzelner im Präparat liegender Objekte. $^{313}$ Anwendung finden sie z.B. bei der Beurteilung von Wachstumsprozessen und anderen Veränderungen, die mit einer präzisen Zeichnung festgehalten werden, um dann im Vergleich betrachtet zu werden.

311 Vgl. Reichenbach (1929) S. 621

312 Vgl. Reichenbach (1929) S. 621

313 Vgl. Reichenbach (1929) S. 624 
Die Zeichenapparate sind von der Konstruktion her so angelegt, dass dem Betrachter über eine Spiegelvorrichtung gleichzeitig das mikroskopische Bild und das der Zeichenebene übereinander liegend dargeboten werden. Es ist somit möglich, direkt auf der Zeichenebene mit einem Bleistift an den zu zeichnenden Konturen entlang zu fahren.

Die Helligkeit der einzelnen Bilder muss über Rauchglasscheiben aufeinander abgestimmt werden. Je nach Objektivstärke müssen entweder Rauchglasscheiben zwischen Spiegelvorrichtung und Okular, oder zwischen Spiegelvorrichtung und Zeichenfläche, eingeschoben werden.

Der klassische Zeichenapparat funktioniert über ein doppelt brechendes Prisma. Die Lichtstrahlen, die von der Zeichenfläche kommen, gelangen über eine zweifache Reflektion im Prisma ins Auge und zwar als parallel zur Mikroskopachse verlaufende Strahlen.

Eine bessere Alternative bietet der „Abbe’sche Zeichenapparat“. ${ }^{314}$ Hier findet die Spiegelung nicht in einem Prisma statt, sondern sie wird getrennt dargestellt. Einmal an einem seitlich angebrachten Spiegel und ein weiteres Mal direkt über dem Okular. Die Spiegelung über dem Okular kommt durch zwei eingesetzte versilberte Prismen zustande, welche man auch als „Abbe’schen Würfel“ bezeichnet.

Es ist möglich, bei den Zeichnungen einen Maßstab anzugeben. Hierzu wird ein Objektmikrometer von bekannter Größe abgezeichnet. Durch das Verhältnis der tatsächlichen Größe des Maßstabes zur Zeichnung lässt sich die durch das Mikroskop verursachte Vergrößerung ermitteln. ${ }^{315}$

\section{Okulare für besondere Zwecke}

Für Demonstrationszwecke wurden Zeigerokulare entwickelt, mit denen es möglich ist, eine bestimmte Stelle des Präparates hervorzuheben. Der dazu verwendete Zeiger befindet sich in der Blendenebene des Okulars. ${ }^{316}$

Weiterhin gibt es Doppelokulare, an welchen zwei Beobachter gleichzeitig ein Präparat betrachten können. Auch ist es möglich, über eine spezielle Vorrichtung zwei Präparate in einem Gesichtsfeld miteinander zu vergleichen. Hier wird nicht wie üblich ein Vergleichsokular auf ein Mikroskop aufgesetzt, sondern das Okular ist mit zwei verschiedenen Mikroskopen verbunden. Das Gesichtsfeld ist in zwei Hälften aufgeteilt und es wird jeweils eine Hälfte von einem Mikroskop geliefert.

314 Vgl. Reichenbach (1929) S. 625

315 Vgl. Reichenbach (1929) S. 626

316 Vgl. Reichenbach (1929) S. 626 


\section{Heizbare Mikroskope und Objekttische}

Gerade in der Mikrobiologie kann es notwendig sein, ein Präparat über einen längeren Zeitraum hinweg bei einer bestimmten Temperatur halten zu müssen. Zu diesem Zweck sind spezielle Heizvorrichtungen im Handel. Nachdem der Objekttisch lange Zeit z.B. mit Gasflamme oder Warmwasser mittels komplexer Vorrichtungen beheizt wurde, verwendet man heute zur Erwärmung Strom. Ein von der Firma Leitz auf den Markt gebrachter Heiztisch wurde von Reichenbach beispielhaft beschrieben. ${ }^{317}$

Bei diesem Exemplar dient als Heizvorrichtung, ein ringförmig gebogenes Messingrohr, welches mit Asbest beschichtet und zusätzlich mit Nickeldraht umwickelt ist. Diese Heizeinheit befindet sich in einer Metalldose, in welche das Präparat über seitliche Schlitze eingeschoben wird. In der Metalldose sind ein Quecksilberthermometer zum Ablesen der Temperatur, sowie ein Luftthermometer, mit welchem die Temperatur über einen Kontakt geregelt wird, angebracht.

Problematisch an allen Heiztischen ist, dass die Temperatur in der Heizvorrichtung nicht unbedingt der Temperatur entspricht, welche das Präparat selber hat. Aus diesem Grund wurden Wärmeschränke entwickelt, in denen das ganze Mikroskop untergebracht wird. Hier kann man sicher sein, das die im Wärmeschrank gemessene Temperatur der Temperatur entspricht, die am Präparat herrscht. ${ }^{318}$

Nachteil dieser Methode ist, dass bei Verwendung eines Wärmeschrankes der Zugang zum Präparat sehr umständlich ist. Wärmeschränke kommen nur dann zum Einsatz, wenn eine bestimmte, konstante Temperatur besonders wichtig ist. Anderenfalls bedient man sich der zuvor beschriebenen Heizkästen, welche deutlich praktischer in der Anwendung sind.

\section{Markierapparate}

Um am Präparat eine bestimmte Stelle jederzeit wieder zu finden, sind Markierapparate entwickelt worden. ${ }^{319}$ Dabei wird eine Vorrichtung, die eine bewegliche Diamantspitze trägt, an das Objektiv angeschraubt. Mit dem Diamanten können feine Kreise auf das Deckglas aufgezeichnet werden, die mühelos wieder aufgefunden werden können. Um in das Deckglas eingravierte Ringe wieder aufzufinden, muss das Objektiv so eingestellt sein, dass es auf der Ebene des Deckglases scharf stellt.

317 Vgl. Reichenbach (1929) S. 628

318 Vgl. Reichenbach (1929) S. 629

319 Vgl. Reichenbach (1929) S. 629 


\section{Die Prüfung des Mikroskops}

Die Mikroskope der bekannten optischen Werkstätten benötigen keine spezielle Prüfung, da die Qualität hohe Konstanz aufweist. ${ }^{320}$ Kauft man hingegen Apparate aus kleineren Unternehmen, tut man gut daran, diese einer Prüfung zu unterziehen, da die Qualität variieren kann.

Es ist wichtig, das Stativ und seine Einstellvorrichtungen zu prüfen. Hier darf weder Schwergängigkeit, noch zu leichtes Verstellen auffällig sein. Auch der Beleuchtungsapparat ist zu kontrollieren. Er muss mühelos in jede Position gebracht werden können, in der er dann feststeht. Es ist darauf zu achten, dass die Irisblende zentriert ist. Dies kann geprüft werden, indem man bei geschlossener Irisblende durch ein schwaches Objektiv schaut. Auf diese Weise werden Abweichungen leicht auffällig.

Zur Prüfung der Objektive sollte man sich der „Abbe’schen Prüfplatte“ bedienen, die im Handel erhältlich ist. Dieser Test ist ausgesprochen zuverlässig, jedoch können weitere Versuche mit Ölimmersion an mikrobiologischen Präparaten sinnvoll sein. Hierzu eignen sich laut Reichenbach insbesondere nach Neisser gefärbte Diphtheriebakterienpräparate. ${ }^{321}$ Zur Prüfung der numerischen Apertur, welche meist auf dem Objektiv notiert ist, bedient man sich des „Abbe’schen Apertometres“, welches eine genaue Beurteilung ermöglicht. 


\section{Zusammenfassung}

Hans Reichenbach wurde am 30.11.1864 in Lüneburg geboren. Hier besuchte er ebenfalls die Schule, die er 1884 mit dem Abitur abschloss. Es folgte das Studium der Medizin in Göttingen, wo er auch einen Großteil seiner Assistentenzeit verbrachte. Zu seinen Lehrern zählten Flügge, Wolfhügel und Esmarch, die darüber hinaus seine Vorgänger in der Funktion als Ordinarius am Hygiene Institut in Göttingen waren. Weitere berufliche Stationen waren München, Marburg, Berlin, Breslau und Bonn.

1911 wurde Reichenbach Ordinarius in Göttingen. Er war in seiner über zwanzigjährigen, leitenden Tätigkeit allgemeinhygienisch und bakteriologisch tätig. Seine Arbeiten behandelten ein breites Spektrum der Hygiene. Reichenbach veröffentlichte auf dem Gebiet der Trinkwasserhygiene, der Beleuchtungshygiene und der Kleidungshygiene. Auch beschäftigte er sich mit Desinfektionsverfahren und der Wohnungshygiene. Zudem behandelte er bakteriologische Themen. Hier veröffentlichte er unter anderem Arbeiten zur Tuberkulose, ging der Frage der Vererbung bei Einzellern nach und nahm eine Einteilung der Krankheitserreger vor.

Die von Reichenbach bearbeiteten Themengebiete lagen eher im Bereich der klassischen Hygiene. (vgl. Kapitel 5) Er beschäftigte sich eingehend mit Fragen zur allgemeinen Hygiene, wie z.B. den Desinfektionsverfahren oder der Beleuchtungshygiene. Auch behandelte er Themen mit bakteriologischer Fragestellung. Aus heutiger Sicht lag er mit seiner Forschungsarbeit im Strom der Zeit und seine Arbeiten behandelten die Themen, an denen großes Interesse bestand. Die spektakulären Erfolge wurden jedoch in kleinen Teilbereichen der Hygiene erzielt, wie die Errungenschaften auf den Gebieten der Serologie und Immunologie zur damaligen Zeit deutlich machten. Diese Themen fanden unter Reichenbach keine Beachtung

Seine gesamte Amtszeit hindurch bemühte sich Reichenbach vergeblich, wie es auch schon sein Vorgänger tat, die mangelhafte räumliche Situation des Hygieneinstituts zu verbessern. Dass diese Bestrebungen ergebnislos blieben, kann sicherlich auf die schwierigen Verhältnisse der damaligen Zeit zurückgeführt werden. In Reichenbachs Amtszeit fiel nicht nur der Erste Weltkrieg. In dieser Zeit ruhte jegliche Forschungstätigkeit. Es folgte die Wirtschaftskrise in den dreißiger Jahren, die die Arbeit am Institut ebenfalls sehr erschwerte. So gesehen kann man Reichenbach, sicher durch die Umstände der Zeit bedingt, mehr als Institutsleiter denn als Forscher betrachten. Er zeigte die Kriegsjahre hindurch großen Einsatz, das Institut trotz der erschwerten Bedingungen aufrecht zu halten und konnte so, mit deutlich 
verringertem Personal die anstehenden Aufgaben bewältigen. Hierbei handelte es sich z.B. um die Herstellung großer Mengen Impfstoff im ersten Weltkrieg, oder um zahlreiche bakteriologische Untersuchungen, die zusätzlich auch für das Heer durchgeführt wurden.

Ein Arbeitsbereich, der Reichenbach sehr am Herzen lag, war die Lehre. Wie man Berichten entnehmen kann, wurde er hierfür nicht nur von Fachkollegen gelobt, auch in der Studentenschaft hatten seine Vorlesungen einen guten Ruf. Reichenbach war hierfür bereit, Unannehmlichkeiten in Kauf $\mathrm{zu}$ nehmen. So hielt er beispielsweise nach dem ersten Weltkrieg Kurse dreifach ab, teilweise bis spät in die Abendstunden, um der Lehre auch bei der größer werdenden Studentenzahl gerecht zu werden. Weiterhin gründete er eine MTASchule, ebenfalls ein Hinweis dafür, dass ihm die Lehre wichtig war. Die Verbundenheit Reichenbachs zu seinem Institut und der aufopfernde Einsatz, den er ihm entgegen brachte, spiegeln sich auch in der Tatsache wieder, dass er nach seiner Emeritierung bis einen Tag vor seinem Tode, weiterhin täglich am Institut arbeitete. Reichenbach starb am 18.01.1937.

In meiner Darstellung Reichenbachs, stellte ich neun seiner Arbeiten vor. Die Arbeiten sollten vermitteln, wie sich Reichenbach mit den Themen der damaligen Zeit auseinandersetzte. Weiterhin sollten sie zeigen, wie breit gefächert und unterschiedlich die Gebiete waren, mit denen sich die Hygieniker auseinandersetzten. Darüber hinaus stellte ich eine Rede Reichenbachs vor, die er 1926 gehalten hatte: „Die Hygiene als Wissenschaft“. Hier beleuchtete Reichenbach das Fach und dessen Aufgabenspektrum.

Der Aufsatz „Die Leistung der Formaldehyd Desinfektion“ behandelte das Thema der Wohnungsdesinfektion. Reichenbach ging der Frage nach, ob die laut werdende Kritik an dem Verfahren Berechtigung hatte. Zu untersuchen sei, so Reichenbach, ob die Kritikpunkte aufgrund modernerer, genauerer Analyseverfahren entstanden seien und somit das anerkannte Verfahren berechtigt in Frage gestellt würde. Um der eingehenden Beschäftigung auf dem Gebiet der Desinfektion gerecht zu werden, wurde hier auch noch die Veröffentlichung „Die desinfizierenden Bestandteile der Seife“ behandelt.

In der Veröffentlichung „Über Wärmestrahlung von Leuchtflammen“ setzte sich Reichenbach mit der Analyse der Wärmestrahlung von Lampen auseinander. Darüber hinaus betrachtete ich die Werke „Bakterien in Luft, Wasser, Erdboden und Milch“ und „Die Vererbung erworbener Eigenschaften bei einzelligen Lebewesen“, um auch einen Eindruck von seiner bakteriologischen Forschungsarbeit zu geben. In dem Zusammenhang stellte ich auch seine umfangreiche Arbeit „Das Mikroskop und seine Nebenapparate“ vor. Weiterhin setzte sich Reichenbach eingehend mit der Frage der Lichtqualität auseinander. Aus diesem Gebiet 
stellte ich folgende Arbeiten vor: „Über den Einfluss der Farbe künstlicher Lichtquellen auf die Sehschärfe“ und „Zur Frage der Tageslichtmessung“, sowie die Arbeit „Die Tageslichtmessung in Schulen“. Diese 3 Arbeiten zeigten, wie breit das Forschungsgebiet der Hygiene selbst in einem kleinen Bereich dieses Faches war. 
9. Anhang 


\subsection{Verzeichnis der Veröffentlichungen Hans Reichenbachs}

1) 1889 Mitteilung aus der syphilitischen Abteilung des Ernst - August - Hospitals zu Göttingen.

Med. diss. Göttingen

2) 1891 Zur Casuistik des chylösen Ascitis.

Virchows Archiv für pathologische Anatomie und Physiologie und für

klinische Medicin, $\underline{123}$,

$183-186$

3) 1891 Beiträge zur Lehre der Wasseraufnahme durch die Kleidung.

Archiv für Hygiene, $\underline{13}$,

$113-121$

4) 1894 Über den gegenwärtigen Stand unserer Kenntnis von den physikalischen

Eigenschaften unserer Kleidung.

Hygienische Rundschau, No. 23 und 24,

$1-22$

5) 1894 Über einen neuen Brütofen für beliebiges Heizmaterial.

Zentralblatt für Bakteriologie Parasitenkunde und Infektionskrankheiten,

15 , No. 22,

$847-850$

6) 1898 Über Wärmestrahlung von Leuchtflammen.

Archiv für Hygiene, 33,

$315-349$

7) 1899 Ein Fall von Rhinitis fibrinosa mit Diphtheriebacillen.

Zeitschrift für klinische Medizin, $\underline{38}$,

$486-505$ 
8) 1901 Zur Messung der Wärmestrahlung.

Archiv für Hygiene, $\underline{39}$,

$252-258$

9) 1901 Über Verzweigung bei Spirillen.

Zentralblatt für Bakteriologie, Parasitenkunde und Infektionskrankheiten, $\underline{29}$, No. 13,

$553-557$

10)

Die Göttinger Brunnenfrage.

Die Überschrift ist in einem maschinengeschriebenen Literaturverzeichnis erfasst. Datum nicht bekannt, der Artikel ist nicht auffindbar.

11) 1902 Versuche über die Formalindesinfektion von Eisenbahnwagen.

Zeitschrift für Hygiene und Infektionskrankheiten, $\underline{39}$, H 3,

$428-446$

12) 1902 Einige Versuche mit staubbindenden Fussbodenoelen.

Zeitschrift für Schulgesundheitspflege, 15, No. 7,

$355-362$

13) 1902 Über den Einfluss der Farbe künstlicher Lichtquellen auf die Sehschärfe.

Zeitschrift für Hygiene und Infektionskrankheiten, $\underline{41}$,

$257-270$

14) 1902 Die 27. Versammlung des Deutschen Vereins für Öffentliche Gesundheitspflege.

Die Überschrift ist in einem maschinengeschriebenen Literaturverzeichnis erfasst. Der Artikel ist nicht auffindbar.

15) 1903 Über Untersuchung und Begutachtung von Trinkwasser mit besonderer Berücksichtigung der Typhusübertragung.

Hygienische Rundschau, 13, No. 9, $433-453$ 
16) 1904 Die Tageslichtmessung in den Schulen.

Klinisches Jahrbuch, $\underline{12}$,

$231-240$

17) 1905 Zur Frage der Tageslichtmessung.

Klinisches Jahrbuch, $\underline{14}$,

$325-336$

18) 1905 Die Leistung der Formaldehyd- Desinfektion.

Zeitschrift für Hygiene und Infektionskrankheiten, 50,

$451-472$

19) 1907 Reichenbach H, Heymann B

Untersuchung über die Wirkungen klimatischer Faktoren auf den Menschen.

I Mitteilung: Beziehung zwischen Haut und Lufttemperatur.

II Mitteilung: Beeinflussung der Körperwärme durch Arbeit und

Beschränkung der Wärmeabgabe.

Zeitschrift für Hygiene und Infektionskrankheiten, 57,

$1-22$ und $22-49$

20) 1908 Experimentelle Untersuchungen über die Eintrittswege des Tuberkelbacillus.

Zeitschrift für Hygiene und Infektionskrankheiten, $\underline{60}$, H 3,

$446-466$

21) 1908 Die desinfizierenden Bestandteile der Seifen.

Zeitschrift für Hygiene und Infektionskrankheiten, $\underline{59}$,

$296-316$ 
22) 1908 Reichenbach H, Bock*

Versuche über die Durchgängigkeit des Darms für Tuberkelbazillen.

Verbreitungsweise und Bekämpfung der Tuberkulose.

hrsg. Flügge C

Veit u Comp. Verlag, Leipzig 1908

$644-659$

23) 1908 Über moderne Beleuchtungsart und ihre hygienische Bedeutung.

Bericht über den 14. internationalen Kongress für Hygiene und

Demographie Berlin, 23. - 29. September 1907.

Bd. 3, Teil 1.

hrsg. Kongressleitung

Hirschwald Verlag, Berlin 1908

$269-278$

24) 1910 Zur Theorie der Desinfektion.

Zentralblatt für Bakteriologie, Beilage, Abt. 1, 느,

$75-80$

25) 1910 Zur Differentialdiagnose der typhusähnlichen Bakterien II.

Die Überschrift ist in einem maschinengeschriebenen Literaturverzeichnis erfasst. Der Artikel ist nicht auffindbar.

26) 1910 Die Beziehung zwischen Luftdruck und Siedetemperatur des Wassers und ihre Bedeutung für den Desinfektor.

Die Überschrift ist in einem maschinengeschriebenen Literaturverzeichnis erfasst. Der Artikel ist nicht auffindbar.

27) 1910 Über Ventilation und Heizung.

Siehe in dieser Liste unter 46.

* $\quad$ Es wurde keine genauere Angabe zu diesem Autor gemacht. 
28) 1911 Die Absterbeordnung der Bakterien und ihre Bedeutung für Theorie und Praxis der Desinfektion.

Zeitschrift für Hygiene und Infektionskrankheiten, $\underline{69}$, H 1, $171-222$

29) 1912 Heizung und Lüftung von Schulen.

Zeitschrift für Schulgesundheitspflege, 25,

$28-59$

30) 1913 Beleuchtung.

Siehe in dieser Liste unter 46.

31) 1913 Die Vererbung erworbener Eigenschaften bei einzelligen Lebewesen. Aus der Berliner Gesellschaft für Rassen- Hygiene (Orginalbericht), Sitzung vom 28.02.1913.

Archiv für Soziale Hygiene, $\underline{8}$,

$323-351$

32) 1915 Erwin von Esmarch.

Deutsche Medizinische Wochenschrift, 41. Jahrgang, 1. Halbjahr, $504-505$

33) 1918 Die Beziehung der Beleuchtungstechnik zur Hygiene.

Deutsche Beleuchtungstechnische Gesellschaft, 12. ordentliche

Mitgliederversammlung, am 16.02.1918, Charlottenburg.

Zeitschrift für Beleuchtungswesen Heizungs- und Lüftungstechnik,

H 10/11 und H 11/12

$41-46$ und 51 - 54 
34) 1919 Einteilung der Krankheitserreger.

Lehrbuch der Mikrobiologie (mit besonderer Berücksichtigung der Seuchenlehre). Bd. 1,

hrsg. Friedberger E, Pfeiffer R

Gustav Fischer Verlag, Jena 1919

$14-15$

35) 1919 Allgemeine Morphologie der Bakterien.

Lehrbuch der Mikrobiologie (Mit besonderer Berücksichtigung der Seuchenlehre). Bd. 1,

hrsg. Friedberger E, Pfeiffer R

Gustav Fischer Verlag, Jena 1919

$16-64$

36) 1919 Bakterien in Luft, Wasser, Erdboden und Milch.

Lehrbuch der Mikrobiologie (mit besonderer Berücksichtigung der Seuchenlehre). Bd. 1,

hrsg. Friedberger E, Pfeiffer R

Gustav Fischer Verlag, Jena 1919

$395-418$

37) 1919 Zur Frage des Einflusses der Luftfeuchtigkeit auf die Ventilation.

Zeitschrift für Hygiene und Infektionskrankheiten, $\underline{88}, \mathrm{H}$ 1,

$100-104$

38) 1921 Ansteckungsquellen und Ansteckungswege.

Bericht der Verhandlung des Deutschen Tuberkulose Kongresses

Bad Elster 19. - 21. Mai 1921.

Zeitschrift für Tuberkulose, $\underline{34}, \mathrm{H}$ 7,

$559-570$ 
39) 1921 Die theoretischen Grundlagen der Normalisierung der Desinfektionsmittel. Die Überschrift ist in einem maschinengeschriebenen Literaturverzeichnis erfasst. Der Aufsatz ist nicht auffindbar.

40) 1922 Carl Flügge zum 75. Geburtstage.

Klinische Wochenschrift, 1. Jahrgang, Nr. 50,

$2502-2503$

41) 1922 Über einen Apparat zur Registrierung des Wärmeverlustes durch die

Witterung.

Zeitschrift für Hygiene und Infektionskrankheiten, $\underline{\text { 89, }}$

$528-5461$

42) 1923 Die theoretischen Grundlagen der Desinfektion.

Zentralblatt für Bakteriologie, Parasitenkunde und Infektionskrankheiten,

89, 1. Abteilung,

$15-18$

43) 1926 Die Hygiene als Wissenschaft.

Festrede gehalten bei der Reichsgründungsfeier der

Georg - August - Universität zu Göttingen, 18.01.1926.

Dieterichsche Universitäts- Buchdruckerei, Göttingen 1926

44) 1928 Die Typhusepidemie in Hannover 1926.

Endgültige Berichte und Sondergutachten.

Hrsg. Hahn M, Reichenbach H

in: Veröffentlichungen aus dem Gebiet der Medizinalverwaltung, Bd. 27, H 6, Verlagsbuchhandlung von Schoetz, Berlin 1928

$5-138$ 
45) 1929 Das Mikroskop und seine Nebenapparate.

Handbuch der pathogenen Mikroorganismen, Bd. 9,

hrsg. Kolle W, Kraus R und Uhlenhuth P

Gustav Fischer Verlag, Jena und Urban \& Schwarzenberg Verlag, Berlin und Wien 1929

$567-632$

46) 1930 E. v. Esmarchs Hygienisches Taschenbuch.

Ein Ratgeber der praktischen Hygiene für Medizinal- und Verwaltungsbeamte, Ärzte, Techniker, Schulmänner, Architekten und Bauherren, 5. Auflage hrsg. Reichenbach $\mathrm{H}$ Springer Verlag, Berlin 1930

Kapitel in „E. v. Esmarchs Hygienisches Taschenbuch“ von Reichenbach geschrieben:

$\begin{array}{lll}\text { Luft Wetter u Klima } & \text { Seite } & 001-032 \\ \text { Ventilation } & \text { Seite } & 061-075 \\ \text { Heizung } & \text { Seite } & 076-100 \\ \text { Beleuchtung } & \text { Seite } & 101-126 \\ \text { Wasserversorgung } & \text { Seite } & 127-166 \\ \text { Ernährung } & \text { Seite } & 323-363\end{array}$




\subsection{Promotionen unter Reichenbach am Hygienischen Institut Göttingen}

Alms E

Amster S

Blum M

Brauweiler M

Buchholz H

Büttger W
Spirochaeten in der Mundhöhle unserer Haustiere verglichen mit den

Spirochaeten der Mundhöhle des Menschen.

Med. Diss. Göttingen 1927

Über die Benutzung von Protozoen als Testobjekte für die quantitative Verfolgung von Desinfektionswirkungen.

Med. Diss. Göttingen 1922

Die bakteriologische Untersuchung und Beurteilung eingesandter Wasserproben.

Med. Diss. Göttingen 1929

Über das Verhalten des Diphtheriebazillus bei Gesunden und

Rekonvaleszenten.

Med. Diss. Göttingen 1913

Über den Einfluss von kohlenhydrathaltigen Stoffen auf die Zähne. Med. Diss. Göttingen 1923

Über die Lidschlagfrequenz als Maß für die Ermüdung des Auges und über den Einfluss von Beleuchtungsstärke und Lichtfarbe auf die Ermüdung.

Med. Diss. Göttingen 1923

Über oligodynamische Wirkungen von Legierungen, die in der Zahnheilkunde verwendet werden.

Med. Diss. Göttingen 1922

Freese T

Die Bedeutung der Härte des Trinkwassers für die Häufigkeit der Zahnkaries.

Med. Diss. Göttingen 1934 
Frei W

Hausmann $\mathrm{H}$

Lauenstein $\mathrm{H}$

Manegold O

Menne H

Müller H

Nebelung F

Oberdieck W

Potthoff P
Versuche über die Kombination von Desinfektionsmitteln.

Med. Diss. Göttingen 1913

Untersuchungen über die Färbemethoden von Tuberkelbazillen.

Med. Diss. Göttingen 1921

Das Katathermometer in der Gewerbehygiene mit besonderer

Berücksichtigung des Kalibergbaus.

Med. Diss. Göttingen 1931

Beiträge zur Biologie des Bazillus anthracis mit Berücksichtigung der

Sporenbildung und ihre Bedeutung für die bakteriologische

Milzbranddiagnose.

Med. Diss. Göttingen 1925

Gewerbehygienische Untersuchungen über den Einfluss von

Kohlehydraten auf die Zähne.

Med. Diss. Göttingen 1924

Über die wärmeisolierenden Eigenschaften neuerer Kleidungstücke mit besonderer Berücksichtigung der Wärmestrahlung.

Med. Diss. Göttingen 1929

Die Bedeutung der Härte des Trinkwassers für die Häufigkeit der

Zahnkaries.

Med. Diss. Göttingen 1923

Versuche über Kataphorese bei Bakterien.

Med. Diss. Göttingen 1922

Über die Einwirkung ultravioletter Strahlen auf Bakterien und

Bakteriensporen.

Med. Diss. Göttingen 1920 
Prelle M

Quantz E

Rosenmeyer K

Rühling M

Saftien W

Schmidt v.

Neidhardt $\mathrm{H}$

Stern M

Wagner J
Untersuchungen über die fadenförmigen Mikroorganismen des

Zahnbelags.

Med. Diss. Göttingen 1923

Über die Bedeutung des Bakterium coli für die Wasserbeurteilung. Med. Diss. Göttingen 1915

Die säurebildenden Streptokokken der Mundhöhle und die Streptokokken in kariösen Zähnen.

Med. Diss. Göttingen 1926

Betrachtungen über den Lebensunterhalt von fünf Arbeiterfamilien in der Stadt Gelsenkirchen.

Med. Diss. Göttingen 1926

Vergleichende Untersuchungen über den Einfluss der Kohlenhydrate auf die Zähne.

Med. Diss. Göttingen 1925

Untersuchungen über die Lebensmittelversorgung der Stadt Göttingen während der Zeit der Rationalisierung (1.07.1916 bis 31.12.1919) Med. Diss. Göttingen 1921

Die Untersuchungen einiger Desinfektionsmittel mit besonderer Berücksichtigung ihrer Spezifität.

Med. Diss. Göttingen 1922

Untersuchungen über die Lebensmittelversorgung der Stadt Cassel während der Zeit der Rationalisierung (1.07.1916 bis 31.12.1919) Med. Diss. Göttingen 1922 
Zeppenfeld K

Wird durch intermittierende Berührung zweier Zähne die Übertragung der Zahnkaries gefördert?

Med. Diss. Göttingen 1924 


\subsection{Bibliographie}

\subsubsection{Quellen Göttinger Universitätsarchiv (GUA)}

Univ. Arch. Kur. XVI III Aa 6

Univ. Arch. Kur. XVI III Ce 10

Univ. Arch. Dek. Med. 75 1910-1911

Univ. Arch. Dek. Med. 95 1933-1935
Personalakte Hans Reichenbach

Institut für Medizinische Chemie und

Hygiene, Verschiedenes

Dekanatsakte Cramer

Dekanatsakte Beumer

\subsubsection{Literatur}

Engels

Engels*: Experimentelle Beiträge zur Wohnungsdesinfektion mit Formaldehyd. Arch Hyg $\underline{49}, 129-197$

Eulner (1970)

Eulner H-H: Die Entwicklung der medizinischen Spezialfächer an den Universitäten des deutschen Sprachgebietes. Ferdinand Enke Verlag, Stuttgart 1970

Fischer

Fischer I: Reichenbach, Hans; in: Biographisches Lexikon der hervorragenden Ärzte der letzten fünfzig Jahre. Bd. 2; hrsg. v. Fischer I; Urban Schwarzberg Verlag, Berlin 1933, 1280

Göttinger Zeitung (1929)

Geheimrat Reichenbach 65 Jahre alt. Göttinger Zeitung vom 30.11.1929, $\underline{67}$, Nummer 22342. o. S.

* Keine näheren Angeben zum Autor gegeben. 
Gotschlich

(1904)

Gotschlich F: Die Tageslichtmessung in Schulen. Klin Jahrb 12, 202 - 230

Hartung

Hartung E: Über das Hygiene- Institut der Universität Göttingen in den ersten

75 Jahren seines Bestehens. Manuskript, Göttingen 1936

Lewaschew

(1904)

Lewaschew*: Über die Gefahr, welche einige zur Entwickelung von Formalindämpfen vorgeschlagene Apparate bieten. Hyg Rundschau 쓰, 997

Mayer

und Wolpert

(1902)

Mayer E und Wolpert H: Über die Verfahren und Apparate zur Entwicklung von

Formaldehyd für die Zwecke der Wohnungsdesinfektion. Arch Hyg 43, H2, 157 - 169

Proskauer

und Elsner

Proskauer* und Elsner*: Die neue Berliner Wohnungsdesinfektion. Festschrift zum

60. Geburtstag von Robert Koch. Hrsg. Keine Angabe, Fischer Verlag, Jena 1903

Reichenbach

Reichenbach H: Mitteilung aus der syphilitischen Abteilung des Ernst - August Hospitals Zu Göttingen. Med. diss. Göttingen 1889

Reichenbach

(1898)

Reichenbach H: Über Wärmestrahlung von Leuchtflammen. Arch Hyg 33, 315 - 349

Reichenbach

Reichenbach H: Über den Einfluss der Farbe künstlicher Lichtquellen auf die Sehschärfe. Z Hyg Infektionskr 41, 257 - 270

\footnotetext{
* Keine näheren Angaben zum Autor gegeben.
} 
Reichenbach

(1904)

Reichenbach H: Die Tageslichtmessung in den Schulen. Klin Jahrb 12, 231 - 240

Reichenbach

(1905a)

Reichenbach H: Zur Frage der Tageslichtmessung. Klin Jahrb 14, 325 - 336

Reichenbach

(1905b)

Reichenbach H: Die Leistung der Formaldehyd - Desinfektion. Z Hyg Infektionskr $\underline{50}, 451-472$

Reichenbach

Reichenbach H: Die desinfizierenden Bestandteile der Seifen. Z Hyg Infektionskr $\underline{59}$, $296-316$

Reichenbach

(1913)

Reichenbach H: Die Vererbung erworbener Eigenschaften bei einzelligen Lebewesen. Z Soz Med $\underline{8}, 323-351$

Reichenbach

Reichenbach H: Bakterien in Luft, Wasser, Erdboden und Milch.

in: Lehrbuch der Mikrobiologie, Bd. 1; (mit besonderer Berücksichtigung der Seuchenlehre); hrsg. v. Friedberger E, Pfeiffer R; Gustav Fischer Verlag, Jena 1919, $395-418$

Reichenbach

Reichenbach H: Die Hygiene als Wissenschaft. Festrede gehalten bei der

Reichsgründungsfeier der Georg - August - Universität zu Göttingen, 18.01.1926.

Dieterichsche Universitäts- Buchdruckerei, Göttingen 1926

Reichenbach

Reichenbach H: Das Mikroskop und seine Nebenapparate. in: Handbuch der pathogenen Mikroorganismen, Bd. 9; hrsg. v. Kolle W, Kraus R, Uhlenhuth P; Gustav Fischer Verlag, Jena 1929, 567 - 632 
Rieberer

(1990)

Rieberer G: Das Institut für Medizinische Chemie und Hygiene der Universität

Göttingen von der Gründung 1883 bis 1955. Med. Diss. Göttingen 1990

Römer

(1903)

Römer P: Zur Frage der Formaldehyddesinfektion. Beitr Exp Ther H6, 113

Rubner

Rubner M: Die Strahlende Wärme irdischer Lichtquellen in hygienischer Hinsicht. Arch Hyg 23, H2, 87 - 144

Rubner

Rubner M: Die Geschichte der Hygiene. in: Handbuch der Hygiene, Bd. 1; hrsg. v.

Rubner M, v. Gruber M, Ficker M; Hirzel Verlag, Leipzig 1911, 19 - 40

Schütz

Schütz F: Ansprache zur Eröffnung des neuen Instituts für medizinische Chemie und Hygiene in Göttingen, gehalten am 29.10.1940 in Göttingen. Mitteilungen des Universitätsbundes Göttingen, 21, H1, 33 - 61

Sprengler

Sprengler C: Tuberkelbazillenzüchtung aus Bakteriengemischen und

Formaldehyddesinfektion. Z Hyg Infektkr 42, 90 - 114

Zimmermann (2009)

Zimmermann V: „Eine Medicinische Facultät in Flor bringen“ Zur Geschichte der Medizinischen Fakultät der Georg-August-Universität Göttingen. Universitätsverlag, Göttingen 2009 


\section{Danksagung}

Herrn Professor Dr. Dr. V. Zimmermann möchte ich für die engagierte, kritische und humorvolle Betreuung ganz herzlich danken.

Auch Frau K. Drost-Siemon, der Bibliothekarin am Institut für Ethik und Geschichte der Medizin in Göttingen, danke ich für ihre Unterstützung in Fragen der Literaturrecherche.

Darüber hinaus danke ich den Bibliotheksmitarbeitern für ihre freundliche und hilfsbereite Zusammenarbeit.

Nicht zuletzt gilt mein Dank meiner Familie die mich fortwährend unterstützt hat. 